\title{
Hunting for hot corinos and WCCC sources in the OMC-2/3 filament
}

\author{
M. Bouvier ${ }^{1}$, A. López-Sepulcre ${ }^{1,2}$, C. Ceccarelli ${ }^{1,3}$, C. Kahane $^{1}$, M. Imai ${ }^{4}$, N. Sakai ${ }^{5}$, \\ S. Yamamoto ${ }^{4,6}$, and P. J. Dagdigian ${ }^{7}$
}

\author{
${ }^{1}$ Univ. Grenoble Alpes, CNRS, Institut de Planétologie et d'Astrophysique de Grenoble (IPAG), 38000 Grenoble, France \\ e-mail: mathilde.bouvier@univ-grenoble-alpes.fr \\ ${ }^{2}$ Institut de Radioastronomie Millimétrique (IRAM), 300 rue de la Piscine, 38406 Saint-Martin-D'Hères, France \\ ${ }^{3}$ CNRS, IPAG, 38000 Grenoble, France \\ ${ }^{4}$ Department of Physics, The University of Tokyo, 7-3-1, Hongo, Bunkyo-ku, Tokyo 113-0033, Japan \\ ${ }^{5}$ RIKEN, Cluster for Pioneering Research, 2-1, Hirosawa, Wako-shi, Saitama 351-0198, Japan \\ ${ }^{6}$ Research Center for the Early Unvierse, The University of Tokyo, 7-3-1, Hongo, Bunkyo-ku, Tokyo 113-0033, Japan \\ 7 Department of Chemistry, The Johns Hopkins University, Baltimore, MD 21218-2685, USA
}

Received 21 November 2019 / Accepted 3 March 2020

\begin{abstract}
Context. Solar-like protostars are known to be chemically rich, but it is not yet clear how much their chemical composition can vary and why. So far, two chemically distinct types of Solar-like protostars have been identified: hot corinos, which are enriched in interstellar Complex Organic Molecules, such as methanol $\left(\mathrm{CH}_{3} \mathrm{OH}\right)$ or dimethyl ether $\left(\mathrm{CH}_{3} \mathrm{OCH}_{3}\right)$, and warm carbon chain chemistry (WCCC) objects, which are enriched in carbon chain molecules, such as butadiynyl $\left(\mathrm{C}_{4} \mathrm{H}\right)$ or ethynyl radical $(\mathrm{CCH})$. However, none of these have been studied so far in environments similar to that in which our Sun was born, that is, one that is close to massive stars.

Aims. In this work, we search for hot corinos and WCCC objects in the closest analogue to the Sun's birth environment, the Orion Molecular Cloud 2/3 (OMC-2/3) filament located in the Orion A molecular cloud.

Methods. We obtained single-dish observations of $\mathrm{CCH}$ and $\mathrm{CH}_{3} \mathrm{OH}$ line emission towards nine Solar-like protostars in this region. As in other similar studies of late, we used the $[\mathrm{CCH}] /\left[\mathrm{CH}_{3} \mathrm{OH}\right]$ abundance ratio in order to determine the chemical nature of our protostar sample.

Results. Unexpectedly, we found that the observed methanol and ethynyl radical emission (over a few thousands au scale) does not seem to originate from the protostars but rather from the parental cloud and its photo-dissociation region, illuminated by the OB stars of the region.

Conclusions. Our results strongly suggest that caution should be taken before using $[\mathrm{CCH}] /\left[\mathrm{CH}_{3} \mathrm{OH}\right]$ from single-dish observations as an indicator of the protostellar chemical nature and that there is a need for other tracers or high angular resolution observations for probing the inner protostellar layers.
\end{abstract}

Key words. astrochemistry - methods: observational - stars: solar-type - ISM: individual objects: OMC-2/3 - stars: formation

\section{Introduction}

A key aspect of the chemical richness of the protostellar stage is the diversity found among Solar-like protostars. Indeed, two chemically distinct types of Solar-like protostars have been identified. On the one hand, hot corinos (Ceccarelli et al. 2000, 2007) are compact $(<100 \mathrm{au})$, dense $\left(>10^{7} \mathrm{~cm}^{-3}\right)$, and hot $(>100 \mathrm{~K})$ regions, enriched in interstellar Complex Organic Molecules (hereafter iCOMs; for example, $\mathrm{CH}_{3} \mathrm{OH}, \mathrm{CH}_{3} \mathrm{CHO}, \mathrm{HCOOCH}_{3}$; Herbst \& Van Dishoeck 2009; Ceccarelli et al. 2017). On the other hand, warm carbon chain chemistry (hereafter WCCC; Sakai et al. 2008, Sakai \& Yamamoto 2013) objects have an inner region deficient in iCOMs but a large $(\approx 2000 \mathrm{au})$ zone enriched in carbon chain molecules (e.g. $\mathrm{CCH}, \mathrm{c}-\mathrm{C}_{3} \mathrm{H}_{2}, \mathrm{C}_{4} \mathrm{H}$ ). This dichotomy does not seem to be absolute as at least one source, the protostar L483, presents both hot corino and WCCC characteristics (Oya et al. 2017). Understanding what causes this chemical diversity is a fundamental step in understanding the formation and the evolution of a planetary system like our own and, perhaps, to understand the appearance of life on Earth. Furthermore, given our Sun was formerly a protostar, it is natural to consider whether it may have experienced a hot corino phase, a
WCCC phase, or neither of the two in its youth. In this respect, we recall that the Solar System formed in a large stellar cluster in proximity to high-mass stars $\left(M_{*} \geq 8 M_{\odot}\right.$; Adams 2010 , Pfalzner et al. 2015).

So far, there have been only a few hot corinos and WCCC objects identified and almost all of them are located in lowmass star forming regions (e.g. Cazaux et al. 2003; Sakai et al. 2008; Taquet et al. 2015). Besides the relatively small number of WCCC objects in low-mass star-forming regions, WCCC characteristics have also been seen in other environments, such as the starless core L1489 (Wu et al. 2019) and in the giant HII region NGC 3576 (Saul et al. 2015). A hot corino was also found in the high-mass star-forming region of Orion, HH212-MM1 (Codella et al. 2016), but as with the other hot corinos, it is located far from massive stars. Previous observational studies have been carried out towards hot corinos and WCCC objects in an effort to better understand them. Some studies have been targeted on just one type of object (either hot corino or WCCC object; e.g. Caux et al. 2011; Jørgensen et al. 2016; López-Sepulcre et al. 2017; Oya et al. 2017; Ospina-Zamudio et al. 2018; Agúndez et al. 2019; Bianchi et al. 2019; Yoshida et al. 2019), or one type of molecular tracer (Carbon-chain or iCOMs; e.g. Law et al. 2018; 
Table 1. Summary of the excitation temperatures $\left(T_{\mathrm{ex}}\right)$ and column densities $\left(N_{\mathrm{tot}}\right)$ of the different tracers of hot corinos $\left(\mathrm{CH}_{3} \mathrm{OH}\right)$ and WCCC objects $\left(\mathrm{CCH}\right.$ and $\left.\mathrm{C}_{4} \mathrm{H}\right)$ derived in previous surveys obtained with single-dish telescope observations.

\begin{tabular}{|c|c|c|c|c|c|c|c|c|c|c|c|}
\hline \multirow[b]{2}{*}{ Object type } & \multirow[b]{2}{*}{ Molecule } & \multicolumn{2}{|c|}{ Graninger et al. (2016) } & \multicolumn{2}{|c|}{ Lindberg et al. (2016) } & \multicolumn{2}{|c|}{ Higuchi et al. (2018) } & \multicolumn{2}{|c|}{$\mathrm{L} 1527^{(b)}$} & \multicolumn{2}{|c|}{ IRAS $16293-2422^{(c)}$} \\
\hline & & $\begin{array}{l}T_{\mathrm{ex}} \\
{[\mathrm{K}]} \\
\end{array}$ & $\begin{array}{c}N_{\mathrm{tot}} \\
{\left[\times 10^{13} \mathrm{~cm}^{-2}\right]}\end{array}$ & $\begin{array}{l}T_{\mathrm{ex}} \\
{[\mathrm{K}]} \\
\end{array}$ & $\begin{array}{c}N_{\mathrm{tot}} \\
{\left[\times 10^{13} \mathrm{~cm}^{-2}\right]}\end{array}$ & $\begin{array}{l}T_{\mathrm{ex}} \\
{[\mathrm{K}]}\end{array}$ & $\begin{array}{c}N_{\mathrm{tot}} \\
{\left[\times 10^{13} \mathrm{~cm}^{-2}\right]} \\
\end{array}$ & $\begin{array}{l}T_{\mathrm{ex}} \\
{[\mathrm{K}]} \\
\end{array}$ & $\begin{array}{c}N_{\mathrm{tot}} \\
{\left[\times 10^{13} \mathrm{~cm}^{-2}\right]} \\
\end{array}$ & $\begin{array}{l}T_{\mathrm{ex}} \\
{[\mathrm{K}]} \\
\end{array}$ & $\begin{array}{c}\mathrm{N}_{\mathrm{tot}} \\
{\left[\times 10^{13} \mathrm{~cm}^{-2}\right]}\end{array}$ \\
\hline \multirow{2}{*}{ WCCC tracers } & $\mathrm{CCH}$ & & $\ldots$ & $\ldots$ & $\ldots$ & $8-21$ & $\leq 52$ & $8 \pm 1$ & $33 \pm 3$ & $18 \pm 6$ & $9 \pm 6$ \\
\hline & $\mathrm{C}_{4} \mathrm{H}$ & $7-15$ & $<4$ & $7-16.5^{(a)}$ & $<1$ & $\ldots$ & $\ldots$ & 12.3 & $20 \pm 4$ & 12.3 & $1.2 \pm 0.3$ \\
\hline Hot corino tracer & $\mathrm{CH}_{3} \mathrm{OH}$ & $4-7$ & $0.2-11$ & $<123^{(a)}$ & $0.2-95$ & $8-21$ & $0.5-16$ & $8 \pm 1$ & $8 \pm 1$ & $84 \pm 6$ & $90 \pm 10$ \\
\hline \multicolumn{2}{|c|}{ Resolution (au) } & \multicolumn{2}{|c|}{$4100-13000$} & \multicolumn{2}{|c|}{$7800-8200$} & \multicolumn{2}{|c|}{$2400-4900$} & \multicolumn{2}{|c|}{$2400-4900$} & \multicolumn{2}{|c|}{$500-2000$} \\
\hline
\end{tabular}

Notes. ${ }^{(a)}$ Excitation temperatures taken from c- $\mathrm{C}_{3} \mathrm{H}_{2}$ and $\mathrm{H}_{2} \mathrm{CO}$ APEX observations for $\mathrm{C}_{4} \mathrm{H}$ and $\mathrm{CH}_{3} \mathrm{OH}$ respectively (Lindberg et al. 2016). References. ${ }^{(b)}$ Higuchi et al. (2018), Sakai et al. (2008). ${ }^{(c)}$ Van Dishoeck et al. (1995), Sakai et al. (2009).

Wu et al. 2019) whereas other studies targeted all kinds of protostars and selected tracers to evaluate their chemical nature (i.e. comparative statistical studies of chemical diversity; e.g. Graninger et al. 2016, Lindberg et al. 2016, Higuchi et al. 2018). For the latter, the method employed is based on observations with single-dish telescopes (scale of $\approx 10000 \mathrm{au}$ ) of small carbon chains (e.g. $\left.\mathrm{CCH}, \mathrm{C}_{4} \mathrm{H}\right)$ and methanol $\left(\mathrm{CH}_{3} \mathrm{OH}\right)$ as tracers of WCCC objects and hot corinos, respectively. However, this method presents some caveats. Indeed, emission of small carbon chains are usually extended and present in the Photo-Dissociation Regions (hereafter PDRs) surrounding the molecular clouds (e.g. Pety et al. 2005; Cuadrado et al. 2015). As for $\mathrm{CH}_{3} \mathrm{OH}$, it is also a species that has been found in PDRs as well as in molecular clouds (e.g. Leurini et al. 2010; Guzmán et al. 2013; Cuadrado et al. 2017; Punanova et al. 2018). Thus, an important contribution from the parental molecular cloud or from the surrounding PDR may occur when observing those molecules with single-dish telescopes.

In this context, the goal of the present work is twofold: (1) to identify the nature of several protostars, hot corinos, or WCCC objects in a region containing high-mass stars and whether it depends on the object position in the cloud; this will help us to understand whether the Sun passed through a hot corino or a WCCC object phase. Indeed, if only hot corinos are found in Orion Molecular Cloud 2/3 (OMC-2/3), this would strongly suggest that our Sun also underwent a hot corino phase during its youth and vice versa; (2) to verify the reliability of using single-dish observations of small hydrocarbons and methanol to classify the chemical nature of the protostars.

To reach these two goals, we obtained new IRAM-30 m and Nobeyama-45 m observations of ethynyl radical $(\mathrm{CCH})$ and methanol towards a sample of nine known protostars in the closest high- and low- mass star forming region, OMC-2/3, and a map of a portion of it. Following Higuchi et al. (2018), we used the $[\mathrm{CCH}] /\left[\mathrm{CH}_{3} \mathrm{OH}\right]$ abundance ratio to make a first assessment of the chemical nature of the targeted sources: a small $(\leq 0.5)$ ratio would be suggestive of a hot corino candidate whereas a large $(\geq 2)$ ratio would rather be suggestive of a WCCC candidate, as we will discuss in detail in Sect. 3. Moreover, this abundance ratio is about one order of magnitude different when comparing the hot corino and WCCC templates sources (see Table 1), which would a priori justify the use of this initial criterion.

This paper is structured as follows. In Sect. 2, we briefly review the previous surveys with single-dish observations aimed to study the chemical nature of low-mass protostars. In Sect. 3, we briefly describe the OMC-2/3 region, the selected source sample and explain the choice of the molecular species that we targeted. A description of the observations are presented in Sect. 4. In Sect. 5, we show the results of the analysis of the observed lines. In Sect. 6, we present the derived physical conditions (temperature and density) of the gas which emits the detected $\mathrm{CCH}$ and $\mathrm{CH}_{3} \mathrm{OH}$ lines and their column densities. In Sect. 7, we discuss our findings. We finally end with some concluding remarks in Sect. 8.

\section{Prior surveys of protostellar chemical diversity with carbon chain-iCOM ratios}

The first efforts aimed at improving statistics on the chemical nature and diversity of low-mass protostars were only recently begun. The chemical tool used is the abundance ratio between carbon chains (e.g. $\mathrm{CCH}, \mathrm{C}_{4} \mathrm{H}$ ) and iCOMs (e.g. $\mathrm{CH}_{3} \mathrm{OH}$ ). Those families of molecules are abundant in WCCC objects and in hot corinos, respectively. We present in this section only surveys that used the chemical tool cited above to identify hot corinos and WCCC sources.

Graninger et al. (2016) investigated the relationship between $\mathrm{C}_{4} \mathrm{H}$ and $\mathrm{CH}_{3} \mathrm{OH}$ in 16 embedded protostars located in the northern hemisphere. The abundance ratio $\left[\mathrm{C}_{4} \mathrm{H}\right] /\left[\mathrm{CH}_{3} \mathrm{OH}\right]$ for a typical WCCC is 2.5 and for typical hot corinos (IRAS 162932422, IRAS 4A, IRAS 4B, Serpens MMS4), <0.15. With this definition, among their 16 sources, there would be five WCCC sources and at most two hot corinos. However, the temperatures derived are likely too low $(\leq 15 \mathrm{~K})$ to correspond to the lukewarm envelope of the protostars. Their main results are: (1) there is a positive correlation between the column densities of $\mathrm{C}_{4} \mathrm{H}$ and $\mathrm{CH}_{3} \mathrm{OH}$, indicating that the two species are present in a lukewarm environment in the protostellar envelopes; and (2) they found a lower amount of $\mathrm{CH}_{3} \mathrm{OH}$ than in hot corinos and a lower amount $\mathrm{C}_{4} \mathrm{H}$ than in WCCC sources. The under-abundance of carbon chains in this source sample has been confirmed by Law et al. (2018).

Similarly, Lindberg et al. (2016), observed 16 low-mass protostars in the southern hemisphere and, including the results from Graninger et al. (2016), they investigated the origin of $\mathrm{C}_{4} \mathrm{H}$ and $\mathrm{CH}_{3} \mathrm{OH}$ in the protostellar envelopes. Using the same abundance ratio, two sources would be labelled as WCCC protostars and about six as hot corinos. Contrary to Graninger et al. (2016), they did not observe evidence of a correlation between the column densities of the two species and they concluded that $\mathrm{CH}_{3} \mathrm{OH}$ would reside in the warmer inner regions of the protostellar environment, whereas $\mathrm{C}_{4} \mathrm{H}$ would reside rather in the cooler outer regions of the protostellar environment. However, the derived excitation temperature for $\mathrm{CH}_{3} \mathrm{OH}$ never exceeds $36 \mathrm{~K}$, except in the well-known hot corino IRAS 16293-2422. 
Table 2. Selected sources and their properties.

\begin{tabular}{|c|c|c|c|c|c|c|c|}
\hline Source & $\begin{array}{c}\text { RA } \\
\text { J2000 } \\
\end{array}$ & $\begin{array}{c}\text { Dec } \\
\text { J2000 }\end{array}$ & $\begin{array}{c}\text { Mass } \\
M_{\odot}\end{array}$ & $\begin{array}{l}\text { Radio } \\
(\mathrm{Y} / \mathrm{N}) \\
\end{array}$ & $\begin{array}{c}\text { Outflow } \\
(\mathrm{Y} / \mathrm{N})\end{array}$ & Notes & Reference \\
\hline CSO33 & $05: 35: 19.50$ & $-05: 15: 35.0$ & 6 & $\mathrm{~N}$ & $Y ?$ & Near HII region (M42) & 1 \\
\hline $\operatorname{FIR6c}^{(a)}$ & $05: 35: 21.60$ & $-05: 13: 14.0$ & $5-9$ & $\mathrm{~N}$ & $\mathrm{Y}$ & Class 0 & 2 \\
\hline FIR2 ${ }^{(a)}$ & $05: 35: 24.40$ & $-05: 08: 34.0$ & $4-10$ & $\mathrm{~N}$ & $\mathrm{Y}$ & Class I & 2 \\
\hline FIR1a & $05: 35: 24.40$ & $-05: 07: 53.0$ & 12 & Y & $\mathrm{N}$ & Class $0 ?$ & 2 \\
\hline MMS9 & $05: 35: 26.20$ & $-05: 05: 44.0$ & 4.7 & $\mathrm{Y}$ & $\mathrm{Y}$ & Class 0 & 2 \\
\hline MMS5 & $05: 35: 22.50$ & $-05: 01: 15.0$ & 4.5 & $\mathrm{~N}$ & $\mathrm{Y}$ & Class 0 , part of the OTF map & 2 \\
\hline MMS2 & $05: 35: 18.50$ & $-05: 00: 30.0$ & 2.8 & $\mathrm{Y}$ & $\mathrm{Y}$ & Class I, binary, part of the OTF map & 2 \\
\hline CSO3 & $05: 35: 15.80$ & $-04: 59: 59.0$ & 12 & $\mathrm{~N}$ & $\mathrm{~N}$ & Binary, part of the OTF map & 1 \\
\hline SIMBA-a ${ }^{(b)}$ & $05: 35: 29.80$ & $-04: 58: 47.0$ & 6.5 & $\ldots$ & $\mathrm{Y}$ & Class 0, isolated, near HII region (NGC 1977) & 3 \\
\hline
\end{tabular}

Notes. The envelope mass of the protostars are taken from Li et al. (2013) and Takahashi et al. (2008). The data for the radio component are taken from VLA cm-radio emission (Reipurth et al. 1999). The data on the outflows are from Takahashi et al. (2008). ${ }^{(a)}$ Left out of the analysis due to prominent non-Gaussian line wings. ${ }^{(b)}$ Data from the $3 \mathrm{~mm}$ only, as there was emission contamination from the wobbler off position for the $1 \mathrm{~mm}$ data set.

References. (1) Lis et al. (1998); (2) Chini et al. (1997); (3) Nielbock et al. (2003).

Those temperatures seem too low for $\mathrm{CH}_{3} \mathrm{OH}$ to originate in the hot corinos. Indeed, for hot corinos $(T \geq 100 \mathrm{~K}$; Ceccarelli et al. 2007), we expect excitation temperatures of at least $50 \mathrm{~K}$ to support an origin of emission dominated by the hot corino.

Finally, Higuchi et al. (2018), performed a survey of 36 low-mass protostars in the Perseus region. They compared the abundance ratio $[\mathrm{CCH}] /\left[\mathrm{CH}_{3} \mathrm{OH}\right]$ of each source to that of L1527, the prototypical WCCC source, to characterise their chemical nature. From this criterion, at most four sources can be WCCC protostars and 14 sources seem to be hot corinos. Two main results of their work are: (1) the majority of the sources have intermediate chemical composition between hot corinos and WCCC types; and (2) WCCC objects tend to be found at the edge of molecular clouds or in relative isolation, whereas the hot corinos tend to be located in the centre of molecular clouds. Also in this case, the derived excitation temperatures are low (in the range of 8-21 K), so it is not entirely clear whether the observed molecular emission is contaminated by the molecular cloud.

Table 1 summarises the derived excitation temperatures and column density of $\mathrm{CCH}, \mathrm{C}_{4} \mathrm{H}$ and $\mathrm{CH}_{3} \mathrm{OH}$ in the three surveys, as well as those derived for L1527 (the WCCC prototype) and IRAS 16293-2422 (the hot corino prototype). Based on these surveys and their definition of hot corinos and WCCC objects, about $33 \%$ of the low-mass protostars are hot corinos, $17 \%$ can be classified as WCCC sources and the rest (50\%) do not seem clearly to belong to any of the two categories. We note that the definition of hot corino and WCCC object varies from one survey to another. Overall, 66 low-mass protostars have been surveyed upon adding up all of these studies, but all of them concern regions with no massive stars nearby, which is basis of the next step and overall goal of our study.

\section{Targeted sources and molecular tracers}

\subsection{Target selection}

OMC-2/3 is part of the Orion A molecular complex and is composed of two major molecular clouds, OMC-2 and OMC3. Those two clouds form a filament-shaped region located between the Trapezium OB stellar cluster and the NGC 1977 HII region, at a distance of $(393 \pm 25)$ pc from the Sun (Großschedl et al. 2018). OMC-2 lies to the north of OMC-1, which is the molecular cloud associated with the Orion Nebula, and was identified by Gatley et al. (1974). The cloud OMC-3, located further north, was labelled later by Chini et al. (1997). OMC-2/3 has been extensively studied since its discovery and multiple protostars, in particular Class 0 protostars, have been identified (e.g Chini et al. 1997), as well as multiple molecular outflows (e.g Reipurth et al. 1999; Williams et al. 2003; Takahashi et al. 2008), and $\mathrm{H}_{2}$ shocks and jets (Yu et al. 1997).

What makes OMC-2/3 particularly interesting is that it is the nearest region containing both low- and high-mass forming stars. In addition, it is surrounded by bright OB stars which create HII regions and PDR. Thus, OMC-2/3 is unique target for the study of a region similar to the one in which the Solar System was born, as well as to probe the effect of different environments. For this reason we carried out a systematic study of several sources with the goal of characterising their chemical nature, that is, hot corino versus WCCC objects, and how this depends on the location of the source within OMC-2/3 and its immediate surroundings.

With this in mind, we selected a sample of low-mass protostellar sources which satisfy the following three criteria: (1) detection in the (sub-)mm continuum emission; (2) estimation (based on the continuum) masses $\leq 12 M_{\odot}$; (3) bona fide Class 0 and I protostars (which excludes pre-stellar cores that may also be present in this region). The resulting sample consists of nine sources, whose coordinates as well as some of their known properties, are listed in Table 2. Their masses (dust+gas) cover from 2.8 to $12 M_{\odot}$ (Takahashi et al. 2008; Li et al. 2013), constituting, therefore, a rather homogeneous sample in this respect. Most of the sources are known to possess outflows, which is in line with their protostellar nature, and one third of them have detected cm-radio emission (Reipurth et al. 1999), which is again a sign of a protostellar nature (e.g. Anglada 1995, 1996). Finally, Fig. 1 shows the distribution along the OMC-2/3 filament of the selected targets: they cover the whole filament from the north end (CSO3 source) to the south one (CSO33 source). Some of them are close to the border of the molecular cloud whereas others lie well inside, where the UV radiation field from the nearby OB stars is expected to be as much as 3 orders of magnitude lower than at the edge of the filament (see López-Sepulcre et al. 2013). This will thus allow us, as we aim, to probe different environments across the filament. We note that we did not add to 


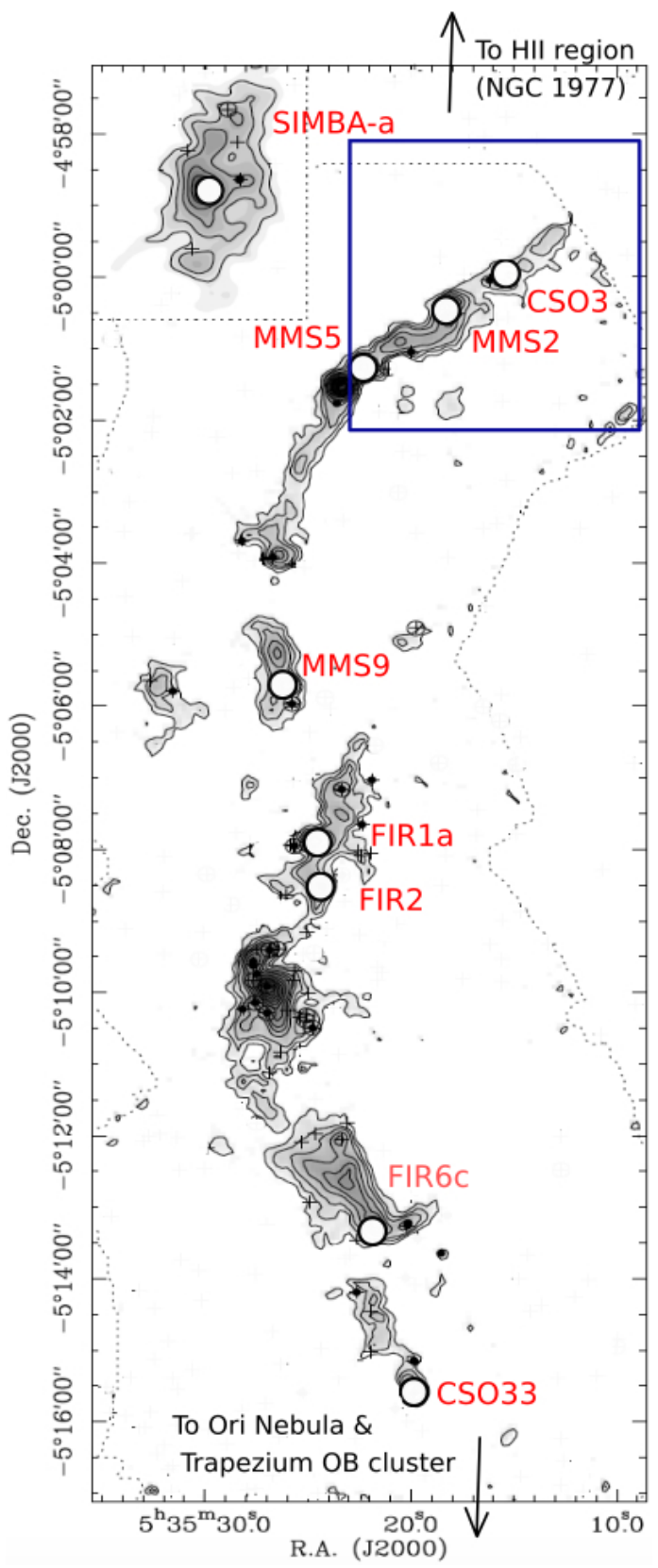

Fig. 1. Map of the continuum at $1.3 \mathrm{~mm}$ towards the OMC-2/3 filament, adapted from Chini et al. (1997) and Nielbock et al. (2003). The upper left insert (square grid) is taken from the SIMBA map of Nielbock et al. (2003) and added on the $1.3 \mathrm{~mm}$ map of Chini et al. (1997) whose limits are represented by the dotted lines. Contours rise linearly from a $3 \sigma$ rms noise level (Nielbock et al. 2003), the rms noise of the map being 25 mJy (Chini et al. 1997). The selected targets of the present study are marked with white circles, which have the size of the IRAM- $30 \mathrm{~m}$ beam at $1.3 \mathrm{~mm}$. The names of the sources are reported in red (see Table 2). Please note that some black crosses and filled dots are present throughout the figure. They represent some of the 2MASS sources and MIR sources from TIMMI 2 observed by Nielbock et al. (2003). The blue square indicates the region mapped with IRAM- $30 \mathrm{~m}$ at $3 \mathrm{~mm}$. The two arrows show the direction of the HII region NGC 1977 (top) and the Ori Nebula and Trapezium OB cluster (bottom).

the study the famous FIR4, the brightest sub-mm source in the OMC-2 cloud, because it is already the focus of several past and future studies (e.g. López-Sepulcre et al. 2013; Kama et al. 2013; Ceccarelli et al. 2014; Fontani et al. 2017; Favre et al. 2018).
Finally, in order to be able to disentangle the contamination of the protostar from the cloud, we also mapped the northern region around MMS5, MMS2, and CSO3 (see Fig. 1). We chose the area to be mapped considering three main criteria. Firstly, the area has to contain both a part of the filament, with at least one protostar from our sample, and a part outside of the filament to see whether the abundance ratio varies across the map and if so, then how. Secondly, we aimed to target the most quiescent environment possible, excluding regions with sources associated with known outflows or jets (Yu et al. 1997; Reipurth et al. 1999; Williams et al. 2003; Takahashi et al. 2008). These two criteria lead us to select OMC-3, which is more quiescent than OMC-2 from this point of view. Finally, we aimed to target more than one protostar from our sample to understand whether the abundance ratio $[\mathrm{CCH}] /\left[\mathrm{CH}_{3} \mathrm{OH}\right]$ varies among the sources and how. Thus, the region centred on $\mathrm{CSO} 3$, which includes three of our protostellar targets, was selected as the best area to map.

\subsection{Selected molecules}

In order to identify whether the targeted sources belong to the hot corino, WCCC sources classes, or none of them, we targeted lines from $\mathrm{CCH}$ and $\mathrm{CH}_{3} \mathrm{OH}$, two molecules that are characteristic of WCCC and hot corinos sources, respectively (Maret et al. 2005; Sakai \& Yamamoto 2013). As in previous similar works (Sect. 2), we used their relative abundance ratio, $[\mathrm{CCH}] /\left[\mathrm{CH}_{3} \mathrm{OH}\right]$, to assess their chemical nature. Specifically, based on the values measured in the two prototypes of hot corinos and WCCC sources (IRAS 16293-2422 and L1527: see Table 1), a $[\mathrm{CCH}] /\left[\mathrm{CH}_{3} \mathrm{OH}\right]$ abundance ratio larger than about 2 would roughly identify a WCCC source while a value lower than about 0.5 would testify for a hot corino nature; sources with values in between may be intermediate cases.

We selected two bands, at 3 and $1 \mathrm{~mm}$, of the hyperfine structure lines of $\mathrm{CCH}$, and several $\mathrm{CH}_{3} \mathrm{OH}$ rotational lines which cover a large range $(\sim 7$ to $\sim 100 \mathrm{~K})$ of transition upper level energy, in order to derive column densities and temperatures of $\mathrm{CCH}$ and $\mathrm{CH}_{3} \mathrm{OH}$. The list of the targeted lines as well as their spectroscopic parameters is reported in Table 3.

\section{Observations}

We obtained single-pointing observations towards the nine sources of Table 2 with the single-dish telescopes IRAM- $30 \mathrm{~m}$, targeting the $\mathrm{CCH}$ and $\mathrm{CH}_{3} \mathrm{OH}$ lines in the 3 and $1 \mathrm{~mm}$ bands, and Nobeyama- $45 \mathrm{~m}$, for additional $3 \mathrm{~mm} \mathrm{CCH}$ lines. In addition, in order to disentangle the inner protostellar emission from that originating from the more external parental cloud, we obtained a $3^{\prime} \times 3^{\prime} \operatorname{arcmin}^{2}$ map of the north end of OMC-3 with the IRAM-30 m (see Fig. 1) in both $\mathrm{CCH}$ and $\mathrm{CH}_{3} \mathrm{OH}$ lines. In the following, we individually describe the observations obtained at the two telescopes.

\subsection{IRAM-30 $m$ telescope}

Single-pointing observations were carried out on January 13th and 17th 2016, and on February 24-25th and 29th 2016. The EMIR receiver E2 $(1.3 \mathrm{~mm})$ was used in order to cover the chosen spectral windows from 239.14 to $246.92 \mathrm{GHz}$ and from 254.82 to $262.6 \mathrm{GHz}$. The Fourier Transform Spectrometer (FTS), providing a spectral resolution of $195 \mathrm{kHz}\left(0.26 \mathrm{~km} . \mathrm{s}^{-1}\right)$, was connected to the receiver. For each source, single-pointing observations in wobbler mode were made, with a wobbler throw of $120^{\prime \prime}$. The resulting beam size is $10^{\prime \prime}$. Focus and pointing were 
Table 3. Targeted lines and their spectroscopic properties.

\begin{tabular}{|c|c|c|c|c|c|c|}
\hline Molecule & Transition & $\begin{array}{l}\text { Freq. } \\
{[\mathrm{GHz}]}\end{array}$ & $\begin{array}{l}E_{\mathrm{up}} \\
{[\mathrm{K}]}\end{array}$ & $\begin{array}{c}A_{\mathrm{ij}} \\
{\left[\mathrm{s}^{-1}\right]}\end{array}$ & $\begin{array}{c}\text { Observation mode } \\
\text { Single-point (S)/Map (M) }\end{array}$ & Telescope \\
\hline \multirow{20}{*}{$\mathrm{CH}_{3} \mathrm{OH}$} & $5_{-1}-4_{0} \mathrm{E}$ & 84.521 & 40.4 & $1.97 \mathrm{E}-06$ & $\mathrm{~S}$ and $\mathrm{M}$ & IRAM-30 m + Nobeyama-45 m \\
\hline & $2_{-1}-1_{-1} \mathrm{E}$ & 96.739 & 12.5 & $2.56 \mathrm{E}-06$ & M & IRAM-30 m \\
\hline & $22_{0}-1_{0} \mathrm{~A}$ & 96.741 & 6.9 & $3.41 \mathrm{E}-06$ & M & IRAM-30 m \\
\hline & $2{ }_{0}-1_{0} \mathrm{E}$ & 96.745 & 20.0 & $3.42 \mathrm{E}-06$ & M & IRAM-30 m \\
\hline & $2{ }_{1}-1, \mathrm{E}$ & 96.755 & 28.0 & $2.62 \mathrm{E}-06$ & M & IRAM-30 m \\
\hline & $5{ }_{1}-4_{1} \mathrm{~A}$ & 239.746 & 49.1 & $5.66 \mathrm{E}-05$ & $\mathrm{~S}$ & IRAM-30 m \\
\hline & $5_{0}-4_{0} \mathrm{E}$ & 241.700 & 47.9 & $6.04 \mathrm{E}-05$ & S & IRAM-30 m \\
\hline & $5-1-4-1 E$ & 241.767 & 40.4 & $5.81 \mathrm{E}-05$ & $S$ & IRAM-30 m \\
\hline & $5_{0}-4_{0} \mathrm{~A}$ & 241.791 & 34.8 & $6.05 \mathrm{E}-05$ & $S$ & IRAM-30 m \\
\hline & $5_{3}-4_{3} \mathrm{~A}$ & $241.832^{(a)}$ & 84.6 & $3.87 \mathrm{E}-05$ & S & IRAM-30 m \\
\hline & $5_{3}-4_{3} \mathrm{~A}$ & $241.833^{(a)}$ & 84.6 & $3.87 \mathrm{E}-05$ & S & IRAM-30 m \\
\hline & $5_{2}-4_{2} \mathrm{~A}$ & 241.842 & 72.5 & $5.11 \mathrm{E}-05$ & $S$ & IRAM-30 m \\
\hline & $5_{3}-4_{3} \mathrm{E}$ & 241.843 & 82.5 & $3.88 \mathrm{E}-05$ & S & IRAM-30 m \\
\hline & $5_{3}-4_{3} \mathrm{E}$ & 241.852 & 97.5 & $3.89 \mathrm{E}-05$ & S & IRAM-30 m \\
\hline & $5,-4_{1} E$ & 241.879 & 55.9 & $5.96 \mathrm{E}-05$ & S & IRAM-30 m \\
\hline & $5_{2}-4_{2} \mathrm{~A}$ & 241.887 & 72.5 & $5.12 \mathrm{E}-05$ & S & IRAM-30 m \\
\hline & $5_{2}-4_{2} \mathrm{E}$ & $241.904^{(a)}$ & 57.1 & $5.03 \mathrm{E}-05$ & S & IRAM-30 m \\
\hline & $5_{2}-4_{2} \mathrm{E}$ & $241.904^{(a)}$ & 60.7 & $5.09 \mathrm{E}-05$ & S & IRAM-30 m \\
\hline & $5{ }_{1}-4_{1} \mathrm{~A}$ & 243.915 & 49.7 & $5.97 \mathrm{E}-05$ & S & IRAM-30 m \\
\hline & $2{ }_{1}-1_{0} \mathrm{E}$ & 261.805 & 28.0 & $5.57 \mathrm{E}-05$ & $S$ & IRAM-30 m \\
\hline \multirow{15}{*}{$\mathrm{CCH}$} & $N=1-0, J=3 / 2-1 / 2, F=1-1$ & 87.284 & 4.2 & $2.60 \mathrm{E}-07$ & $\mathrm{~S}$ and $\mathrm{M}$ & IRAM-30 m + Nobeyama-45 m \\
\hline & $N=1-0, J=3 / 2-1 / 2, F=2-1$ & 87.316 & 4.2 & $1.53 \mathrm{E}-06$ & $\mathrm{~S}$ and $\mathrm{M}$ & IRAM-30 m + Nobeyama-45 m \\
\hline & $N=1-0, J=3 / 2-1 / 2, F=1-0$ & 87.328 & 4.2 & $1.27 \mathrm{E}-06$ & $\mathrm{~S}$ and $\mathrm{M}$ & IRAM-30 m + Nobeyama-45 m \\
\hline & $N=1-0, J=1 / 2-1 / 2, F=1-1$ & 87.402 & 4.2 & $1.27 \mathrm{E}-06$ & $\mathrm{~S}$ and $\mathrm{M}$ & IRAM-30 m + Nobeyama- $45 \mathrm{~m}$ \\
\hline & $N=1-0, J=1 / 2-1 / 2, F=0-1$ & 87.407 & 4.2 & $1.54 \mathrm{E}-06$ & $\mathrm{~S}$ and $\mathrm{M}$ & IRAM-30 m + Nobeyama-45 m \\
\hline & $N=1-0, J=1 / 2-1 / 2, F=1-0$ & 87.446 & 4.2 & $2.61 \mathrm{E}-07$ & $\mathrm{~S}$ and $\mathrm{M}$ & IRAM-30 m + Nobeyama-45 m \\
\hline & $N=3-2, J=7 / 2-5 / 2, F=3-3$ & 261.978 & 25.1 & $1.96 \mathrm{E}-06$ & $\mathrm{~S}$ & IRAM-30 m \\
\hline & $N=3-2, J=7 / 2-5 / 2, F=4-3$ & 262.004 & 25.1 & $5.32 \mathrm{E}-05$ & $\mathrm{~S}$ & IRAM-30 m \\
\hline & $N=3-2, J=7 / 2-5 / 2, F=3-2$ & 262.006 & 25.1 & $5.12 \mathrm{E}-05$ & $\mathrm{~S}$ & IRAM-30 m \\
\hline & $N=3-2, J=5 / 2-3 / 2, F=3-2$ & 262.064 & 25.2 & 4.89E-05 & $\mathrm{S}$ & IRAM-30 m \\
\hline & $N=3-2, J=5 / 2-3 / 2, F=2-1$ & 262.067 & 25.2 & $4.47 \mathrm{E}-05$ & $\mathrm{~S}$ & IRAM-30 m \\
\hline & $N=3-2, J=5 / 2-3 / 2, F=2-2$ & 262.078 & 25.2 & $6.02 \mathrm{E}-06$ & $\mathrm{~S}$ & IRAM-30 m \\
\hline & $N=3-2, J=5 / 2-5 / 2, F=3-3$ & 262.208 & 25.2 & $3.96 \mathrm{E}-06$ & $\mathrm{~S}$ & IRAM-30 m \\
\hline & $N=3-2, J=5 / 2-5 / 2, F=3-2$ & 262.236 & 25.2 & $4.04 \mathrm{E}-07$ & $\mathrm{~S}$ & IRAM-30 m \\
\hline & $N=3-2, J=5 / 2-5 / 2, F=2-2$ & 262.250 & 25.2 & $2.27 \mathrm{E}-06$ & $\mathrm{~S}$ & IRAM-30 m \\
\hline
\end{tabular}

Notes. The last two columns indicate whether the line is observed in the single-pointing observations (S) or in the OTF map (M), and the used telescope. The spectroscopic data for CCH are from Padovani et al. (2009) through the CDMS (Cologne Database for Molecular Spectroscopy: Müller et al. 2005) and for $\mathrm{CH}_{3} \mathrm{OH}$, from Xu et al. (2008) through the JPL molecular spectroscopy database (Jet Propulsion Laboratory: Pickett et al. 1998) databases. ${ }^{(a)}$ Lines blended, they are not used in the LTE and LVG analysis.

checked every $1.5 \mathrm{~h}$ and every six hours respectively throughout the observations and with a pointing accuracy of $\leq 2 \operatorname{arcsec}$ at $1 \mathrm{~mm}$ and of $\leq 5 \operatorname{arcsec}$ at $3 \mathrm{~mm}$.

Additionally, an on-the-fly (OTF) map of size $3^{\prime} \times 3^{\prime} \operatorname{arcmin}^{2}$, centred on the source CSO3 was observed on October 22nd 2018 (see Fig. 1) with a beam size of $30^{\prime \prime}$. The dump time was $1 \mathrm{~s}$ and the sampling interval $10^{\prime \prime}$. The map was repeatedly scanned both along the right ascension (RA) and the declination (Dec) directions until the required root mean square (rms) was reached. We used the EMIR receiver and the FTS units to cover the frequencies from 80.2 to $87.8 \mathrm{GHz}$ and from 95.7 to $103.3 \mathrm{GHz}$. The spectral resolution obtained is $0.7 \mathrm{~km} \mathrm{~s}^{-1}$.

We used the Continuum and Line Analysis Single-dish Software (CLASS) from the GILDAS package ${ }^{1}$ to reduce the two sets

\footnotetext{
1 http://wWw.iram.fr/IRAMFR/GILDAS
}

of data. For the single-pointing observations, a baseline of a firstorder polynomial was subtracted for each scan. Then all spectral scans were stitched together to get a final spectrum for each source. Finally, the intensity was converted from antenna temperature $\left(T_{\mathrm{A}}^{*}\right)$ to main beam temperature $\left(T_{\mathrm{mb}}\right)$ using the Ruze's formula $B_{\text {eff }}=B_{0} \cdot \exp \left[-(4 \pi \sigma / \lambda)^{2}\right]$, the scaling factor $B_{0}=0.863$ and the width factor $\sigma=66 \mu \mathrm{m}$ (from the IRAM website ${ }^{2}$ ). For the OTF map, the baseline was corrected before conversion from $T_{\mathrm{A}}^{*}$ to $T_{\mathrm{mb}}$.

Through an inspection of individual scans, the calibration uncertainties were estimated to be better than 20 and $15 \%$ for the single-pointing and the OTF observations, respectively. The rms sensitivity for a channel width of $195 \mathrm{kHz}$ is in the range

\footnotetext{
2 http://wWw.iram.es/IRAMES/mainWiki/ Iram30mEfficiencies
} 
Table 4. All detected and non-detected lines for each source for the single-pointing observations.

\begin{tabular}{|c|c|c|c|c|c|c|c|c|c|c|}
\hline Molecule & Freq. (GHz) & CSO33 & SIMBA-a & MMS5 & FIR2 ${ }^{(a)}$ & FIR6c $^{(b)}$ & FIR1a & MMS9 & MMS2 & $\mathrm{CSO} 3$ \\
\hline \multirow{14}{*}{$\mathrm{CH}_{3} \mathrm{OH}$} & 84.521 & $\mathrm{Y}$ & $Y$ & $\mathrm{Y}$ & $\mathrm{Y}$ & $\mathrm{O}$ & $\mathrm{Y}$ & $\mathrm{Y}$ & $\mathrm{Y}$ & $\mathrm{Y}$ \\
\hline & 239.746 & Y & $\ldots$ & Y & $\mathrm{O}$ & $\mathrm{O}$ & Y & $\mathrm{Y}$ & Y & $\mathrm{N}$ \\
\hline & 241.700 & $\mathrm{Y}$ & $\ldots$ & $\mathrm{Y}$ & $\mathrm{O}$ & $\mathrm{O}$ & $\mathrm{Y}$ & $\mathrm{Y}$ & $\mathrm{Y}$ & $\mathrm{Y}$ \\
\hline & 241.767 & $\mathrm{Y}$ & $\ldots$ & $\mathrm{Y}$ & $\mathrm{O}$ & $\mathrm{O}$ & $\mathrm{Y}$ & $\mathrm{Y}$ & $\mathrm{Y}$ & $\mathrm{Y}$ \\
\hline & 241.791 & $\mathrm{Y}$ & $\ldots$ & $\mathrm{Y}$ & $\mathrm{O}$ & $\mathrm{O}$ & $\mathrm{Y}$ & $\mathrm{Y}$ & $\mathrm{Y}$ & $\mathrm{Y}$ \\
\hline & 241.832 & $\mathrm{~N}$ & $\ldots$ & $\mathrm{N}$ & $\mathrm{O}$ & $\mathrm{O}$ & $\mathrm{N}$ & $\mathrm{N}$ & $\mathrm{N}$ & $\mathrm{N}$ \\
\hline & 241.833 & $\mathrm{~N}$ & $\ldots$ & $\mathrm{N}$ & $\mathrm{O}$ & $\mathrm{O}$ & $\mathrm{N}$ & $\mathrm{N}$ & $\mathrm{N}$ & $\mathrm{N}$ \\
\hline & 241.842 & $\mathrm{~N}$ & $\ldots$ & $\mathrm{N}$ & $\mathrm{O}$ & $\mathrm{O}$ & $\mathrm{N}$ & $\mathrm{N}$ & $\mathrm{N}$ & $\mathrm{N}$ \\
\hline & 241.879 & $\mathrm{Y}$ & $\ldots$ & $\mathrm{Y}$ & $\mathrm{O}$ & $\mathrm{O}$ & $\mathrm{Y}$ & $\mathrm{Y}$ & $\mathrm{Y}$ & $\mathrm{Y}$ \\
\hline & 241.887 & $\mathrm{~N}$ & $\ldots$ & $\mathrm{Y}$ & $\mathrm{N}$ & $\mathrm{O}$ & $\mathrm{N}$ & $\mathrm{N}$ & $\mathrm{N}$ & $\mathrm{N}$ \\
\hline & 241.904 & Y & $\ldots$ & Y & $\mathrm{O}$ & $\mathrm{O}$ & Y & Y & Y & Y \\
\hline & 241.904 & $\mathrm{Y}$ & $\ldots$ & $\mathrm{Y}$ & $\mathrm{O}$ & $\mathrm{O}$ & $\mathrm{Y}$ & $\mathrm{Y}$ & $\mathrm{Y}$ & $\mathrm{Y}$ \\
\hline & 243.915 & $\mathrm{Y}$ & $\ldots$ & $\mathrm{Y}$ & $\mathrm{Y}$ & $\mathrm{O}$ & $\mathrm{Y}$ & $\mathrm{Y}$ & $\mathrm{Y}$ & $\mathrm{N}$ \\
\hline & 261.805 & $\mathrm{Y}$ & $\ldots$ & $\mathrm{Y}$ & $\mathrm{Y}$ & $\mathrm{O}$ & $\mathrm{Y}$ & $\mathrm{Y}$ & $\mathrm{Y}$ & $\mathrm{Y}$ \\
\hline \multirow{15}{*}{$\mathrm{CCH}$} & 87.284 & $\mathrm{Y}$ & $\mathrm{Y}$ & $\mathrm{Y}$ & $\mathrm{O}$ & $\mathrm{Y}$ & $\mathrm{Y}$ & $\mathrm{Y}$ & $\mathrm{Y}$ & $\mathrm{Y}$ \\
\hline & 87.316 & $\mathrm{Y}$ & $Y$ & $\mathrm{Y}$ & $\mathrm{O}$ & $\mathrm{Y}$ & $\mathrm{Y}$ & $\mathrm{Y}$ & $\mathrm{Y}$ & $\mathrm{Y}$ \\
\hline & 87.328 & $\mathrm{Y}$ & $Y$ & $\mathrm{Y}$ & $\mathrm{O}$ & $\mathrm{Y}$ & $\mathrm{Y}$ & $\mathrm{Y}$ & $\mathrm{Y}$ & $\mathrm{Y}$ \\
\hline & 87.402 & $\mathrm{Y}$ & Y & Y & $\mathrm{O}$ & $\mathrm{Y}$ & Y & Y & $\mathrm{Y}$ & Y \\
\hline & 87.407 & $\mathrm{Y}$ & $\mathrm{Y}$ & $\mathrm{Y}$ & $\mathrm{O}$ & $\mathrm{Y}$ & $\mathrm{Y}$ & $\mathrm{Y}$ & $\mathrm{Y}$ & $\mathrm{Y}$ \\
\hline & 87.446 & $\mathrm{Y}$ & $Y$ & $\mathrm{Y}$ & $\mathrm{O}$ & $\mathrm{Y}$ & $\mathrm{Y}$ & $\mathrm{Y}$ & $\mathrm{Y}$ & $\mathrm{Y}$ \\
\hline & 261.978 & $\mathrm{Y}$ & $\ldots$ & $\mathrm{Y}$ & $\mathrm{O}$ & $\mathrm{Y}$ & $\mathrm{Y}$ & $\mathrm{Y}$ & $\mathrm{Y}$ & $\mathrm{Y}$ \\
\hline & 262.004 & $\mathrm{Y}$ & $\ldots$ & $\mathrm{Y}$ & $\mathrm{O}$ & $\mathrm{Y}$ & $\mathrm{Y}$ & $\mathrm{Y}$ & $\mathrm{Y}$ & $\mathrm{Y}$ \\
\hline & 262.006 & $\mathrm{Y}$ & $\ldots$ & $\mathrm{Y}$ & $\mathrm{O}$ & $\mathrm{Y}$ & $\mathrm{Y}$ & $\mathrm{Y}$ & $\mathrm{Y}$ & $\mathrm{Y}$ \\
\hline & 262.064 & $\mathrm{Y}$ & $\ldots$ & $\mathrm{Y}$ & $\mathrm{O}$ & $\mathrm{Y}$ & $\mathrm{Y}$ & $\mathrm{Y}$ & $\mathrm{Y}$ & $\mathrm{Y}$ \\
\hline & 262.067 & $\mathrm{Y}$ & $\ldots$ & $\mathrm{Y}$ & $\mathrm{O}$ & $\mathrm{Y}$ & $\mathrm{Y}$ & $\mathrm{Y}$ & $\mathrm{Y}$ & $\mathrm{Y}$ \\
\hline & 262.078 & $\mathrm{Y}$ & $\ldots$ & $\mathrm{Y}$ & $\mathrm{O}$ & $\mathrm{Y}$ & $\mathrm{Y}$ & $\mathrm{Y}$ & $\mathrm{Y}$ & $\mathrm{Y}$ \\
\hline & 262.208 & Y & $\ldots$ & Y & $\mathrm{Y}$ & $\mathrm{Y}$ & Y & Y & $\mathrm{Y}$ & $\mathrm{Y}$ \\
\hline & 262.236 & $\mathrm{~N}$ & $\ldots$ & $\mathrm{Y}$ & $\mathrm{Y}$ & $\mathrm{N}$ & $\mathrm{N}$ & $\mathrm{N}$ & $\mathrm{N}$ & $\mathrm{N}$ \\
\hline & 262.250 & $\mathrm{Y}$ & $\ldots$ & $\mathrm{Y}$ & $\mathrm{Y}$ & $\mathrm{Y}$ & $\mathrm{Y}$ & $\mathrm{Y}$ & $\mathrm{Y}$ & $\mathrm{Y}$ \\
\hline
\end{tabular}

Notes. Y stands for detected (SNR $\geq 3$ )and $\mathrm{N}$ for non-detected. The symbol "O" indicates that the line is contaminated by the emission of the outflow wing of an adjacent line making the assessment of a detection impossible. ${ }^{(a)}$ Source left out of analysis due to prominent outflow features (see Table 2). ${ }^{(b)}$ Source left out of analysis due to non-Gaussian shapes in the line profile (see Table 2).

of 9.2-9.6 $\mathrm{mK}\left[T_{\mathrm{A}}^{*}\right]$ for single-pointing and is $20 \mathrm{mK}\left[T_{\mathrm{A}}^{*}\right]$ for the OTF map. The spectra of the source SIMBA-a showed emission at the offset position thus contaminating the final spectrum. This source has thus been left out from any further analysis concerning the IRAM-30 m observations.

\subsection{Nobeyama-45 $m$ telescope}

The observations were carried out between the 10th and the 17th of January 2016. The T70 receiver was used in order to cover the chosen spectral windows from 72 to $76 \mathrm{GHz}$ and from 84 to $88 \mathrm{GHz}$ in the $3 \mathrm{~mm}$ band. A bank of $16 \mathrm{SAM} 45$ auto-correlators were used with a spectral resolution of $244 \mathrm{kHz}$. The resulting beam size is $20^{\prime \prime}$. For each source, position-switch observations were made. Pointing of the telescope was checked by using Orion KL SiO maser emission (Snyder \& Buhl 1974; Wright \& Plambeck 1983) every $1.5 \mathrm{~h}$ throughout the observations with a pointing accuracy of about 4 arcsec.

After inspection of individual scans, the calibration uncertainties were estimated to be better than $40 \%$. The mainbeam temperature $\left(T_{\mathrm{mb}}\right)$ was derived using the telescope main beam efficiency, which is obtained by comparing the $\mathrm{CCH}$ (87.316 GHz) and $\mathrm{H}_{2} \mathrm{CO}(72.84 \mathrm{GHz})$ lines observed towards Orion KL, the reference source. We used the software JNewstar ${ }^{3}$

\footnotetext{
3 https://www.nro.nao.ac.jp/ jnewstar/html
}

developed by the Nobeyama Radio Observatory to reduce the data. The rms sensitivity acquired for a channel width of 244 $\mathrm{kHz}$ is $5 \mathrm{mK}\left[T_{\mathrm{A}}^{*}\right]$.

\section{Results}

In all three data sets, the two single-pointing observations with IRAM-30 $\mathrm{m}$ and Nobeyama- $45 \mathrm{~m}$ plus the map with IRAM$30 \mathrm{~m}$, we extracted the spectra of the lines in Table 3 and fitted the detected ones with Gaussian functions in order to derive the usual parameters, the velocity-integrated intensity, rest velocity, and line full width at half maximum (FWHM).

\subsection{Single-pointing}

The intensity threshold set for the line detection is $3 \sigma$ on the peak intensity of the line for a channel width of $\approx 0.2 \mathrm{~km} \mathrm{~s}^{-1}$ and of $\approx 0.4 \mathrm{~km} \mathrm{~s}^{-1}$ for the IRAM-30 $\mathrm{m}$ and Nobeyama- $45 \mathrm{~m}$ data, respectively. A summary of all transitions of $\mathrm{CCH}$ and of $\mathrm{CH}_{3} \mathrm{OH}$ that have been detected in the source sample is shown in Table 4. Samples of the observed spectra are shown in Fig. 2. The Local Standard Rest velocities $V_{\mathrm{lsr}}$ derived are in the range $10.5-11.6 \mathrm{~km} \mathrm{~s}^{-1}$ for both species. We find line widths in the range from 0.8 to $1.6 \mathrm{~km} \mathrm{~s}^{-1}$ for $\mathrm{CCH}$ and $\mathrm{CH}_{3} \mathrm{OH}$ both at $1 \mathrm{~mm}$ and $3 \mathrm{~mm}$, as shown in Fig. 3. Furthermore, when superimposing 


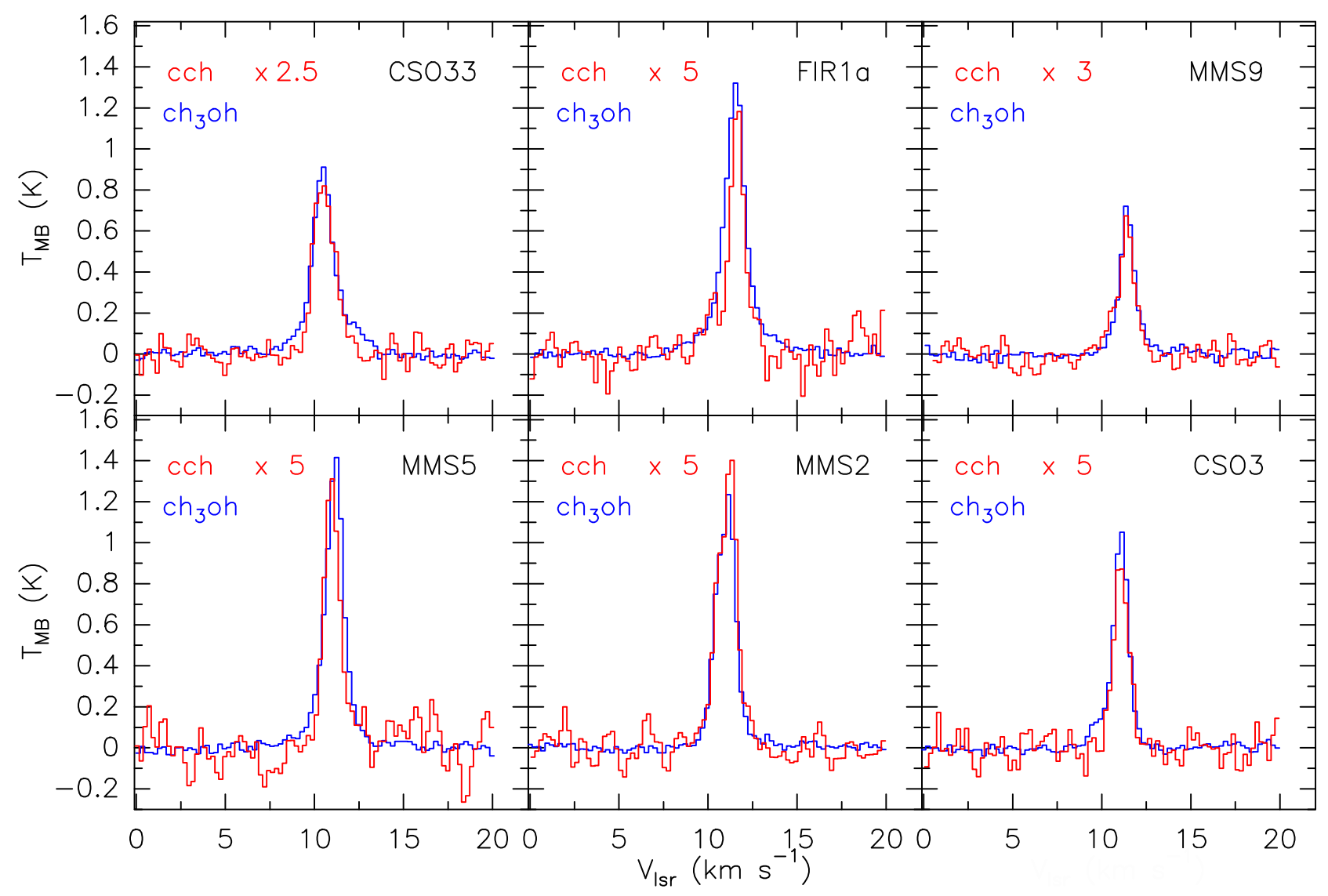

Fig. 2. Spectra of the $\mathrm{CCH}(N=3,2, J=5 / 2-3 / 2, F=2-2$; red $)$ and $\mathrm{CH}_{3} \mathrm{OH}\left(5_{0}-4_{0}\right.$ A; blue $)$ lines observed with the IRAM-30 $\mathrm{m}$ telescope towards six sources of the sample that show well-constrained line profiles suitable for the analysis (see Sect. 5.1) and for which $1 \mathrm{~mm}$ data are available (see Table 2). For the purposes of visibility, the spectra of $\mathrm{CCH}$ has been increased by various scale factors in order to match the size of the $\mathrm{CH}_{3} \mathrm{OH}$ lines.

the most intense ${ }^{4}$ lines of $\mathrm{CCH}$ and $\mathrm{CH}_{3} \mathrm{OH}$ from the IRAM$30 \mathrm{~m}$ data, as shown in Fig. 2, the similarity of the shape of the lines is evident. The detected lines of each species for each source are reported in Appendix A.

In FIR2, high-velocity components suggestive of outflows have been detected around multiple lines. In particular, $\mathrm{CH}_{3} \mathrm{OH}$ lines display a prominent high-velocity component that blends with the ambient component at the $V_{\text {lsr }}$ of the source. Disentangling the ambient from the high-velocity component of $\mathrm{CH}_{3} \mathrm{OH}$ lines with the current data set was thus impossible. Similarly, in FIR6c, important high-velocity emission is present and as a consequence, the lines of $\mathrm{CH}_{3} \mathrm{OH}$ have non-Gaussian shapes. We could not isolate the component tracing the ambient envelope. These two sources have been left out from further analysis. The $N=5-4$ transition of $\mathrm{CH}_{3} \mathrm{OH}$ for those two sources is shown in Appendix A.

Table 5 presents the statistics results from the Gaussian fits. The fit parameters for each molecule and for each source are presented in Appendix B.1. In most cases, we could fit the lines with a single Gaussian component. The most intense lines of $\mathrm{CH}_{3} \mathrm{OH}$ and $\mathrm{CCH}$ show a broad $\left(\sim 4 \mathrm{~km} \mathrm{~s}^{-1}\right)$ component and could be fitted with two Gaussian curves. However, due to the small number of broad components clearly detected for each source, we do not have enough data to characterise this second component which could be associated with outflowing motions. We will thus

\footnotetext{
4 The most intense lines of $\mathrm{CCH}$ being blended, we chose the next intense one.
}

focus on the narrow component $\left(\leq 2 \mathrm{~km} \mathrm{~s}^{-1}\right)$ of the lines in what follows.

\subsection{Maps}

The intensity threshold set for the line detection is $3 \sigma$ on the peak intensity of the line and for a channel width of $\approx 0.7 \mathrm{~km} \mathrm{~s}^{-1}$. Figure 4 shows velocity-integrated maps of the $\mathrm{CCH}(N=1-0$, $J=3 / 2-1 / 2, F=1-0)$ and of the $\mathrm{CH}_{3} \mathrm{OH}\left(2_{-1}-1_{-1}\right.$ E) lines. The integration has been done in the velocity range of 7.9$12.8 \mathrm{~km} \mathrm{~s}^{-1}$ for both lines. The sources MMS5, MMS2, and $\mathrm{CSO} 3$ are in the field of the mapped region. In Fig. 4, we can see that the two lines peak at the position near the sources MMS2 and $\mathrm{CSO} 3$. In addition, $\mathrm{CH}_{3} \mathrm{OH}$ shows two other peaks, south and west of the protostars. The emission of $\mathrm{CCH}$ is more extended than that of the $\mathrm{CH}_{3} \mathrm{OH}$. For clarity, we will refer to the West peak of methanol as the position "W". Based on the $\mathrm{CH}_{3} \mathrm{OH}$ observations, the peak which is located south of the sources can be explained by the presence of outflows that are driven by MMS5 and MMS2 (also seen in CO by Takahashi et al. 2008). The methanol peak at position "W" does not seem to correspond with any outflow. The reason of this peak is thus unknown and we will not discuss any further its origin as it is not the goal of this paper. All the lines presented in Table 3 have been detected. For $\mathrm{CCH}$, the most intense line at $87.316 \mathrm{GHz}$ is detected in $99 \%$ of the map. The next two most intense lines ( 87.328 and $87.402 \mathrm{GHZ}$ ) are detected in $90 \%$ of the map. The line at $87.407 \mathrm{GHz}$ is detected in $85 \%$ of the map. Finally, the 
Table 5. Mean derived properties from Gaussian fits for each source and for each set of observations.

\begin{tabular}{|c|c|c|c|c|c|c|c|c|}
\hline \multirow[b]{2}{*}{ Source } & \multicolumn{2}{|c|}{ IRAM } & \multicolumn{2}{|c|}{ Nobeyama } & \multicolumn{2}{|c|}{ IRAM } & \multicolumn{2}{|c|}{ Nobeyama } \\
\hline & $\begin{array}{l}V_{\mathrm{lsr} \mathrm{CH}_{3} \mathrm{OH}} \\
{\left[\mathrm{km} \mathrm{s}^{-1}\right]}\end{array}$ & $\begin{array}{c}V_{1 \mathrm{lsr} \mathrm{CCH}} \\
{\left[\mathrm{km} \mathrm{s}^{-1}\right]}\end{array}$ & $\begin{array}{l}V_{\mathrm{lsr} \mathrm{CH}_{3} \mathrm{OH}} \\
{\left[\mathrm{km} \mathrm{s}^{-1}\right]}\end{array}$ & $\begin{array}{c}V_{\mathrm{lsr} \mathrm{CCH}} \\
{\left[\mathrm{km} \mathrm{s}^{-1}\right]}\end{array}$ & $\begin{array}{c}F W \mathrm{HM}_{\mathrm{CH}_{3} \mathrm{OH}} \\
{\left[\mathrm{km} \mathrm{s}^{-1}\right]}\end{array}$ & $\begin{array}{c}F W H M_{\mathrm{CCH}} \\
{\left[\mathrm{km} \mathrm{s}^{-1}\right]}\end{array}$ & $\begin{array}{c}F W H M_{\mathrm{CH}_{3} \mathrm{OH}} \\
{\left[\mathrm{km} \mathrm{s}^{-1}\right]}\end{array}$ & $\begin{array}{c}F W H M_{\mathrm{CCH}} \\
{\left[\mathrm{km} \mathrm{s}^{-1}\right]}\end{array}$ \\
\hline CSO33 & $10.5 \pm 0.1$ & $10.5 \pm 0.1$ & $10.7 \pm 0.2$ & $10.6 \pm 0.2$ & $1.6 \pm 0.2$ & $1.4 \pm 0.1$ & $1.4 \pm 0.2$ & $1.3 \pm 0.2$ \\
\hline FIR1a & $11.6 \pm 0.1$ & $11.6 \pm 0.1$ & $11.3 \pm 0.2$ & $11.3 \pm 0.2$ & $1.2 \pm 0.1$ & $1.0 \pm 0.1$ & $1.4 \pm 0.2$ & $1.2 \pm 0.2$ \\
\hline MMS9 & $11.4 \pm 0.1$ & $11.4 \pm 0.1$ & $11.5 \pm 0.2$ & $11.6 \pm 0.2$ & $1.0 \pm 0.1$ & $0.8 \pm 0.1$ & $1.3 \pm 0.2$ & $1.0 \pm 0.2$ \\
\hline MMS5 & $11.1 \pm 0.1$ & $11.0 \pm 0.1$ & $11.4 \pm 0.2$ & $11.2 \pm 0.2$ & $1.2 \pm 0.1$ & $1.0 \pm 0.1$ & $1.1 \pm 0.2$ & $1.0 \pm 0.2$ \\
\hline MMS2 & $11.1 \pm 0.1$ & $11.2 \pm 0.1$ & $11.1 \pm 0.2$ & $10.8 \pm 0.2$ & $1.2 \pm 0.1$ & $1.4 \pm 0.1$ & $1.2 \pm 0.2$ & $1.6 \pm 0.2$ \\
\hline CSO3 & $11.1 \pm 0.1$ & $11.1 \pm 0.1$ & $11.2 \pm 0.2$ & $10.9 \pm 0.2$ & $0.8 \pm 0.1$ & $0.9 \pm 0.1$ & $1.0 \pm 0.2$ & $1.0 \pm 0.2$ \\
\hline SIMBA-a & $\ldots$ & $\ldots$ & $10.5 \pm 0.2$ & $10.5 \pm 0.2$ & $\ldots$ & $\ldots$ & $0.9 \pm 0.2$ & $1.1 \pm 0.2$ \\
\hline
\end{tabular}

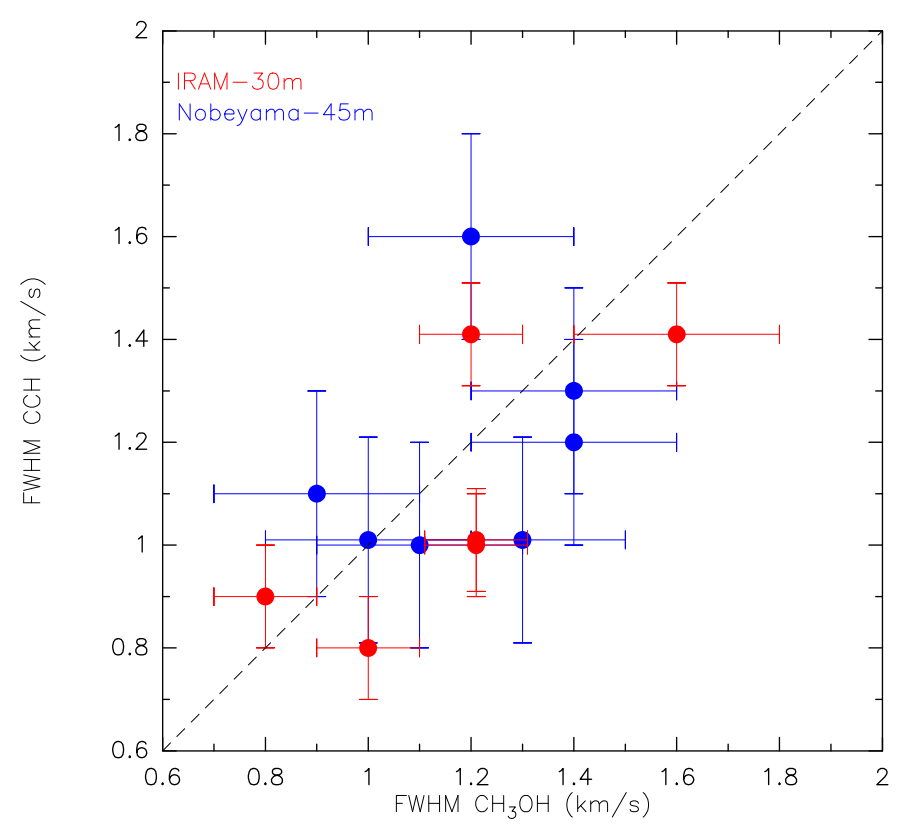

Fig. 3. Average widths (FWHM) of the $\mathrm{CCH}$ (y-axis) and $\mathrm{CH}_{3} \mathrm{OH}$ ( $x$-axis) lines observed in each source of Table 2, using the IRAM$30 \mathrm{~m}$ (red) and the Nobeyama-45 m (blue), respectively. The errors are $1 \sigma$ of the average values. This shows that the two molecules are emitted in a similar and quiescent region (Sect. 5.1). We note that only six sources are reported for the IRAM-30 m observations and seven for the Nobeyama- $45 \mathrm{~m}$ : this is because the sources FIR6c and FIR2 have been left out from the analysis in both set of observations, the lines being blended with outflows (see Table 2). The source SIMBA-a is contaminated by the wobbler off position only in the IRAM-30 m data set. We could thus perform the analysis with Nobeyama- $45 \mathrm{~m}$ (see Table 2).

two least intense lines ( 87.284 and $87.446 \mathrm{GHz})$ are detected in $58 \%$ of the map. For $\mathrm{CH}_{3} \mathrm{OH}$, the most intense lines (96.741 and $96.739 \mathrm{GHz}$ ) are present on $65 \%$ of the map on average. Then the lines at 84.521 and $96.445 \mathrm{GHz}$ are present on $30 \%$ of the map. Finally, the least intense line at $96.755 \mathrm{GHz}$ is present on $6 \%$ of the map and its emission is concentrated at the methanol peak at position "W".

Moments 1 and 2 for those same lines are shown in Fig. B.1. From the moment maps, we see that the velocities are rather constant throughout the map with a low-velocity region at the location of the second peak of $\mathrm{CH}_{3} \mathrm{OH}$. The line widths of $\mathrm{CH}_{3} \mathrm{OH}$ are slightly larger $\left(1.5 \mathrm{~km} \mathrm{~s}^{-1}\right.$ instead of $1 \mathrm{~km} \mathrm{~s}^{-1}$ in the rest of the filament) where the methanol peaks, south-east of the sources. Considering that the sources MMS5 and MMS2 drive outflows, this may be the reason of this slight increase. For $\mathrm{CCH}$, the line width is on average 1 to $1.5 \mathrm{~km} \mathrm{~s}^{-1}$ towards the centre and gets larger $\left(>2.0 \mathrm{~km} \mathrm{~s}^{-1}\right)$ to the North West. From the line shapes, we find that the $\mathrm{CCH}$ is double peaked in the north of the region, explaining the increase of the line width. A further analysis of the line shape shows that there is a second component located at a rest velocities at $10 \mathrm{~km} \mathrm{~s}^{-1}$ in the North west of the filament and $9 \mathrm{~km} \mathrm{~s}^{-1}$ where there is the $\mathrm{CH}_{3} \mathrm{OH}$ peak. This specific line shape is only seen in the $\mathrm{CCH}$ and not in the $\mathrm{CH}_{3} \mathrm{OH}$ lines suggesting an even more external component with mainly $\mathrm{CCH}$ in the north of the filament. This could be explained by the fact that $\mathrm{CCH}$ is more enhanced by the UV photons than $\mathrm{CH}_{3} \mathrm{OH}$. This $\mathrm{CCH}$ component would thus probe the outer layers of the cloud, an area that is more exposed to the interstellar field. In the following, we will consider only the component of $\mathrm{CCH}$ that is common with the $\mathrm{CH}_{3} \mathrm{OH}$, as the second component of $\mathrm{CCH}$ does not coincide with the position of the sources and as our goal is solely to place constraints on the region of emission in which both $\mathrm{CCH}$ and $\mathrm{CH}_{3} \mathrm{OH}$ are present.

\section{Physical parameters and $[\mathrm{CCH}] /\left[\mathrm{CH}_{3} \mathrm{OH}\right]$ abundance ratios}

\subsection{Description of the modelling}

We used two methods to derive the physical parameters of the emitting gas and the $[\mathrm{CCH}] /\left[\mathrm{CH}_{3} \mathrm{OH}\right]$ abundance ratios. We first used an approach based on the local thermal equilibrium (LTE) approximation (as a consistency check) and then we carried out a non-LTE analysis.

In the LTE approach, we used the usual rotational diagram for the $\mathrm{CH}_{3} \mathrm{OH}$ lines and the fitting of the hyperfine structure for the $\mathrm{CCH}$ lines. Both methods allow us to derive the rotational or excitation temperature and the beam-averaged column density, assuming that the emission is extended, as shown by the maps (Sect. 5). In addition, the rotational diagram approach assumes that the lines are optically thin, an assumption which we verified a posteriori to be correct (see below).

For the non-LTE analysis, we used the large velocity gradient (LVG) model developed by Ceccarelli et al. (2003). For $\mathrm{CH}_{3} \mathrm{OH}$, we used the $\mathrm{CH}_{3} \mathrm{OH}-\mathrm{H}_{2}$ collisional rates from Flower et al. (2010) through the BASECOL database ${ }^{5}$ (Dubernet et al. 2013). Please note that for the LVG analysis, we used the $\mathrm{CH}_{3} \mathrm{OH}-\mathrm{E}$ species and assumed a ratio $\mathrm{CH}_{3} \mathrm{OH}-\mathrm{E} / \mathrm{CH}_{3} \mathrm{OH}-\mathrm{A}$ equal to 1 to retrieve the total column density of $\mathrm{CH}_{3} \mathrm{OH}$ and thus calculate the abundance ratio $[\mathrm{CCH}] /\left[\mathrm{CH}_{3} \mathrm{OH}\right]$. For $\mathrm{CCH}$, we used

5 https://basecol.vamdc.eu 


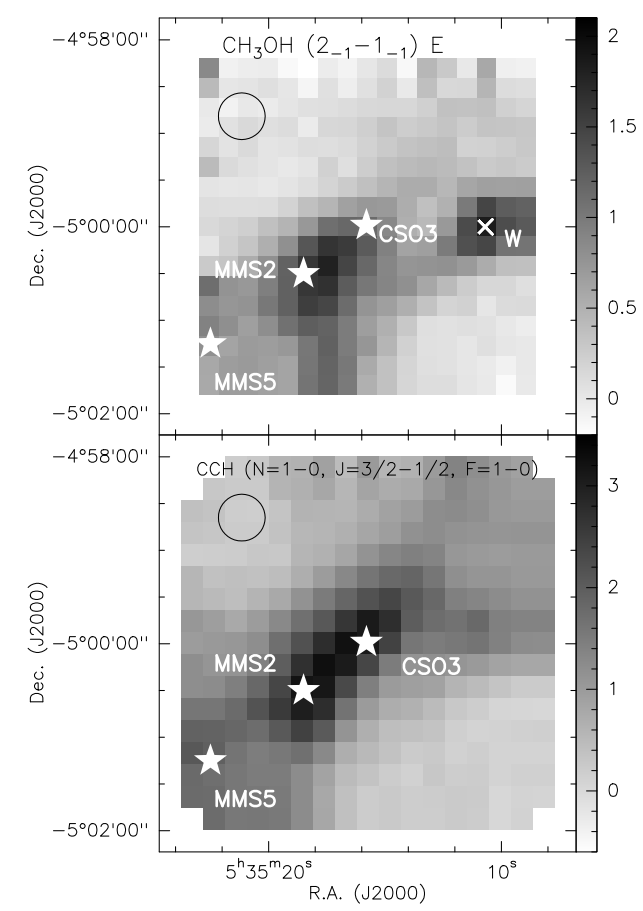

Fig. 4. Map of $\mathrm{CH}_{3} \mathrm{OH}\left(2_{-1}-1_{-1} \mathrm{E}\right)$ and $\mathrm{CCH}(N=1-0, J=3 / 2-1 / 2$, $F=1-0)$ lines, integrated between 7.9 and $12.8 \mathrm{~km} \mathrm{~s}^{-1}$. The stars represents the sources MMS5, MMS2 and CSO3. The West peak of methanol is represented by a white cross. The filled circle represent the IRAM-30 $\mathrm{m}$ beam size of $30^{\prime \prime}$.

the $\mathrm{CCH}-\mathrm{H}_{2}$ collisional rates, from Dagdigian (2018). For each source, we ran large grids of models varying the model parameters: the $\mathrm{CH}_{3} \mathrm{OH}-\mathrm{E}$ and $\mathrm{CCH}$ column density, $N_{\mathrm{CH}_{3} \mathrm{OH}-\mathrm{E}}$ and $N_{\mathrm{CCH}}$, from $5 \times 10^{11}$ to $1 \times 10^{17} \mathrm{~cm}^{-2}$ the kinetic temperature, $T_{\text {kin }}$, from 2 to $200 \mathrm{~K}$; the gas density, $n\left(\mathrm{H}_{2}\right)$, from $5 \times 10^{3}$ to $1 \times 10^{10} \mathrm{~cm}^{-3}$. Those ranges of parameters have been chosen according to the values typically found in molecular cores, PDRs, and protostellar envelopes, as we expect the emission to come from those types of environments. The source size was fixed and set as extended. We ran beforehand the LVG model for the source MMS2, present in the OTF map, with the source size set as a free parameter. The result gave a source size significantly larger than the beam size $\left(\geq 150^{\prime \prime}\right)$, confirming the extended characteristic of the source. We thus fixed the source size as extended (the filling factor is thus equal to 1) for the LVG analysis. Finally, the line width was taken equal to the measured FWHM for each source (Table 5).

In the following, we present the non-LTE analysis results of both the single pointing observations towards six out of the nine target sources (Table 2) and the map of the northern cloud (Fig. 4). The results of the LTE analysis for both single pointing observations and for the OTF map are presented in Appendix C.

\subsection{Physical parameters and abundance ratio towards the sources}

We analysed the line emission towards six out of the nine sources of Table 2. In SIMBA-a, the number of detected lines is too small to obtain meaningful results, while in FIR2 and FIR6c, the line emission is dominated by the outflow.

For each source, the best fit values were found by comparing the LVG model predictions with the observations as follows: for each column density, the minimum $\chi^{2}$ was found with respect to the density-temperature parameter space, and then the best fit values of density and temperature were derived. The error on each fitted parameter was defined by the $1 \sigma$ distribution. The results of the analysis are summarised in Table 6 and the densitytemperature $\chi^{2}$ contour plots obtained for each source are shown in Figs. 5 and 6 (source CSO33).

The following results are immediately evident, when one excludes CSO33, the source of the sample closest to the Trapezium OB stars cluster:

1. All sources have similar gas density and temperature.

2. While the density and temperature of the gas emitting the methanol lines are well constrained, the density and temperature values are degenerate for the gas emitting $\mathrm{CCH}$. This is because the $\mathrm{CCH}$ lines cover a relatively smaller transition upper level energy range with respect to the methanol lines.

3. The gas emitting methanol and $\mathrm{CCH}$ do not have the same density and temperature. Either $\mathrm{CCH}$ originates in a less dense or a colder gas, or both, than the gas emitting methanol. The case of MMS9 would suggest that $\mathrm{CCH}$ is emitted in a colder gas than methanol.

4. The gas emitting methanol lines has a temperature that is relatively similar, between 12 and $30 \mathrm{~K}$ (considering the errors), and a density also rather similar among the different sources, $(1-3) \times 10^{6} \mathrm{~cm}^{-3}$. These low temperatures are incompatible with the hypothesis that methanol lines originate in a hot corino like region, as we will discuss in more detail in Sect. 7.

5. In the same vein, the relatively low temperatures, $\leq 30 \mathrm{~K}$, of the gas emitting $\mathrm{CCH}$ are compatible with an origin from the cold envelopes of the sources or their parental molecular cloud.

6. What is particularly relevant to the goal of this work is that the $[\mathrm{CCH}] /\left[\mathrm{CH}_{3} \mathrm{OH}\right]$ abundance ratio is similar in all sources, within the errors, and equal to about 6 (with a range from 1.5 to 13.5 considering the errors).

\subsection{Temperature and density of the extended gas}

We also ran the LVG model for the map. However, considering that for $\mathrm{CCH}$ we have only the $N=1-0$ transition, it was not possible to do an LVG analysis with this species. For $\mathrm{CH}_{3} \mathrm{OH}-\mathrm{E}$, we took into account positions with at least three lines to perform the LVG analysis. As for the single-pointing, the gas temperature and gas density derived for each position are based on the best fit for the column density.

The results of the LVG analysis of $\mathrm{CH}_{3} \mathrm{OH}-\mathrm{E}$ are shown in Fig. 7. Within the error bars (about 5-10 K), the temperature of the gas emitting the methanol is rather constant across the cloud, around $15-20 \mathrm{~K}$, with a slightly lower temperature, between 12$10 \mathrm{~K}$, at the border of the cloud. Again within the error bars (a factor two), the $\mathrm{H}_{2}$ density is also relatively constant across the cloud, with the bulk of the emission originating from a gas at density (5-9) $\times 10^{6} \mathrm{~cm}^{-3}$ and possibly a slightly less dense halo surrounding it. We verified the non-variation of the properties of the $\mathrm{CH}_{3} \mathrm{OH}$ emitting gas throughout the filament by deriving the intensity ratio of two optically thin lines of methanol (see Appendix B.2). When considering the error bars, both the temperature and the density are very similar to those derived towards the three sources in the field: CSO3, MMS2, and MMS5. In other words, there is no clear evidence that the detected methanol emission originates in the three sources rather than in the parent cloud gas belonging to the cloud.

Finally, also the methanol column density is, within a factor of 3 , constant across the cloud and no obvious increase is seen 
Table 6. Kinetic temperature $\left(T_{\text {kin }}\right)$, total column densities $\left(N_{\text {tot }}\right)$ and abundance ratio $[\mathrm{CCH}] /\left[\mathrm{CH}_{3} \mathrm{OH}\right]$ derived from $\mathrm{CH}_{3} \mathrm{OH}-\mathrm{E}$ and $\mathrm{CCH}$.

\begin{tabular}{|c|c|c|c|c|c|c|c|}
\hline Source & $\begin{array}{c}T_{\text {kin }}\left(\mathrm{CH}_{3} \mathrm{OH}\right) \\
{[\mathrm{K}]} \\
\end{array}$ & $\begin{array}{c}N_{\mathrm{CH}_{3} \mathrm{OH}-\mathrm{E}} \\
{\left[\times 10^{13} \mathrm{~cm}^{-2}\right]}\end{array}$ & $\begin{array}{c}n\left(\mathrm{H}_{2}\right) \\
{\left[\times 10^{6} \mathrm{~cm}^{-3}\right]}\end{array}$ & $\begin{array}{c}T_{\mathrm{kin}}(\mathrm{CCH}) \\
{[\mathrm{K}]} \\
\end{array}$ & $\begin{array}{c}N_{\mathrm{CCH}} \\
{\left[\times 10^{14} \mathrm{~cm}^{-2}\right]}\end{array}$ & $\begin{array}{c}n\left(\mathrm{H}_{2}\right) \\
{\left[\times 10^{4} \mathrm{~cm}^{-3}\right]}\end{array}$ & {$[\mathrm{CCH}] /\left[\mathrm{CH}_{3} \mathrm{OH}\right]$} \\
\hline $\mathrm{CSO} 33$ & $70_{-28}^{+40}$ & $2_{-0.5}^{+3}$ & $5_{-2}^{+7}$ & $15_{-4}^{+105}$ & $3_{-1.5}^{+1}$ & $>5$ & $7.5_{-4}^{+6}$ \\
\hline FIR1a & $22_{-6}^{+6}$ & $3_{-1}^{+1}$ & $2_{-0.5}^{+2}$ & $11_{-2}^{+24}$ & $2_{-1}^{+1}$ & $>4$ & $3.5_{-2}^{+2}$ \\
\hline MMS9 & $24_{-6}^{+11}$ & $1.5_{-0.5}^{+0.5}$ & $2_{-1}^{+1}$ & $10_{-2}^{+5}$ & $2_{-1}^{+1}$ & $>8$ & $6.5_{-3.5}^{+3.5}$ \\
\hline MMS5 & $19_{-5}^{+9}$ & $3_{-1}^{+1.5}$ & $9_{-6}^{+400}$ & $8_{-1}^{+8}$ & $4_{-2}^{+3}$ & $>4$ & $6.5_{-3.5}^{+5}$ \\
\hline MMS2 & $19_{-4}^{+4}$ & $4_{-1.5}^{+2}$ & $1_{-0.3}^{+1.5}$ & $11_{-3}^{+5}$ & $6_{-3.5}^{+4}$ & $>4$ & $7.5_{-3}^{+5}$ \\
\hline CSO3 & $14_{-2}^{+3}$ & $3_{-1}^{+1.5}$ & $1_{-0.6}^{+1.5}$ & $8_{-1}^{+8}$ & $3_{-1.5}^{+2.5}$ & $>4$ & $5_{-3}^{+4}$ \\
\hline
\end{tabular}

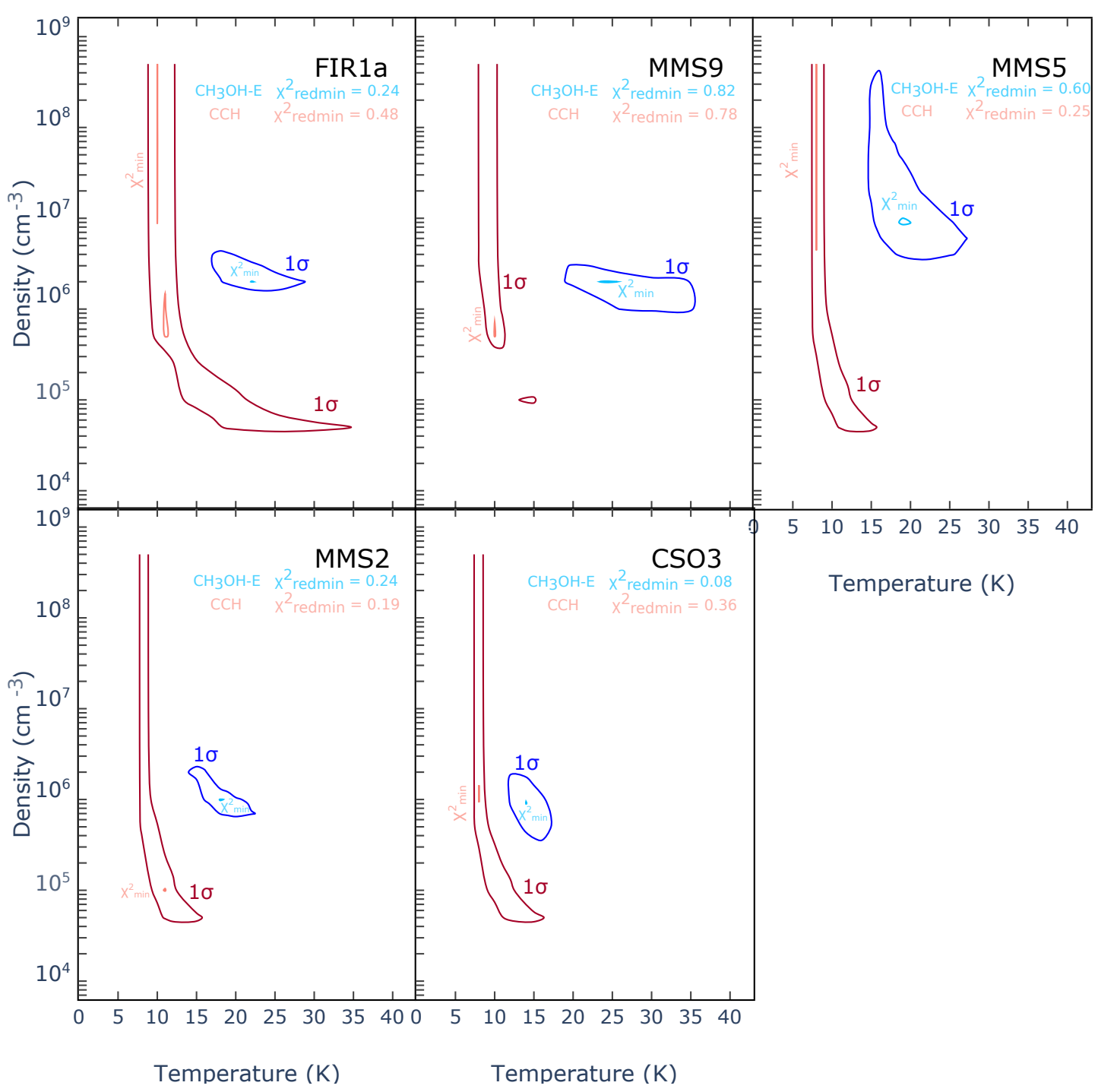

Fig. 5. Density versus temperature contour plot for all the sources except CSO33 (see Fig. 6). The minimum $\chi^{2}$ and the $1 \sigma$ contour plot are obtained for a minimum value of the $\chi^{2}$ in the column density parameter. The values of the reduced $\chi_{\text {redmin }}^{2}$ are quoted in the upper corner of each panel.

in correspondence with CSO3, and only by a factor of 5 towards MMS2 and MMS5 (which lies at the border of the map, so the result has to be taken with caution).

\section{4. $[\mathrm{CCH}] /\left[\mathrm{CH}_{3} \mathrm{OH}\right]$ abundance ratio across the northern cloud}

As we stated in the previous section, in the map of the northern cloud, we could not derive the $[\mathrm{CCH}] /\left[\mathrm{CH}_{3} \mathrm{OH}\right]$ abundance ratio via a non-LTE analysis because of the limited number of $\mathrm{CCH}$ lines observed. We therefore used the LTE approach for deriving the $\mathrm{CCH}$ and methanol column density in each pixel, which is sampled every half beam. In order to derive the abundance ratio, we assume that $\mathrm{CCH}$ and $\mathrm{CH}_{3} \mathrm{OH}$ are emitted in the same region. In total, 81 positions throughout the map were extracted and analysed. Of those, we took into account positions with at least three lines for both $\mathrm{CCH}$ and $\mathrm{CH}_{3} \mathrm{OH}$. For $\mathrm{CCH}$ we used the hyperfine line structure whereas for $\mathrm{CH}_{3} \mathrm{OH}$ we used the 


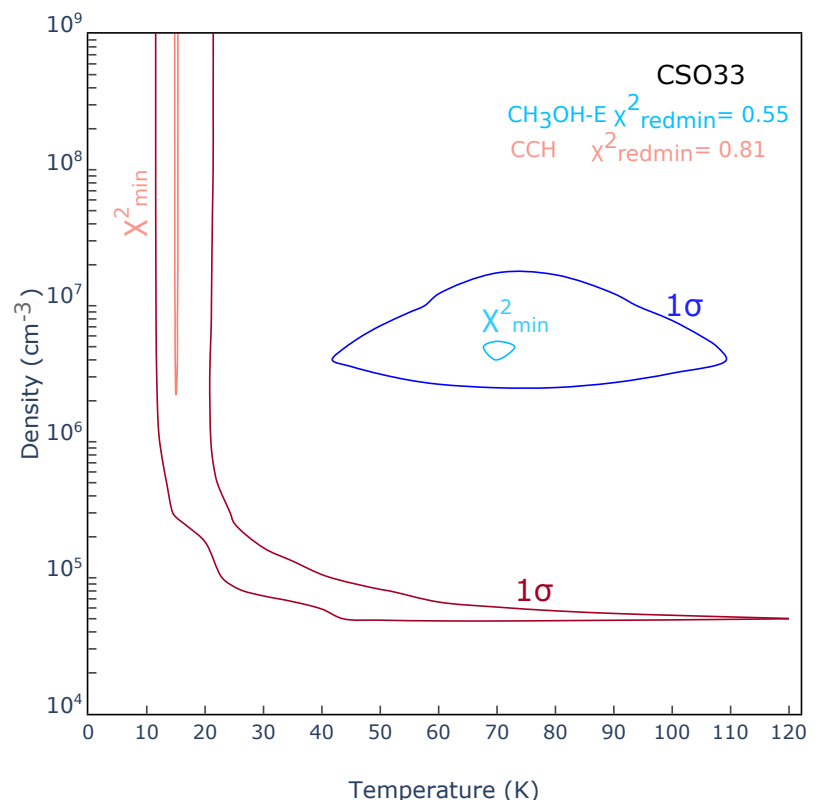

Fig. 6. Density versus temperature contour plot for the source CSO33. The source CSO33 represents an extreme case, with the largest temperature of the analysed sample. This is probably because CSO33 is the closest to the Trapezium OB stars cluster. The minimum $\chi^{2}$ and the $1 \sigma$ contour plot are obtained for a minimum value of the $\chi^{2}$ in the column density parameter. The values of the reduced $\chi_{\text {redmin }}^{2}$ are quoted in the upper corner of the panel.

rotational diagram method, as described in Sect. 6.1. The results of the LTE analysis are reported in Table C.3.

The derived total column densities are in the range $(2-11) \times$ $10^{14} \mathrm{~cm}^{-2}$ for $\mathrm{CCH}$ and in the range $(2-16) \times 10^{13} \mathrm{~cm}^{-2}$ for $\mathrm{CH}_{3} \mathrm{OH}$, which is in quite good agreement with the values derived by the non-LTE analysis. The map of the $[\mathrm{CCH}] /\left[\mathrm{CH}_{3} \mathrm{OH}\right]$ abundance ratio is shown in Fig. 8. It shows an overall gradient from north to south, with the northern part of the cloud more enriched in $\mathrm{CCH}$ with respect to $\mathrm{CH}_{3} \mathrm{OH}$ than the southern part. On the other hand, we do not see any significant variation of the abundance ratio in correspondence of the positions of the protostars in the field. In other words, the $[\mathrm{CCH}] /\left[\mathrm{CH}_{3} \mathrm{OH}\right]$ abundance ratio is more associated with the parent cloud gas in the cloud than with the protostars themselves.

\section{Discussion}

\subsection{The ambiguous origin of the $\mathrm{CCH}$ and $\mathrm{CH}_{3} \mathrm{OH}$ line emission towards the targeted sources}

The first goal of this work is to identify the nature of the surveyed sources, whether they are hot corinos or WCCC objects (Sect. 1). As done in previous surveys (Sect. 2), we observed several $\mathrm{CCH}$ and $\mathrm{CH}_{3} \mathrm{OH}$ lines in order to derive their relative abundance ratio and, consequently, to assess the sources chemical nature: it is a hot corino if $[\mathrm{CCH}] /\left[\mathrm{CH}_{3} \mathrm{OH}\right]$ is less than about 0.5 and WCCC object if larger than about 2. Based on this definition and the derived $[\mathrm{CCH}] /\left[\mathrm{CH}_{3} \mathrm{OH}\right]$ abundance ratios $(\sim 6$ : Table 6), we could argue that all the sources in OMC-2/3 are WCCC objects. However, before taking this conclusion as final, we have to be sure that the emission towards the sources is due to the sources themselves and that it is not polluted, nor dominated, by the emission from the cloud to which the sources belong -which is the second goal of this study. We therefore start the discussion on this point first.
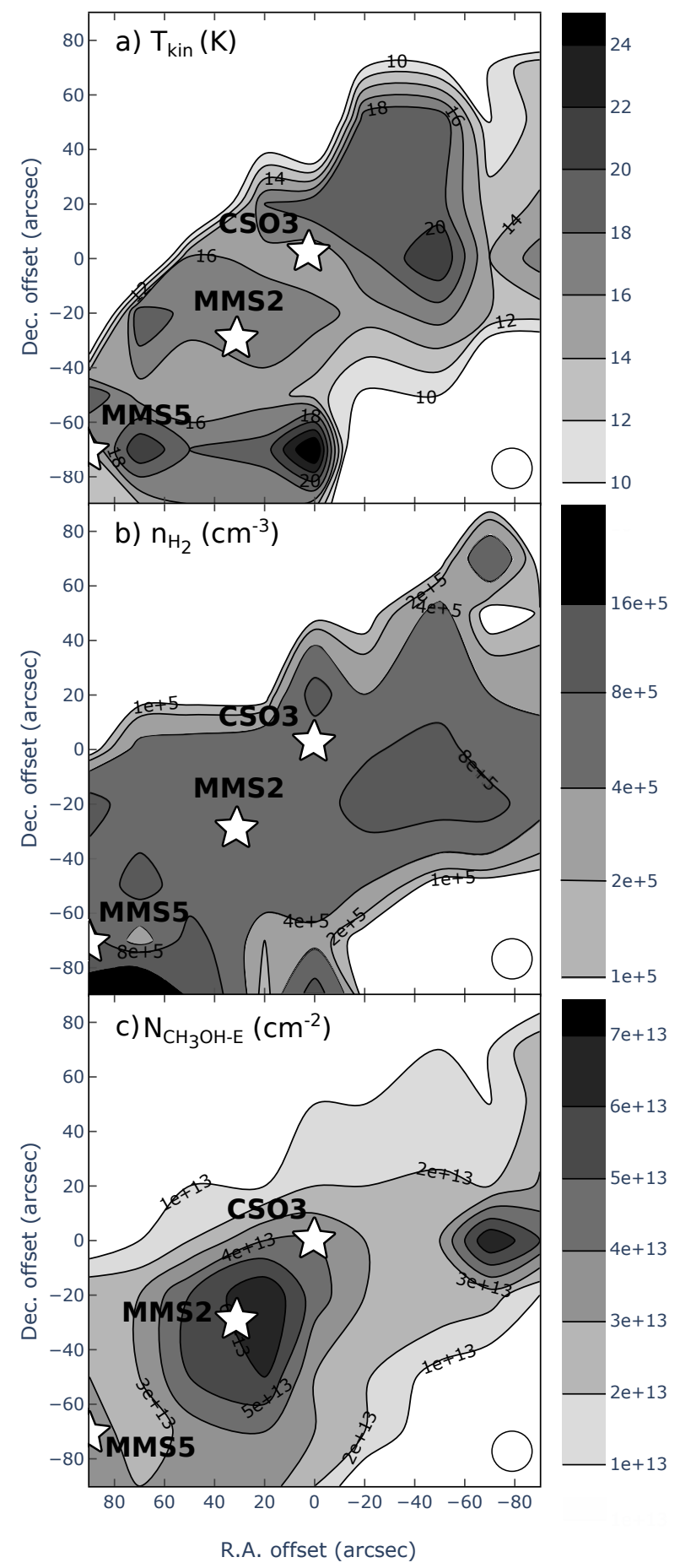

Fig. 7. Map of the $\mathrm{CH}_{3} \mathrm{OH}-\mathrm{E}$ column density (bottom panel), temperature (top panel), and density (central panel) of the gas emitting the methanol lines in the northern cloud, which is shown in Fig. 1, as derived by the non-LTE analysis described in Sect. 6.4. The size of the beam $\left(30^{\prime \prime}\right)$ is shown by a white filled circle at the bottom right of each map, the position of the protostars are represented by white stars. We note that the average error bar in the derived temperature is $5-10 \mathrm{~K}$; in the density, it is a factor of two and in the $\mathrm{CH}_{3} \mathrm{OH}-\mathrm{E}$ column density, it is $3 \times 10^{13} \mathrm{~cm}^{-3}$.

We begin by summarising the results of our analysis of the observations towards the sources:

1. The $\mathrm{CCH}$ and $\mathrm{CH}_{3} \mathrm{OH}$ line widths are narrow $(0.8-$ $1.6 \mathrm{~km} \mathrm{~s}^{-1}$ : Fig. 2) and their spectral shapes (Fig. 3) are very similar between them and among the sources: this first result 


\section{$[\mathrm{CCH}] /\left[\mathrm{CH}_{3} \mathrm{OH}\right]$}

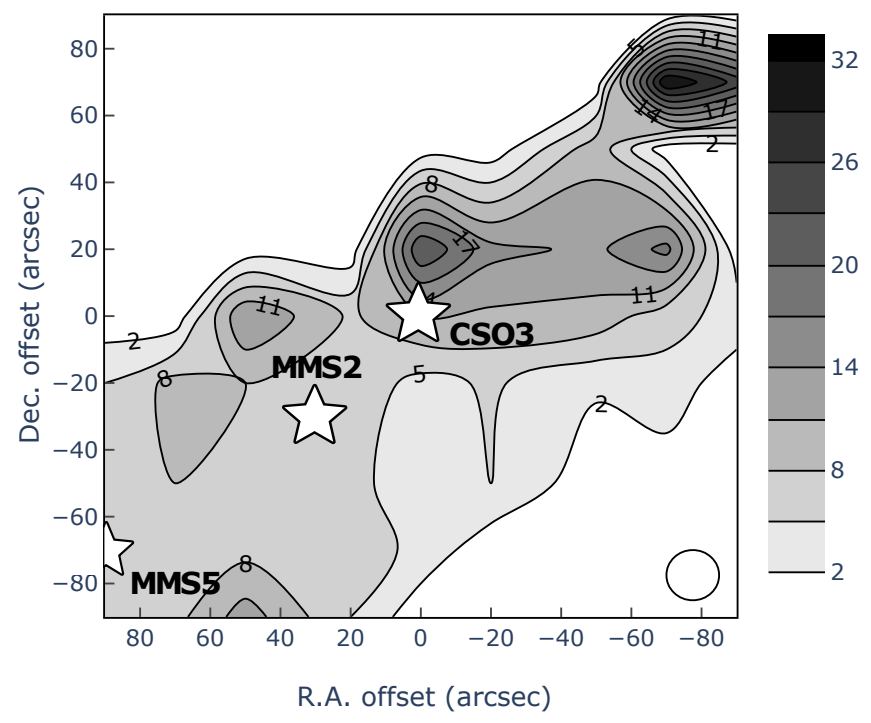

Fig. 8. Map of the $[\mathrm{CCH}] /\left[\mathrm{CH}_{3} \mathrm{OH}\right]$ abundance ratio as derived via the LTE analysis described in Sect. 6.4. The sources MMS5, MMS2, and $\mathrm{CSO} 3$ are represented by white stars. The beam size is the white circle at the bottom right of the figure. We note that the error bar in the derived $[\mathrm{CCH}] /\left[\mathrm{CH}_{3} \mathrm{OH}\right]$ abundance ratio is about 4 (see Table C. 3 of Appendix C).

suggests that the lines are emitted approximately in the same region and that this region is rather quiescent.

2. The temperature of the gas emitting methanol is always lower than $30 \mathrm{~K}$ (with the exception of CSO33; see text above: Fig. 5 and Table 6), which certainly does not support the hypothesis of an origin in the sources' hot corino. However, the methanol could be associated with the cold envelope of the sources (e.g. Maret et al. 2005; Vastel et al. 2014) or the parental cloud.

3. The $\mathrm{CCH}$ and $\mathrm{CH}_{3} \mathrm{OH}$ lines probe a gas at likely different temperatures: The $\mathrm{CCH}$ lines trace a gas at about $10 \mathrm{~K}$ while $\mathrm{CH}_{3} \mathrm{OH}$ traces a slightly warmer gas, at about $20 \mathrm{~K}$ (Table 6). This could be consistent with the emission arising from the two molecules in the source envelopes, where methanol originates slightly deeper in the envelope (larger density and higher temperature) than $\mathrm{CCH}$. However, the uncertainty on the $\mathrm{CCH}$ density-temperature values (Figs. 5 and 6) also makes it possible that the two molecules lie in the cloud and, specifically, in its surrounding (chemically stratified) PDR.

4. The $\mathrm{CCH}$ and $\mathrm{CH}_{3} \mathrm{OH}-\mathrm{E}$ derived column densities are rather similar among the sources: either the envelopes have all the same characteristics or the emission is associated with the cloud or its PDR.

5. To give an idea of the behaviour of the targeted sources over the full OMC-2/3 filament, in Fig. 9 we show the gas temperature and density, $\mathrm{CCH}$ and $\mathrm{CH}_{3} \mathrm{OH}-\mathrm{E}$ column densities, and the $[\mathrm{CCH}] /\left[\mathrm{CH}_{3} \mathrm{OH}\right]$ abundance ratio derived towards each source from the non-LTE analysis as a function of the source projected distance from the Trapezium OB cluster. We do not see any variation of any of those quantities along the filament. The only exception is CSO33, which stands out from the other sources as it has a larger gas temperature; however, the difference is not significant and it is probably due to the fact that this source is the closest to the Trapezium
OB cluster. This uniformity of the various derived quantities towards the sources regardless of their position in the filament favours the hypothesis that the emission is dominated by the cloud and/or PDR rather than the sources' envelopes. In summary, based on the single-dish observations, we conclude that the $\mathrm{CCH}$ and $\mathrm{CH}_{3} \mathrm{OH}$ lines are either associated with the cold envelopes of the sources or the cloud to which they belong to or the PDR encircling the cloud, with hints that the first hypothesis for the source envelope origin is likely to be incorrect.

\subsection{The emission from the cloud and its surrounding PDR}

The analysis of the $\mathrm{CCH}$ and $\mathrm{CH}_{3} \mathrm{OH}$ line maps of the northern portion of OMC-3/3 filament (Sect. 6.4) allow us to disentangle the ambiguity described above. We start by summarising the results from the OTF map observations analysis.

1. The maps of the gas temperature and density, derived by our non-LTE analysis of the $\mathrm{CH}_{3} \mathrm{OH}-\mathrm{E}$ lines and shown in Fig. 7, clearly indicate that there is no increase (or decrease) of these physical parameters in coincidence with the three sources in the field. The density map shows a sharp increase of the cloud density at its borders and then a ridge with a rather constant density at $(4-8) \times 10^{5} \mathrm{~cm}^{-3}$. The temperature map also shows a sharp increase at the cloud border and then a rather constant value, 14-16 K, across the ridge.

2. The $\mathrm{CH}_{3} \mathrm{OH}-\mathrm{E}$ column density shows a gradient which, however, seems associated, rather, with the penetration into the cloud rather than with the sources themselves (Fig. 7): the $\mathrm{CH}_{3} \mathrm{OH}-\mathrm{E}$ column density increases going inwards the central regions of the filament, the ones more shielded by the external photons illumination. There is a marginal increase of the $\mathrm{CH}_{3} \mathrm{OH}-\mathrm{E}$ column density in correspondence of MMS2, from $2 \times 10^{13}$ to $6 \times 10^{13} \mathrm{~cm}^{-2}$, namely, about a factor of three with respect to the value in the ridge.

3. The map of the $[\mathrm{CCH}] /\left[\mathrm{CH}_{3} \mathrm{OH}\right]$ abundance ratio (Fig. 8) does not show any variation caused by the presence of the sources: the $[\mathrm{CCH}] /\left[\mathrm{CH}_{3} \mathrm{OH}\right]$ abundance ratio is relatively constant across the region with a possible gradient in the north-east to south-west direction, which could be due to the UV illumination from the nearby HII region NGC 1977 (located at $\leq 10^{\prime \prime}$ from CSO3, so $\leq 2 \mathrm{pc}$ ), located to the north-east of the map.

When considering the map observations and the derived values (gas temperature and density, $\mathrm{CCH}$ and $\mathrm{CH}_{3} \mathrm{OH}-\mathrm{E}$ column densities, and the $[\mathrm{CCH}] /\left[\mathrm{CH}_{3} \mathrm{OH}\right]$ abundance ratio) of all the sources along the filament OMC-2/3 (Fig. 9), it seems inevitable to conclude that the observed $\mathrm{CCH}$ and $\mathrm{CH}_{3} \mathrm{OH}$ line emission is dominated by the cloud in which the sources are embedded or the PDR that surrounds it.

\subsection{What does the $[\mathrm{CCH}] /\left[\mathrm{CH}_{3} \mathrm{OH}\right]$ abundance ratio probes? - WCCC objects, hot corinos, molecular clouds, or PDRs}

Figure 10 reports a compilation of the $\mathrm{CCH}$ and $\mathrm{CH}_{3} \mathrm{OH}$ total column densities observed towards WCCC objects, hot corinos, molecular clouds, and PDRs, all derived with single-dish telescopes observations. We label as a "molecular cloud" every object where we think the emission $\mathrm{CCH}$ and $\mathrm{CH}_{3} \mathrm{OH}$ is dominated by the non-PDR, such as pre-stellar cores, even though we know it might be not completely true. Nonetheless, they give an indication how a possible emission from the bulk or parts not illuminated by the UV would position the object on the diagram.

The figure immediately shows that the sources in OMC- $2 / 3$ have $\mathrm{CCH}$ and $\mathrm{CH}_{3} \mathrm{OH}$ total column densities similar to those of 

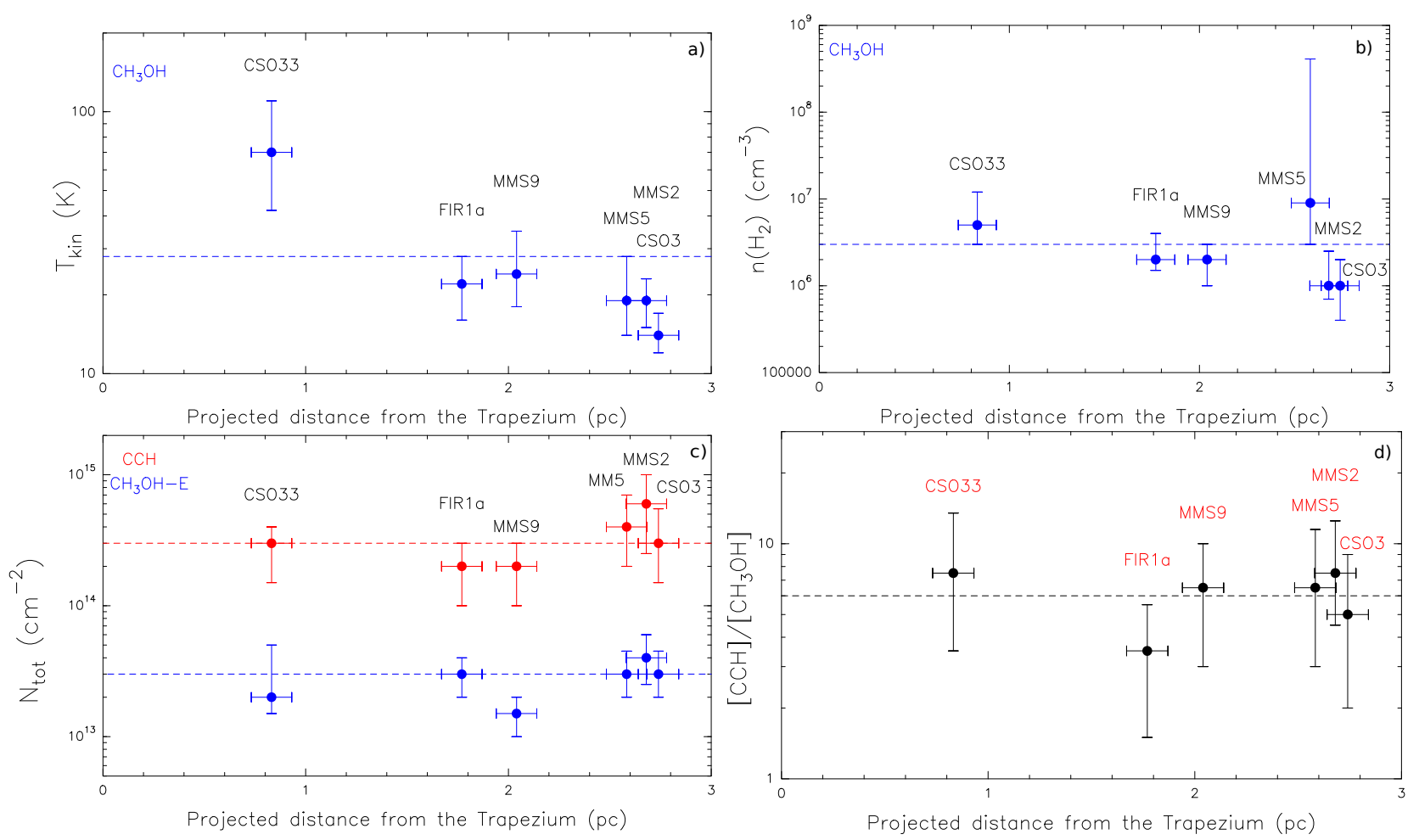

Fig. 9. Results of the LVG analysis for each source. (a) kinetic temperatures $\left(T_{\text {kin }}\right)$ of $\mathrm{CH}_{3} \mathrm{OH}$ as a function of the distance to the Trapezium; (b) column densities $\left(N_{\text {tot }}\right)$ of $\mathrm{CCH}$ and of $\mathrm{CH}_{3} \mathrm{OH}-\mathrm{E}$ as a function of the distance to the Trapezium; $(c)$ derived gas density $\left(n_{\mathrm{H} 2}\right)$ for $\mathrm{CH}_{3} \mathrm{OH}$ and $\mathrm{CCH} ;(d)$ abundance ratio $[\mathrm{CCH}] /\left[\mathrm{CH}_{3} \mathrm{OH}-\mathrm{E}\right]$ as a function of the distance from the Trapezium. The red- and blue- dashed lines are the derived averaged values for each parameters for $\mathrm{CCH}$ and $\mathrm{CH}_{3} \mathrm{OH}-\mathrm{E}$ respectively. The error bars are at $1 \sigma$.

Table 7. Comparison of the results derived from the LTE analysis of the Higuchi et al. (2018) survey with the results derived in the present work (both LTE and non-LTE LVG results).

\begin{tabular}{cccccc}
\hline \hline Paper & $\begin{array}{c}T_{\mathrm{CCH}} \\
{[\mathrm{K}]}\end{array}$ & $\begin{array}{c}N_{\mathrm{CCH}} \\
{\left[\times 10^{13} \mathrm{~cm}^{-2}\right]}\end{array}$ & $\begin{array}{c}T_{\mathrm{CH}_{3} \mathrm{OH}}[\mathrm{K}] \\
{\left[\begin{array}{c}N_{\mathrm{CH}_{3} \mathrm{OH}-\mathrm{E}} \\
{\left[\times 10^{14} \mathrm{~cm}^{-2}\right]}\end{array}\right.}\end{array}$ & {$[\mathrm{CCH}] /\left[\mathrm{CH}_{3} \mathrm{OH}\right]$} \\
\hline Higuchi et al. (2018) & $8-21$ & $0.5-16$ & $8-21$ & $<5.2$ & $0.04-3.9$ \\
\hline This work, LTE & $5-17$ & $60-110$ & $10-17$ & $0.1-0.7$ & $14-50$ \\
\hline This work, LVG & $8-15$ & $20-60$ & $14-70$ & $0.2-0.4$ & $3.5-7.5$ \\
\hline
\end{tabular}

the WCCC prototype L1527 and the PDRs. Since we demonstrated in Sects. 7.1 and 7.2 that the $\mathrm{CCH}$ and $\mathrm{CH}_{3} \mathrm{OH}$ line emission is dominated by the extended emission rather than the source envelopes; this similarity leads us to conclude that in the specific case of OMC-2/3, the emission is in fact dominated by the PDR encircling the molecular cloud. This is fully consistent with the fact that the OMC-2/3 filament is surrounded by luminous OB stars, the Trapezium cluster and NGC 1799 HII region, namely exposed to an intense UV illumination.

On the other hand, the $\mathrm{CCH}$ and $\mathrm{CH}_{3} \mathrm{OH}$ total column densities observed towards the sources in Perseus surveyed by Higuchi et al. (2018) are definitively different from those of the PDRs, perhaps close to those in molecular clouds, and in between the PDRs and the IRAS 16293-2224 hot corino. Given the observed (rotational) temperatures measured towards the Perseus sources by Higuchi et al. (2018), similar to those measured in our OMC2/3 sample (see Table 7), it remains to be verified whether the emission is not polluted or dominated by the surrounding cloud emission. In Table 7, we note that the small difference observed in the derived column densities of $\mathrm{CCH}$ with the two different methods can be due to the sensitivity of the input parameters of the Hyperfine fitting structure Tool used for the LTE analysis (see Appendix C.1.2). Moreover, four of the Perseus sources, namely, SVS 13A, IRAS 2A, IRAS 4A and IRAS 4B, are confirmed hot corinos by interferometric observations (Bottinelli et al. 2004, 2007; Jørgensen et al. 2005; Sakai et al. 2006; Taquet et al. 2015; De Simone et al. 2017; López-Sepulcre et al. 2017). In Fig. 10, these sources are scattered from the hot corino prototype and their hot corino nature is not always obvious (e.g. SVS 13A, IRAS 2A) if we refer to this plot only.

Finally, a similar word of caution may apply to the surveys by Graninger et al. (2016) and Lindberg et al. (2016), given, again, the measured low (rotational) temperatures (Table 1). Besides, the methanol column densities in their sources are lower than $\sim 10^{13} \mathrm{~cm}^{-2}$, namely less than for the Perseus sources (see Fig. 10), which would suggest, again emission from dense cold cloud gas.

In conclusion, our results strongly suggest that the $[\mathrm{CCH}] /$ $\left[\mathrm{CH}_{3} \mathrm{OH}\right]$ abundance ratio derived by single-dish observations is not reliable enough to trace the envelope of the protostars. 


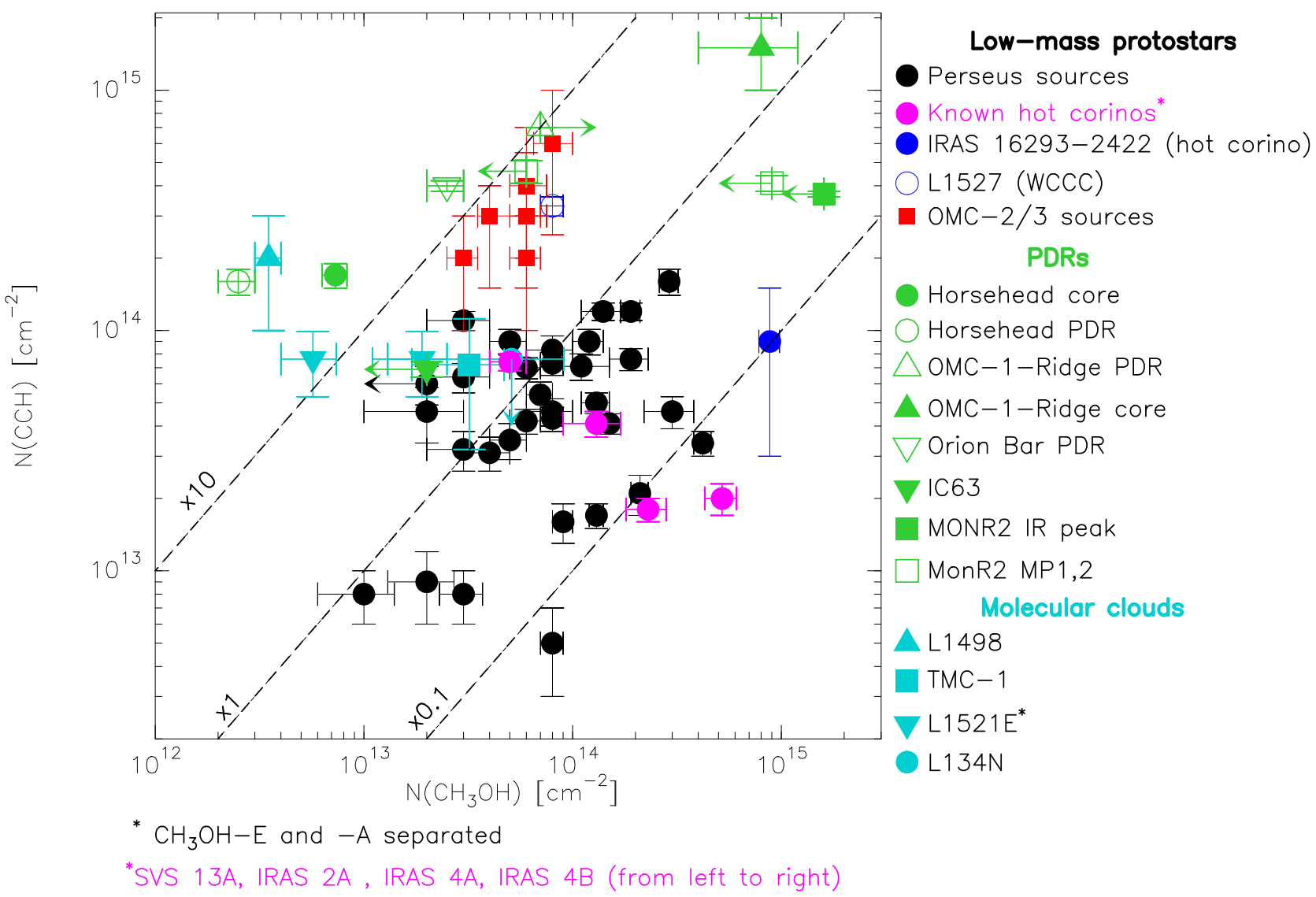

Fig. 10. Compilation of the $\mathrm{CCH}$ ( $y$-axis) and $\mathrm{CH}_{3} \mathrm{OH}$ ( $x$-axis) total column densities, derived with single-dish observations towards WCCC objects, hot corinos, molecular clouds, and PDRs. The points refer to measurement towards: the WCCC object prototype L1527 (blue open circle: Sakai et al. 2008); the hot corino prototype IRAS 16293-2422 (filled blue circle: Van Dishoeck et al. 1995); the sources in the Perseus cloud (black: Higuchi et al. 2018); the known hot corinos among the Perseus sources (filled pink circle: Higuchi et al. 2018), the sources in OMC-2/3 (red: this work); various PDRs (green): Horsehead nebula (Teyssier et al. 2004; Guzmán et al. 2013), OMC-1 Ridge PDR and core (Ungerechts et al. 1997), Orion Bar (Cuadrado et al. 2015, 2017), IC63 (Jansen et al. 1994; Teyssier et al. 2004), and Mon R2 (Ginard et al. 2012); various pre-stellar cores (light blue): L1498 (Padovani et al. 2009, Daprà et al. 2017), TMC-1 (Friberg et al. 1988, Pratap et al. 1997, Soma et al. 2015), L1521E (Nagy et al. 2019) and L134N (Dickens et al. 2000) as representatives of cold molecular clouds. Upper limits are represented by arrows.

Since several WCCC objects and hot corinos have been classified solely based on single-dish observations of small carbon chains and $\mathrm{CH}_{3} \mathrm{OH}$ (see Sect. 2), we suggest those classifications be verified by better spatial resolution or higher excitation lines observations that would be capable of focusing on the inner protostellar envelopes and getting rid of the extended emission from the cloud and the PDR necessarily associated with the targeted sources.

\section{Conclusions}

We carried out $\mathrm{CCH}$ and $\mathrm{CH}_{3} \mathrm{OH}$ observations with the singledish IRAM- $30 \mathrm{~m}$ and the Nobeyama- $45 \mathrm{~m}$ telescopes of nine Solar-like protostars located in the OMC-2/3 filament in order to determine their chemical nature. Here are our main conclusions:

1. The derived gas temperatures and gas densities of $\mathrm{CCH}$ and $\mathrm{CH}_{3} \mathrm{OH}$ towards the six sources out of the nine sources and the results from the map observations indicates that the two species are emitted from an external layer not associated with the protostars.

2. The column density ratios $[\mathrm{CCH}] /\left[\mathrm{CH}_{3} \mathrm{OH}\right]$, from 1.5 to 13.5 within the error bars, derived for our source sample specify that this external layer is likely the PDR.

3. We could not achieve the first goal of our study that is finding hot corino or WCCC candidates in the OMC-2/3 filament. The abundance ratio used is not reliable for singledish observations. We thus need to choose other tracers for single-dish observations or to employ interferometric observations to avoid contamination from the cloud and/or the associated PDR.

Acknowledgements. We thank the referee for the careful reading and the constructive remarks that helped to improve the paper. This project has received funding from the European Research Council (ERC) under the European Union's Horizon 2020 research and innovation programme, for the Project "The Dawn of Organic Chemistry" (DOC), grant agreement No 741002 and from the European Union's Horizon 2020 research and innovation programme under the Marie SkłodowskaCurie grant agreement No 811312. This work is based on observations carried out under the project numbers D01-18 and p279673 with the IRAM-30 m telescope and based on observations carried out with the Nobeyama- $45 \mathrm{~m}$. IRAM is supported by INSU/CNRS (France), MPG (Germany) and IGN (Spain). The Nobeyama 45-m radio telescope is operated by Nobeyama Radio Observatory, a branch of National Astronomical Observatory of Japan.

\section{References}

Adams, F. C. 2010, ARA\&A, 48, 47

Agúndez, M., Marcelino, N., Cernicharo, J., Roueff, E., \& Tafalla, M. 2019, A\&A, 625, A147

Anglada, G. 1995, Rev. Mex. Astron. Astrofis., 1, 67

Anglada, G. 1996, ASP Conf. Ser. 93, 3

Bianchi, E., Codella, C., Ceccarelli, C., et al. 2019, MNRAS, 483, 1850

Bottinelli, S., Ceccarelli, C., Lefloch, B., et al. 2004, ApJ, 615, 354 
Bottinelli, S., Ceccarelli, C., Williams, J. P., \& Lefloch, B. 2007, A\&A, 463, 601

Caux, E., Kahane, C., Castets, A., et al. 2011, A\&A, 532, A23

Cazaux, S., Caux, E., Parise, B., \& Teyssier, D. 2003, ApJ, 593, 51

Ceccarelli, C., Loinard, L., \& Castets, A. 2000, A\&A, 357, L9

Ceccarelli, C., Maret, S., Tielens, A. G. G. M., Castets, A., \& Caux, E. 2003, A\&A, 410, 587

Ceccarelli, C., Caselli, P., Herbst, E., Tielens, A. G. G. M., \& Caux, E. 2007, Protostars and Planets V, eds. B. Reipurth, D. Jewitt \& K. Keil (Tucson: University of Arizona Press)

Ceccarelli, C., Dominik, C., López-Sepulcre, A., et al. 2014, ApJ, 790, L1

Ceccarelli, C., Caselli, P., Fontani, F., et al. 2017, ApJ, 850, 176

Chini, R., Reipurth, B., Ward-Thompson, D., et al. 1997, ApJ, 474, L135

Codella, C., Ceccarelli, C., Cabrit, S., et al. 2016, A\&A, 586, A3

Cuadrado, S., Goicoechea, J. R., Pilleri, P., et al. 2015, A\&A, 575, A82

Cuadrado, S., Goicoechea, J. R., Cernicharo, J., et al. 2017, A\&A, 603, A124

Dagdigian, P. J. 2018, MNRAS, 479, 3227

Daprà, M., Henkel, C., Levshakov, S. A., et al. 2017, MNRAS, 472, 4434

De Simone, M., Codella, C., Testi, L., et al. 2017, A\&A, 599, A121

Dickens, J. E., Irvine, W. M., Snell, R. L., et al. 2000, ApJ, 542, 870

Dubernet, M.-L., Alexander, M. H., Ba, Y. A., et al. 2013, A\&A, 553, A50

Favre, C., Ceccarelli, C., López-Sepulcre, A., et al. 2018, ApJ, 859, 136

Flower, D. R., Pineau des Forêts, G., \& Rabli, D. 2010, MNRAS, 409, 29

Fontani, F., Ceccarelli, C., Favre, C., et al. 2017, A\& A, 605, A57

Friberg, P., Madden, S., Hjalmarson, A., \& Irvine, W. 1988, A\& A, 195, 281

Gatley, I., Becklin, E. E., Mattews, K., et al. 1974, ApJ, 191L, 121

Ginard, D., González-García, M., Fuente, A., et al. 2012, A\&A, 543, A27

Graninger, D. M., Wilkins, O. H., \& Öberg, K. I. 2016, ApJ, 819, 140

Großschedl, J. E., Alves, J., Meingast, S., et al. 2018, A\&A, 619, A106

Guzmán, V. V., Goicoechea, J. R., Pety, J., et al. 2013, A\&A, 560, A73

Herbst, E., \& Van Dishoeck, E. F. 2009, ARA\& A, 47, 427

Higuchi, A. E., Sakai, N., Watanabe, Y., et al. 2018, ApJS, 236, 52

Jansen, D. J., Van Dishoeck, E. F., \& Black, J. H. 1994, A\&A, 282, 605

Jørgensen, J. K., Bourke, T. L., Myers, P. C., et al. 2005, ApJ, 632, 973

Jørgensen, J. K., van der Wiel, M. H. D., Coutens, A., et al. 2016, A\&A, 595, A117

Kama, M., López-Sepulcre, A., Dominik, C., et al. 2013, A\&A, 556, A57

Law, C., Öberg, K. I., Bergner, J. B., \& Graninger, D. 2018, ApJ, 863, 88

Leurini, S., Parise, B., Schilke, P., Pety, J., \& Rolffs, R. 2010, A\&A, 511, A82

Li, D., Kauffmann, J., Zhang, Q., \& Chen, W. 2013, ApJ, 768, L5

Lindberg, J. E., Charnley, S. B., \& Cordiner, M. A. 2016, ApJ, 833, L14
Lis, D. C., Serabyn, E., Keene, J., et al. 1998, ApJ, 509, 299

López-Sepulcre, A., Taquet, V., Sánchez-Monge, A., et al. 2013, A\&A, 556, A62

López-Sepulcre, A., Sakai, N., Neri, R., et al. 2017, A\&A, 606, A121

Maret, S., Ceccarelli, C., Tielens, A. G. G. M., et al. 2005, A\&A, 442, 527

Müller, H. S. P., Schlöder, F., Stutzki, J., et al. 2005, IAU Symp., 235, 62

Nagy, Z., Spezzano, S., Caselli, P., et al. 2019, A\&A, 630, A136

Nielbock, M., Chini, R., \& Müller, S. A. H. 2003, A\&A, 408, 245

Ospina-Zamudio, J., Lefloch, B., Ceccarelli, C., et al. 2018, A\&A, 618, A145

Oya, Y., Sakai, N., Watanabe, Y., et al. 2017, ApJ, 837, 174

Padovani, M., Walmsley, C. M., Tafalla, M., Galli, D., \& Müller, H. S. P. 2009, A\&A, 505, 1199

Pety, J., Teyssier, D., Fosse, D., et al. 2005, A\&A, 435, 885

Pfalzner, S., Davies, M. B., Gounelle, M., et al. 2015, PhyS, 90f8001P, 068001

Pickett, H. M., Poynter, R. L., Cohen, E. A., et al. 1998, J. Quant. Spectr. Rad. Transf., 60, 883

Pratap, P., Dickens, J. E., Snell, R. L., et al. 1997, ApJ, 486, 862

Punanova, A., Caselli, P., Feng, S., et al. 2018, ApJ, 855, 112

Reipurth, B., Rodríguez, L. F., \& Chini, R. 1999, ApJ, 118, 983

Sakai, N., \& Yamamoto, S. 2013, Chem. Rev., 113, 8981

Sakai, N., Sakai, T., \& Yamamoto, S. 2006, PASJ, 58, 1

Sakai, N., Sakai, T., Hirota, T., \& Yamamoto, S. 2008, ApJ, 672, 371

Sakai, N., Sakai, T., Hirota, T., Burton, M., \& Yamamoto, S. 2009, ApJ, 697, 769

Saul, M., Tothill, N. F. H., \& Purcell, C. R. 2015, ApJ, 798, 36

Snyder, L. E., \& Buhl, D. 1974, ApJ, 189, L31

Soma, T., Sakai, N., Watanabe, Y., \& Yamamoto, S. 2015, ApJ, 802, 74

Takahashi, S., Saito, M., Ohashi, N., et al. 2008, ApJ, 688, 244

Taquet, V., López-Sepulcre, A., Ceccarelli, C., et al. 2015, ApJ, 804, 81

Teyssier, D., Fossé, D., Gerin, M., et al. 2004, A\&A, 417, 135

Ungerechts, H., Bergin, E. A., Goldsmith, P. F., et al. 1997, ApJ, 482, 245

Van Dishoeck, E. F., Blake, G. A., Jansen, D. J., \& Groesbeck, T. D. 1995, ApJ, 447,760

Vastel, C., Ceccarelli, C., Lefloch, B., \& Bachiller, R. 2014, ApJ, 795, L2

Williams, J. P., Plambeck, R. L., \& Heyer, M. H. 2003, ApJ, 591, 1025

Wright, M. C. H., \& Plambeck, R. L. 1983, ApJ, 267, L115

Wu, Y., Liu, X., Chen, X., et al. 2019, MNRAS, 488, 495

Xu, L.-H., Fisher, J., Lees, R. M., et al. 2008, J. Mol. Struct. 251, 305

Yoshida, K., Sakai, N., Nishimura, Y., et al. 2019, PASJ, 71, 18

Yu, K. C., Bally, J., \& Devine, D. 1997, ApJ, 485, 45

Ziurys, L. M., Saykally, R. J., Plambeck, R. L., \& Erickson, N. R. 1982, ApJ, 254,94 


\section{Appendix A: Sample of lines}

Sample of $\mathrm{CCH}$ and $\mathrm{CH}_{3} \mathrm{OH}$ lines detected at $1.3 \mathrm{~mm}$ (IRAM$30 \mathrm{~m}$ ) and at $3 \mathrm{~mm}$ (Nobeyama-45 $\mathrm{m}$ ) for each source (except for SIMBA-a, FIR6c and FIR2 as explained in Sects. 4.1 and 5.1).

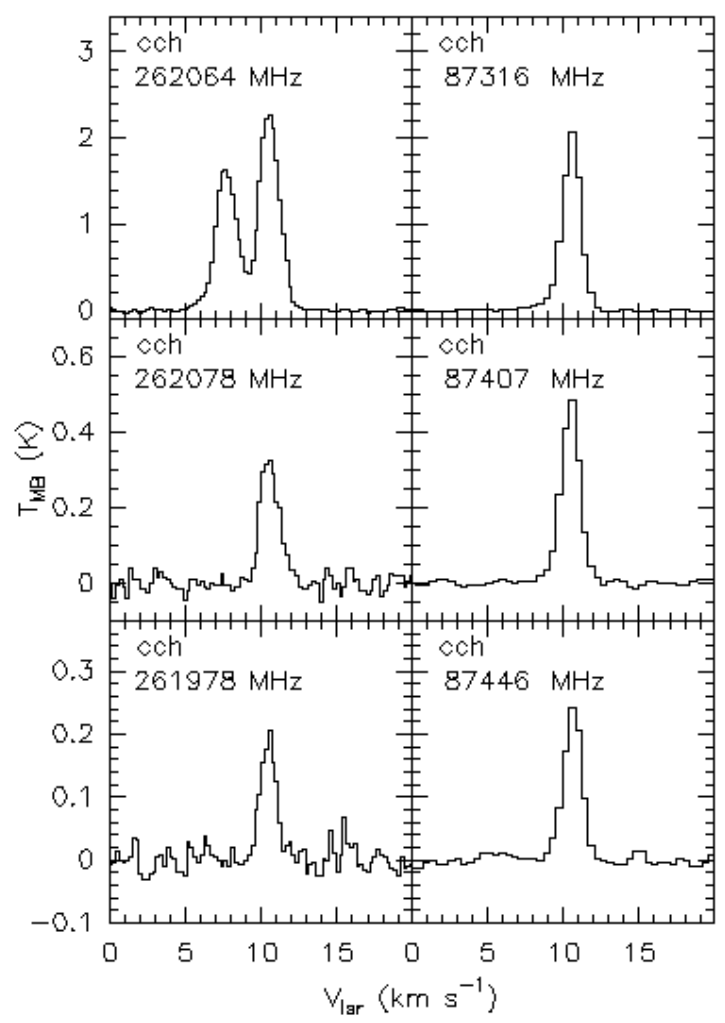

$\mathrm{CSO33}$
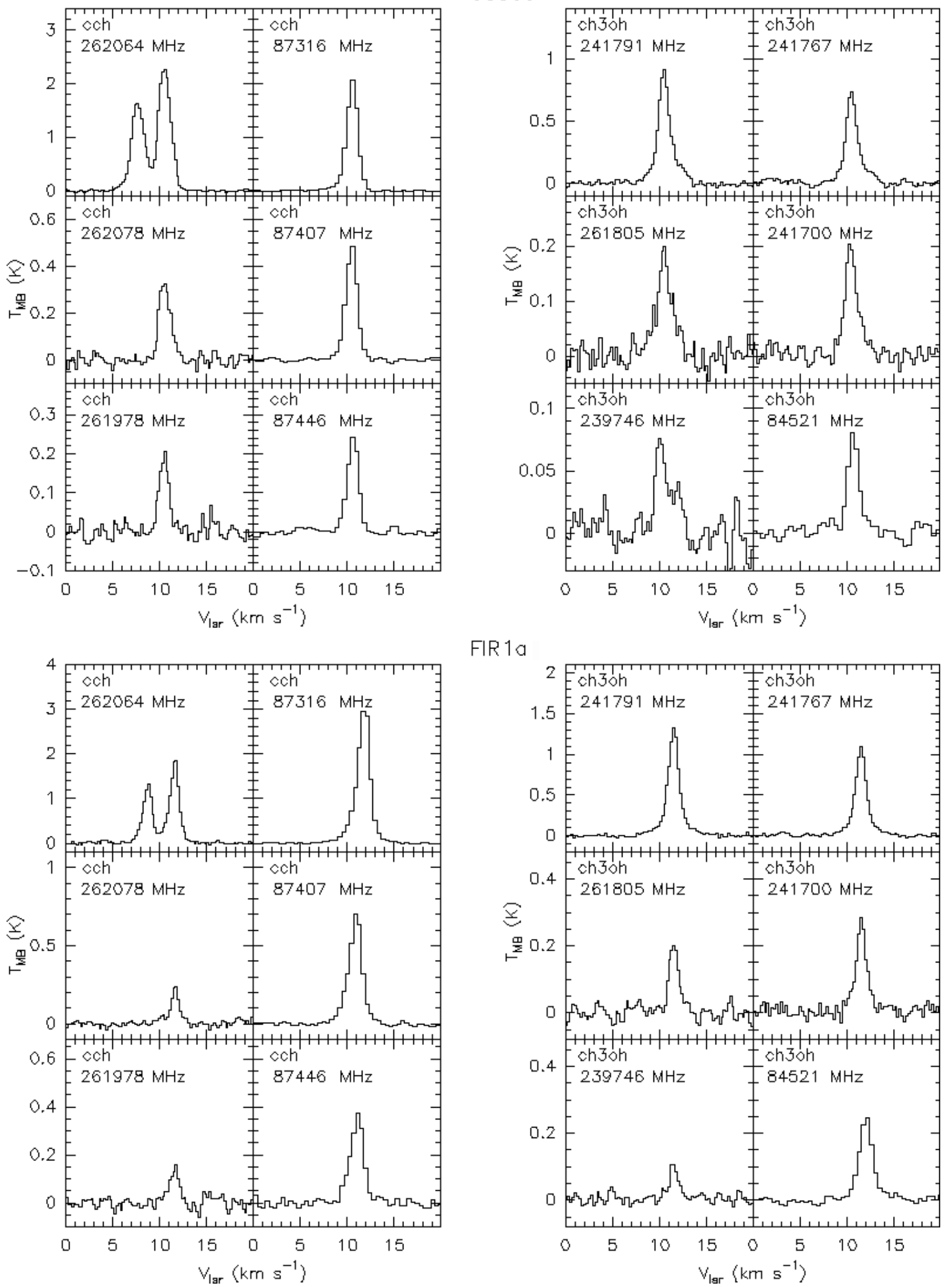

FIR 1a

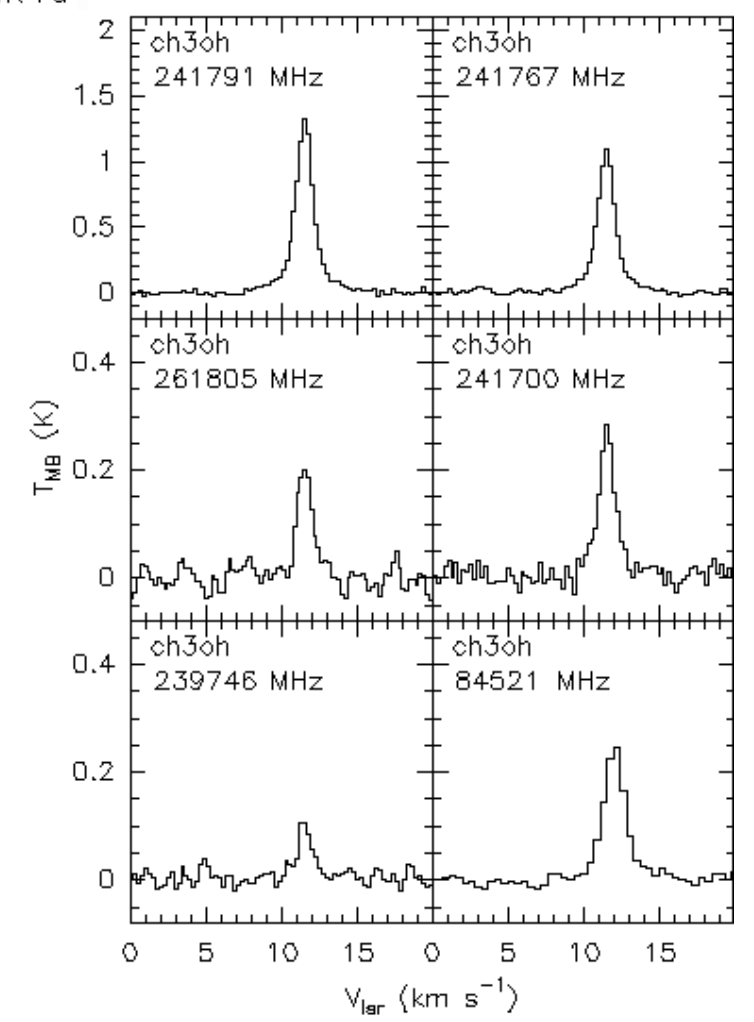

Fig. A.1. Sample of $\mathrm{CCH}$ and $\mathrm{CH}_{3} \mathrm{OH}$ lines of the sources CSO33 (top) and FIR1a (bottom). 
M. Bouvier et al.: Hunting for hot corinos and WCCC sources in the OMC-2/3 filament

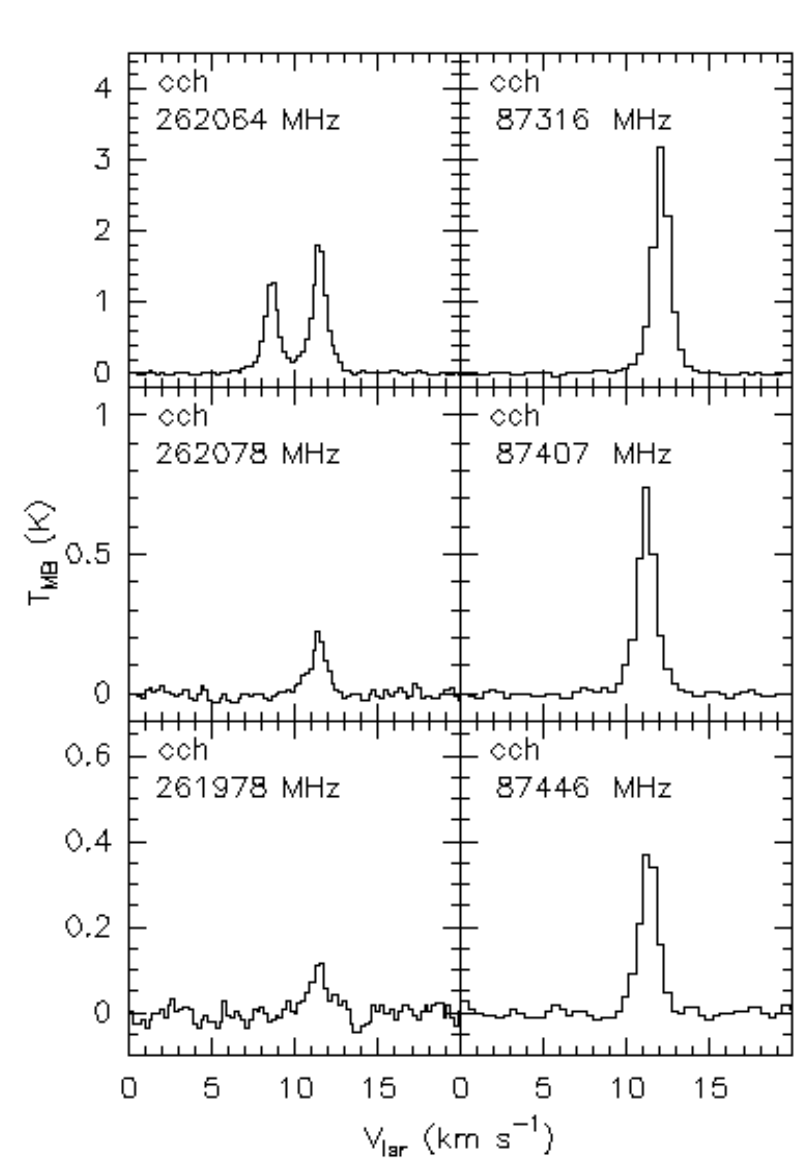

MMSg
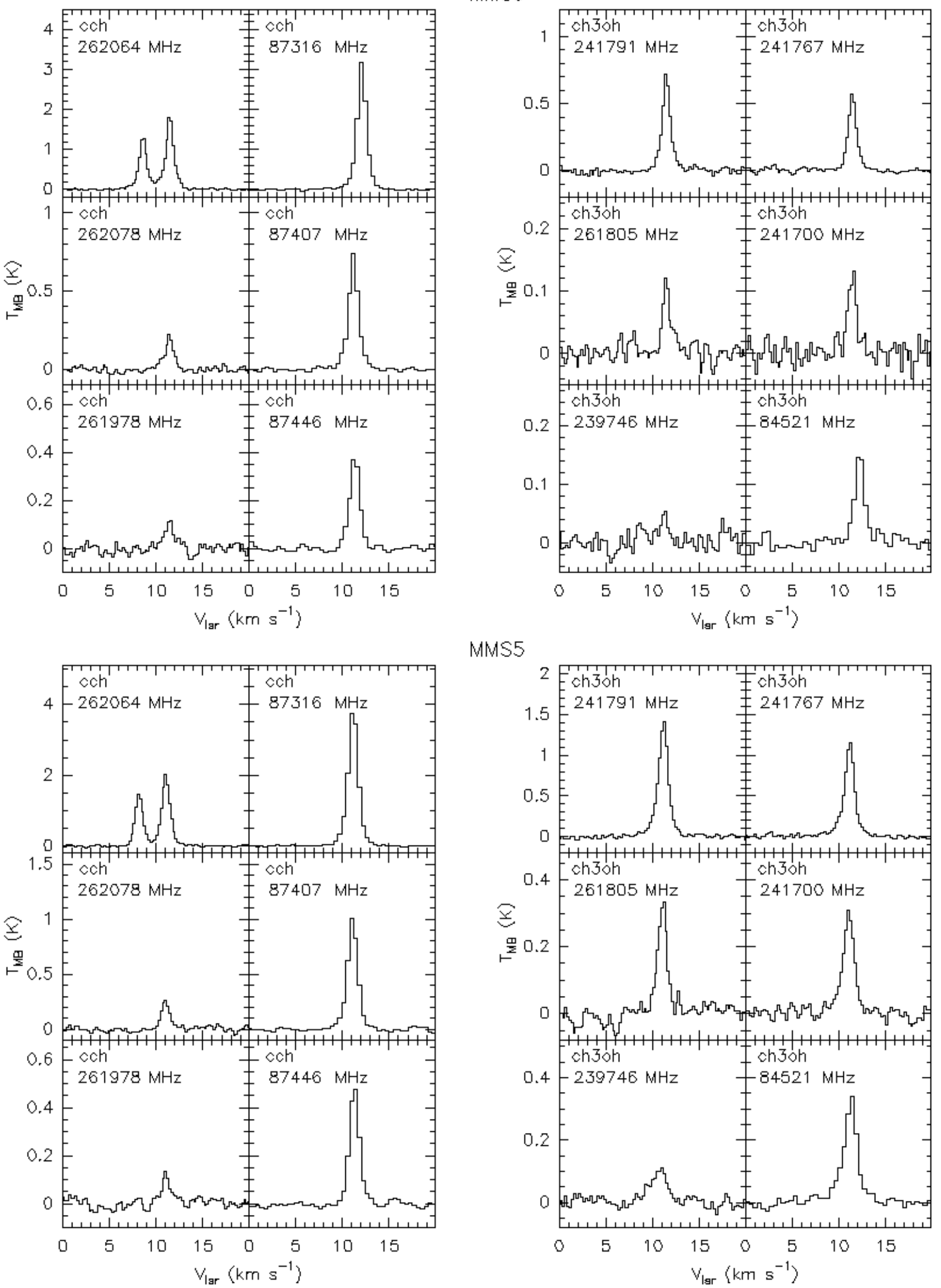

MMS5

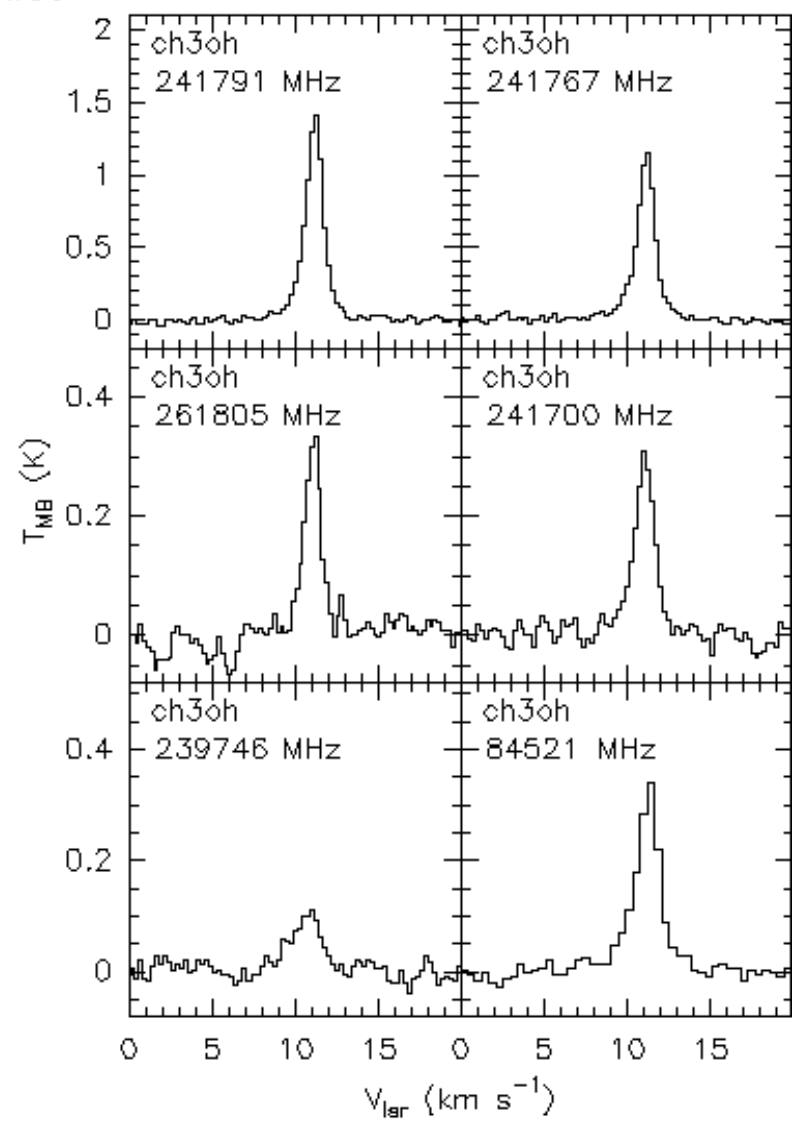

Fig. A.2. Sample of $\mathrm{CCH}$ and $\mathrm{CH}_{3} \mathrm{OH}$ lines of the sources MMS9 (top) and MMS5 (bottom). 


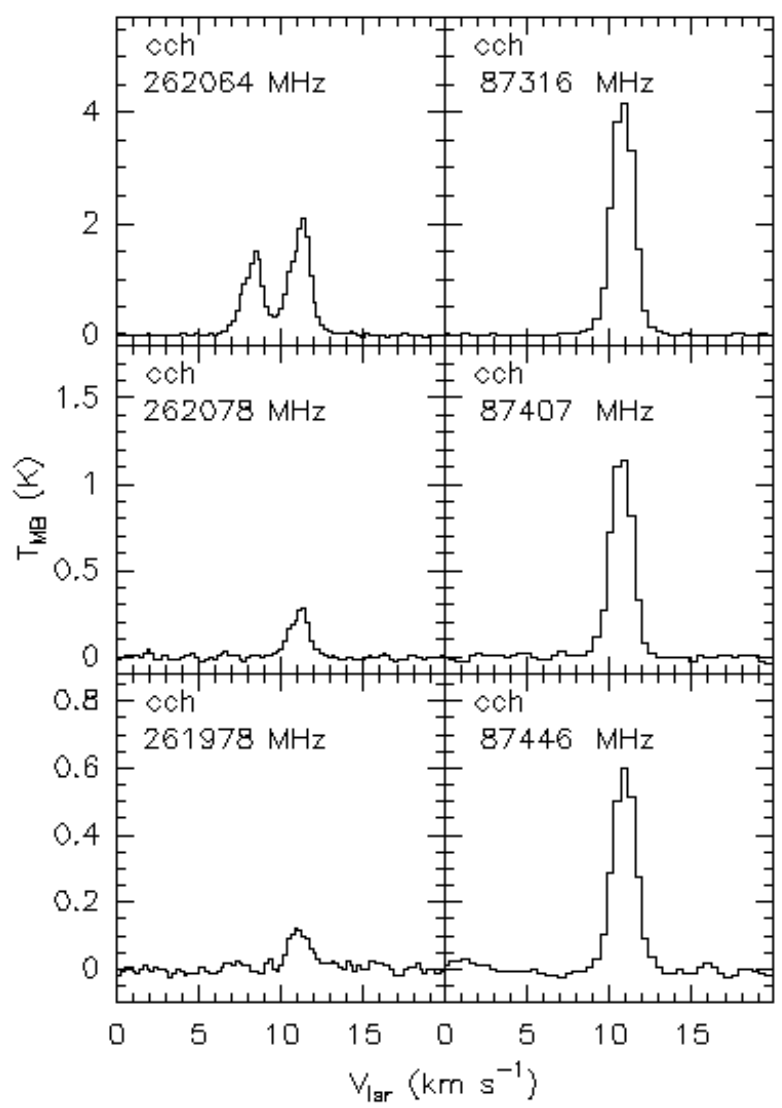

MMS2
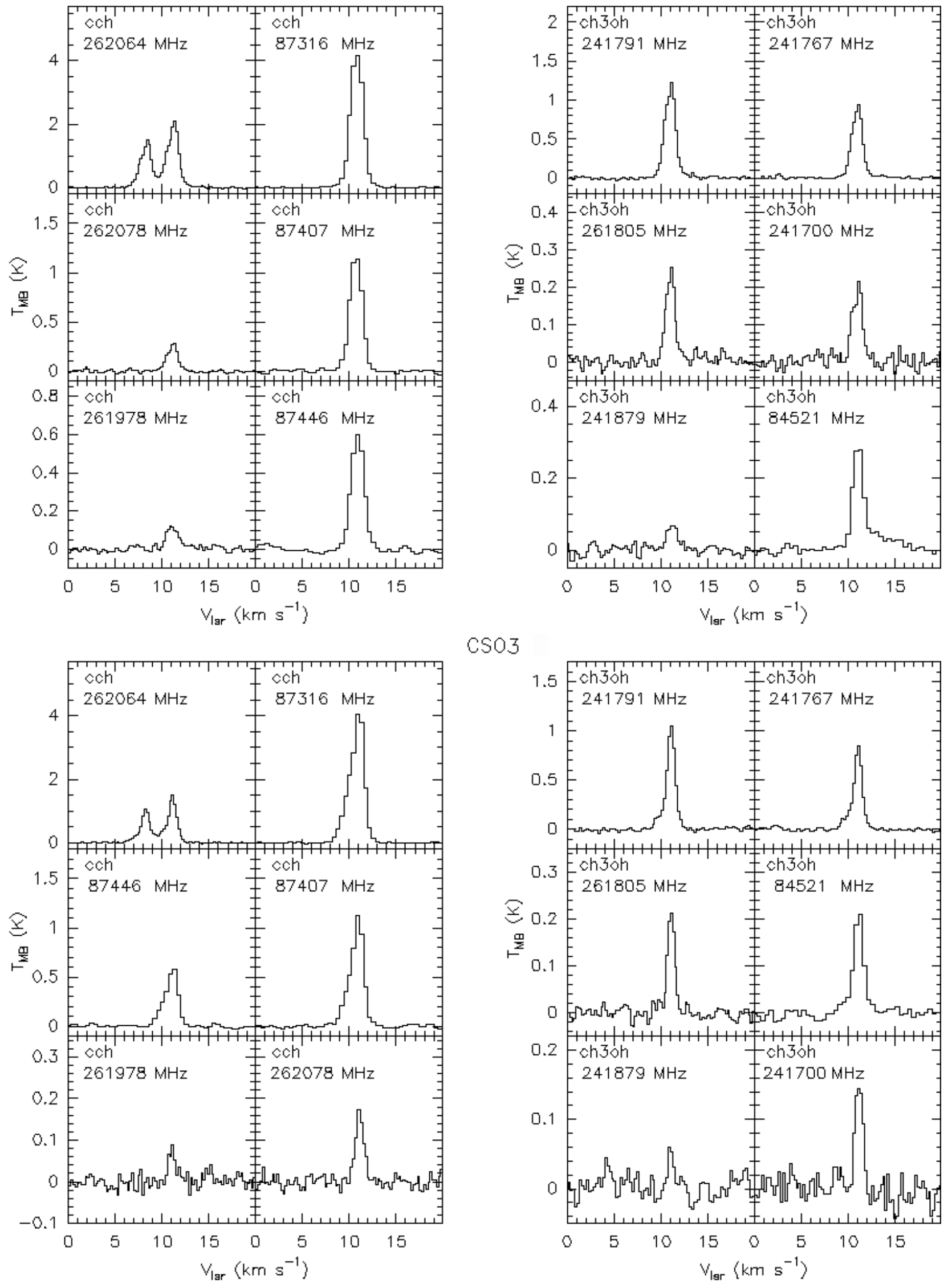

$\mathrm{CSO} 3$

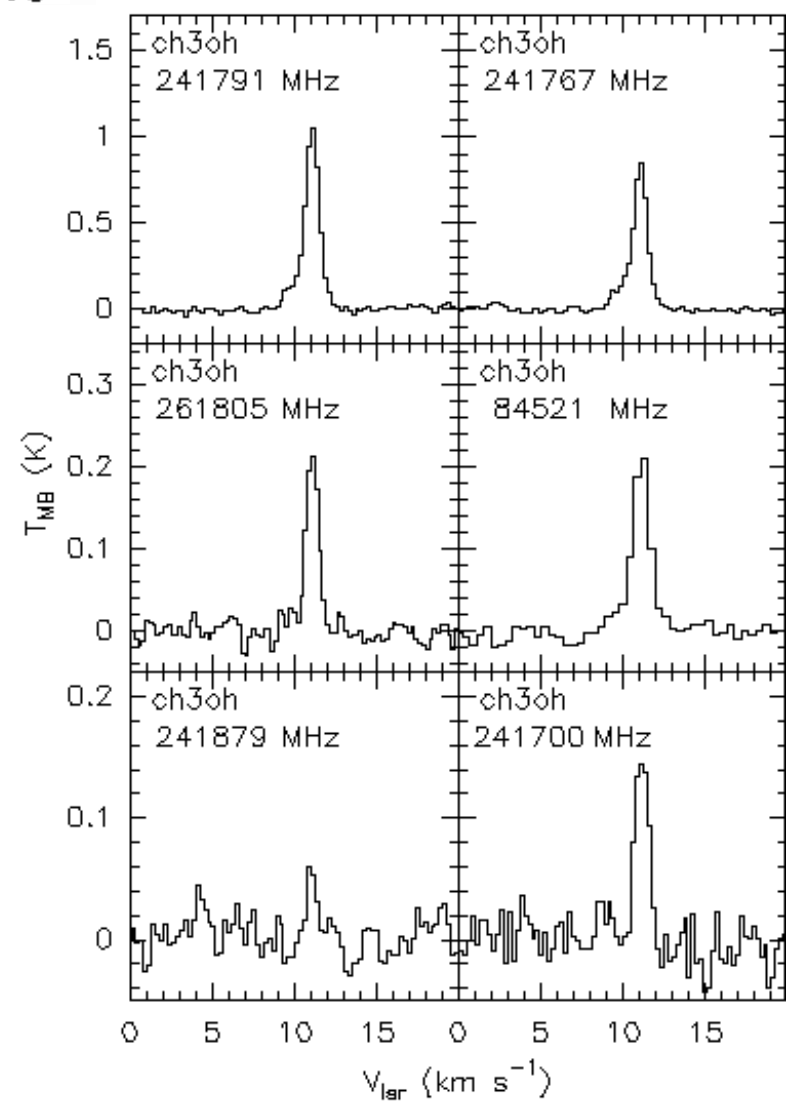

Fig. A.3. Sample of $\mathrm{CCH}$ and $\mathrm{CH}_{3} \mathrm{OH}$ lines of the sources MMS2 (top) and $\mathrm{CSO} 3$ (bottom). 
M. Bouvier et al.: Hunting for hot corinos and WCCC sources in the OMC-2/3 filament

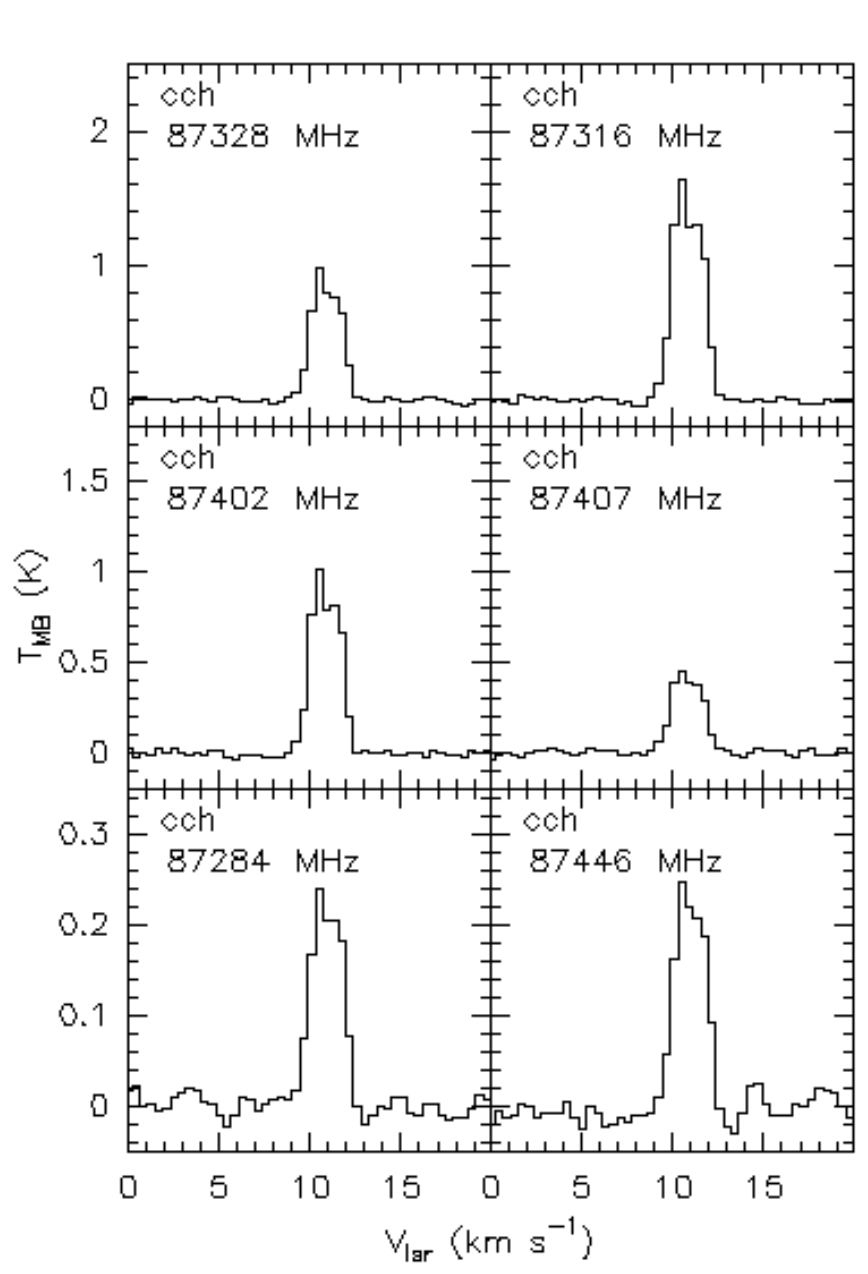

SIMBA-

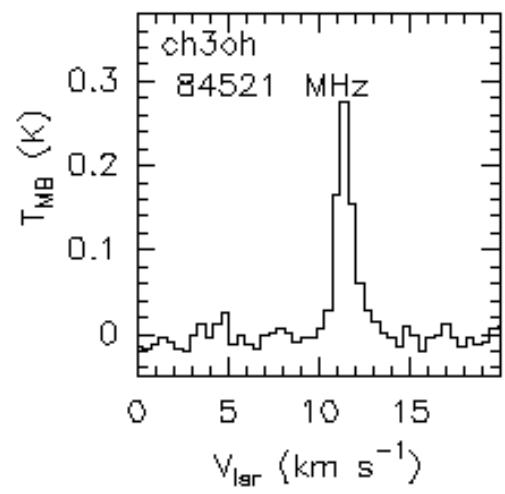

Fig. A.4. Sample of $\mathrm{CCH}$ and $\mathrm{CH}_{3} \mathrm{OH}$ lines of the source SIMBA-a.

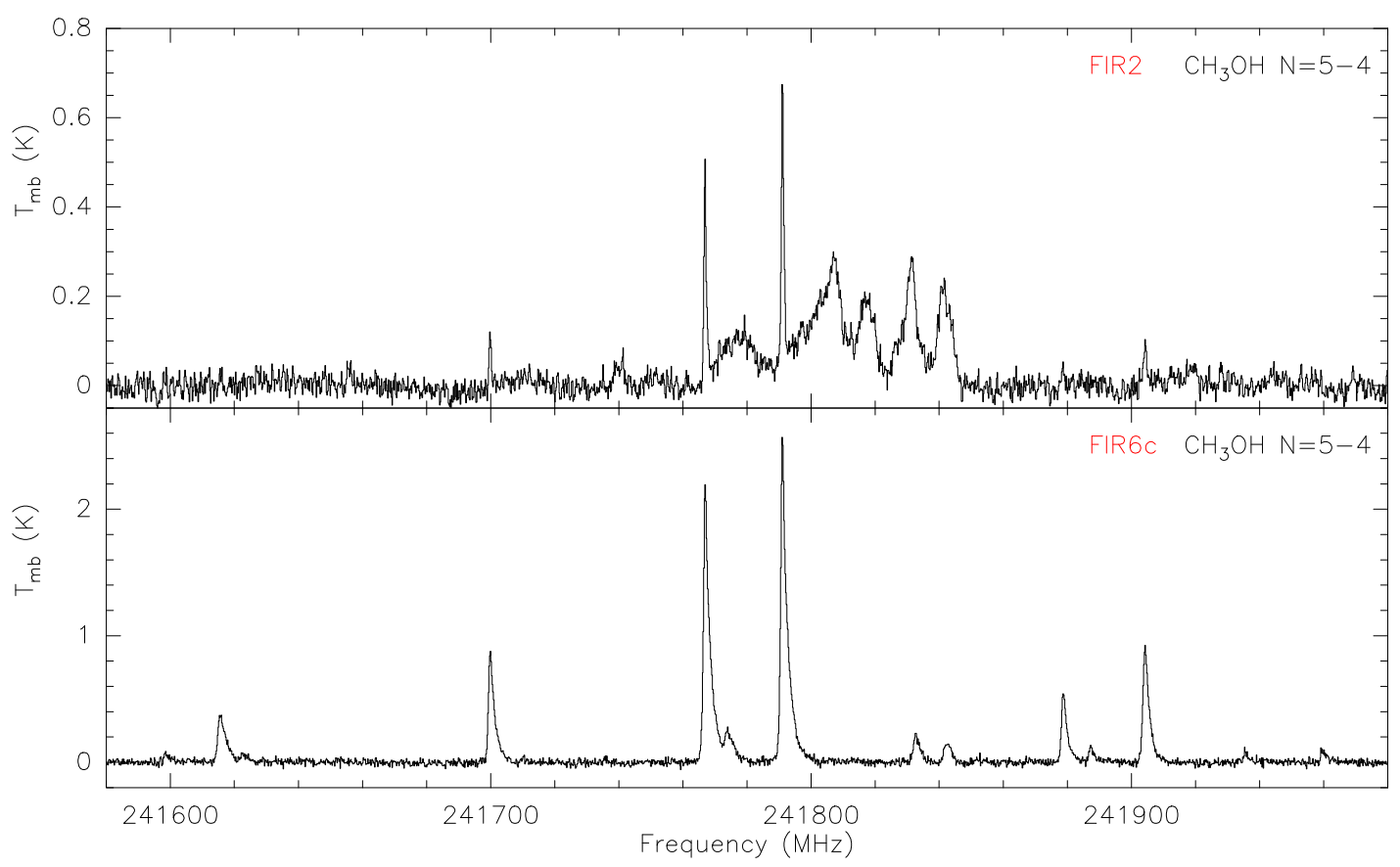

Fig. A.5. Lines of the $N=5-4$ transition of $\mathrm{CH}_{3} \mathrm{OH}$ for FIR2 (top) and FIR6c (bottom). In both spectra, broad shoulders indicating the presence of outflows are present. 


\section{Appendix B: Gaussian fit results}

\section{B.1. Single-pointing}

Here we present the Gaussian fits performed on each of the detected lines of $\mathrm{CCH}$ and $\mathrm{CH}_{3} \mathrm{OH}$ for each sources. Calibration errors of $20 \%$ and $40 \%$ for the IRAM-30 m and Nobeyama- $45 \mathrm{~m}$ observations have not been included.

\section{B.2. OTF Map}

Maps of moments 1 and 2 of the lines $\mathrm{CCH}(N=1-0, J=3 / 2-$ $1 / 2, F=1-0)$ and $\mathrm{CH}_{3} \mathrm{OH}\left(2_{-1}-1_{-1}\right.$ E) with a threshold of $3 \sigma$. Here we also show the intensity ratio map of two optically thin lines of methanol, $\left(2_{-1}-1_{-1}\right) \mathrm{E}$ and $\left(2_{0}-1_{0}\right) \mathrm{E}$.

Table B.1. Gaussian fit parameters for narrow component in CSO33.

\begin{tabular}{|c|c|c|c|c|c|}
\hline Molecule & Frequency & 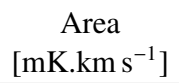 & $\begin{array}{c}V_{\mathrm{lsr}} \\
{\left[\mathrm{km} \mathrm{s}^{-1}\right]}\end{array}$ & $\begin{array}{l}F W H M \\
{\left[\mathrm{~km} \mathrm{~s}^{-1}\right]}\end{array}$ & $\begin{array}{l}T_{\text {peak }} \\
{[\mathrm{mK}]}\end{array}$ \\
\hline \multirow{8}{*}{$\mathrm{CH}_{3} \mathrm{OH}$} & 84.521 & $122 \pm 10$ & $10.7 \pm 0.2$ & $1.4 \pm 0.2$ & $80 \pm 10$ \\
\hline & 239.746 & $146 \pm 18$ & $10.6 \pm 0.1$ & $2.5 \pm 0.3$ & $74 \pm 14$ \\
\hline & 241.700 & $114 \pm 40$ & $10.3 \pm 0.1$ & $0.9 \pm 0.2$ & $202 \pm 13$ \\
\hline & 241.767 & $668 \pm 44$ & $10.5 \pm 0.1$ & $1.1 \pm 0.1$ & $569 \pm 17$ \\
\hline & 241.791 & $740 \pm 42$ & $10.4 \pm 0.1$ & $1.1 \pm 0.1$ & $656 \pm 15$ \\
\hline & 241.879 & $171 \pm 16$ & $10.3 \pm 0.1$ & $1.4 \pm 0.2$ & $117 \pm 16$ \\
\hline & 243.915 & $155 \pm 14$ & $10.4 \pm 0.1$ & $2.1 \pm 0.2$ & $70 \pm 13$ \\
\hline & 261.805 & $268 \pm 20$ & $10.5 \pm 0.1$ & $1.9 \pm 0.1$ & $198 \pm 19$ \\
\hline \multirow{14}{*}{$\mathrm{CCH}$} & 87.284 & $333 \pm 10$ & $10.6 \pm 0.2$ & $1.4 \pm 0.2$ & $224 \pm 10$ \\
\hline & 87.316 & $2614 \pm 30$ & $10.6 \pm 0.2$ & $1.3 \pm 0.2$ & $1910 \pm 10$ \\
\hline & 87.328 & $1397 \pm 10$ & $10.6 \pm 0.2$ & $1.3 \pm 0.2$ & $1030 \pm 10$ \\
\hline & 87.402 & $1405 \pm 60$ & $10.6 \pm 0.2$ & $1.3 \pm 0.2$ & $1050 \pm 10$ \\
\hline & 87.407 & $599 \pm 90$ & $10.6 \pm 0.2$ & $1.3 \pm 0.2$ & $430 \pm 10$ \\
\hline & 87.446 & $367 \pm 10$ & $10.6 \pm 0.2$ & $1.4 \pm 0.2$ & $244 \pm 10$ \\
\hline & 261.978 & $256 \pm 14$ & $10.5 \pm 0.1$ & $1.2 \pm 0.1$ & $195 \pm 18$ \\
\hline & 262.004 & $4868 \pm 50$ & $10.5 \pm 0.1$ & $1.5 \pm 0.1$ & $3020 \pm 17$ \\
\hline & 262.006 & $3902 \pm 70$ & $10.5 \pm 0.1$ & $1.5 \pm 0.1$ & $2470 \pm 19$ \\
\hline & 262.064 & $3677 \pm 34$ & $10.5 \pm 0.1$ & $1.5 \pm 0.1$ & $2260 \pm 14$ \\
\hline & 262.067 & $2334 \pm 15$ & $10.5 \pm 0.1$ & $1.4 \pm 0.1$ & $1520 \pm 17$ \\
\hline & 262.078 & $504 \pm 18$ & $10.5 \pm 0.1$ & $1.4 \pm 0.1$ & $332 \pm 21$ \\
\hline & 262.208 & $526 \pm 16$ & $10.5 \pm 0.1$ & $1.5 \pm 0.1$ & $332 \pm 18$ \\
\hline & 262.250 & $180 \pm 14$ & $10.5 \pm 0.1$ & $1.3 \pm 0.1$ & $137 \pm 16$ \\
\hline
\end{tabular}

Table B.2. Gaussian fit parameters for narrow component in FIR1a.

\begin{tabular}{|c|c|c|c|c|c|}
\hline Molecule & Frequency & 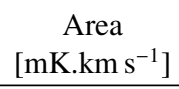 & $\begin{array}{c}V_{\mathrm{lsr}} \\
{\left[\mathrm{km} \mathrm{s}^{-1}\right]}\end{array}$ & $\begin{array}{c}F W H M \\
{\left[\mathrm{~km} \mathrm{~s}^{-1}\right]}\end{array}$ & $\begin{array}{c}T_{\text {peak }} \\
{[\mathrm{mK}]}\end{array}$ \\
\hline \multirow{8}{*}{$\mathrm{CH}_{3} \mathrm{OH}$} & 84.521 & $411 \pm 10$ & $11.7 \pm 0.2$ & $1.7 \pm 0.2$ & $229 \pm 10$ \\
\hline & 239.746 & $123 \pm 13$ & $11.6 \pm 0.1$ & $1.1 \pm 0.2$ & $102 \pm 13$ \\
\hline & 241.700 & $290 \pm 14$ & $11.6 \pm 0.1$ & $1.1 \pm 0.1$ & $230 \pm 16$ \\
\hline & 241.767 & $1020 \pm 60$ & $11.5 \pm 0.1$ & $1.1 \pm 0.1$ & $853 \pm 17$ \\
\hline & 241.791 & $1260 \pm 50$ & $11.5 \pm 0.1$ & $1.1 \pm 0.1$ & $1050 \pm 14$ \\
\hline & 241.879 & $162 \pm 12$ & $11.6 \pm 0.1$ & $1.3 \pm 0.1$ & $119 \pm 14$ \\
\hline & 243.915 & $182 \pm 18$ & $11.7 \pm 0.1$ & $1.6 \pm 0.2$ & $105 \pm 16$ \\
\hline & 261.805 & $265 \pm 16$ & $11.5 \pm 0.1$ & $1.2 \pm 0.1$ & $203 \pm 20$ \\
\hline \multirow{14}{*}{$\mathrm{CCH}$} & 87.284 & $346 \pm 116$ & $11.4 \pm 0.2$ & $1.3 \pm 0.2$ & $131 \pm 10$ \\
\hline & 87.316 & $2910 \pm 33$ & $11.3 \pm 0.2$ & $1.2 \pm 0.2$ & $2260 \pm 11$ \\
\hline & 87.328 & $1210 \pm 103$ & $11.3 \pm 0.2$ & $1.1 \pm 0.2$ & $1030 \pm 11$ \\
\hline & 87.402 & $1597 \pm 10$ & $11.1 \pm 0.2$ & $1.2 \pm 0.2$ & $1270 \pm 14$ \\
\hline & 87.407 & $890 \pm 88$ & $11.1 \pm 0.2$ & $1.0 \pm 0.2$ & $388 \pm 10$ \\
\hline & 87.446 & $312 \pm 18$ & $11.3 \pm 0.2$ & $1.2 \pm 0.2$ & $249 \pm 13$ \\
\hline & 261.978 & $140 \pm 17$ & $11.6 \pm 0.1$ & $1.1 \pm 0.1$ & $147 \pm 21$ \\
\hline & 262.004 & $2435 \pm 28$ & $11.5 \pm 0.1$ & $1.0 \pm 0.1$ & $2230 \pm 23$ \\
\hline & 262.006 & $1714 \pm 35$ & $11.5 \pm 0.1$ & $1.0 \pm 0.1$ & $1560 \pm 20$ \\
\hline & 262.064 & $1841 \pm 31$ & $11.6 \pm 0.1$ & $1.0 \pm 0.1$ & $1680 \pm 28$ \\
\hline & 262.067 & $1184 \pm 36$ & $11.5 \pm 0.1$ & $1.0 \pm 0.1$ & $1060 \pm 25$ \\
\hline & 262.078 & $210 \pm 42$ & $11.6 \pm 0.1$ & $1.0 \pm 0.2$ & $235 \pm 54$ \\
\hline & 262.208 & $181 \pm 18$ & $11.6 \pm 0.1$ & $1.2 \pm 0.1$ & $199 \pm 21$ \\
\hline & 262.250 & $90 \pm 10$ & $11.8 \pm 0.2$ & $0.8 \pm 0.1$ & $103 \pm 21$ \\
\hline
\end{tabular}

Table B.3. Gaussian fit parameters for narrow component in MMS9.

\begin{tabular}{cccccc}
\hline \hline Molecule & Frequency & $\begin{array}{c}\text { Area } \\
{\left[\mathrm{mK}_{\mathrm{km} \mathrm{s}}{ }^{-1}\right]}\end{array}$ & $\begin{array}{c}V_{\text {lsr }} \\
{\left[\mathrm{km} \mathrm{s}^{-1}\right]}\end{array}$ & $\begin{array}{c}F W H M \\
{\left[\mathrm{~km} \mathrm{~s}^{-1}\right]}\end{array}$ & $\begin{array}{c}T_{\text {peak }} \\
{[\mathrm{mK}]}\end{array}$ \\
\hline & 84.521 & $213 \pm 10$ & $11.5 \pm 0.2$ & $1.3 \pm 0.2$ & $154 \pm 10$ \\
& 239.746 & $47 \pm 9$ & $11.2 \pm 0.1$ & $0.8 \pm 0.2$ & $52 \pm 13$ \\
& 241.700 & $150 \pm 15$ & $11.4 \pm 0.1$ & $1.1 \pm 0.1$ & $132 \pm 19$ \\
$\mathrm{CH}_{3} \mathrm{OH}$ & 241.767 & $220 \pm 12$ & $11.4 \pm 0.1$ & $0.7 \pm 0.1$ & $308 \pm 15$ \\
& 241.791 & $300 \pm 60$ & $11.4 \pm 0.1$ & $0.7 \pm 0.1$ & $430 \pm 19$ \\
& 241.879 & $57 \pm 9$ & $11.4 \pm 0.1$ & $0.7 \pm 0.1$ & $74 \pm 13$ \\
& 243.915 & $105 \pm 12$ & $11.5 \pm 0.1$ & $1.8 \pm 0.2$ & $55 \pm 12$ \\
& 261.805 & $115 \pm 12$ & $11.4 \pm 0.1$ & $0.8 \pm 0.1$ & $130 \pm 16$ \\
\hline & 87.284 & $471 \pm 15$ & $11.6 \pm 0.2$ & $1.3 \pm 0.2$ & $343 \pm 13$ \\
& 87.316 & $2046 \pm 10$ & $11.6 \pm 0.2$ & $0.9 \pm 0.2$ & $2230 \pm 12$ \\
& 87.328 & $1128 \pm 118$ & $11.6 \pm 0.2$ & $0.9 \pm 0.2$ & $1200 \pm 12$ \\
& 87.402 & $1494 \pm 32$ & $11.6 \pm 0.2$ & $0.9 \pm 0.2$ & $1510 \pm 13$ \\
& 87.407 & $463 \pm 79$ & $11.6 \pm 0.2$ & $0.9 \pm 0.2$ & $483 \pm 12$ \\
& 87.446 & $519 \pm 11$ & $11.5 \pm 0.2$ & $1.3 \pm 0.2$ & $378 \pm 11$ \\
$\mathrm{CCH}$ & 261.978 & $70 \pm 30$ & $11.5 \pm 0.1$ & $0.6 \pm 0.2$ & $123 \pm 16$ \\
& 262.004 & $1830 \pm 24$ & $11.4 \pm 0.1$ & $0.8 \pm 0.1$ & $2030 \pm 21$ \\
& 262.006 & $1370 \pm 16$ & $11.4 \pm 0.1$ & $0.9 \pm 0.1$ & $1520 \pm 17$ \\
& 262.064 & $1500 \pm 12$ & $11.5 \pm 0.1$ & $0.9 \pm 0.1$ & $1610 \pm 19$ \\
& 262.067 & $990 \pm 10$ & $11.4 \pm 0.1$ & $0.9 \pm 0.1$ & $1100 \pm 16$ \\
& 262.078 & $214 \pm 13$ & $11.4 \pm 0.1$ & $1.0 \pm 0.1$ & $210 \pm 18$ \\
& 262.208 & $197 \pm 12$ & $11.4 \pm 0.1$ & $0.8 \pm 0.1$ & $235 \pm 17$ \\
& 262.250 & $68 \pm 11$ & $11.5 \pm 0.1$ & $0.7 \pm 0.1$ & $91 \pm 18$ \\
\hline
\end{tabular}


M. Bouvier et al.: Hunting for hot corinos and WCCC sources in the OMC-2/3 filament
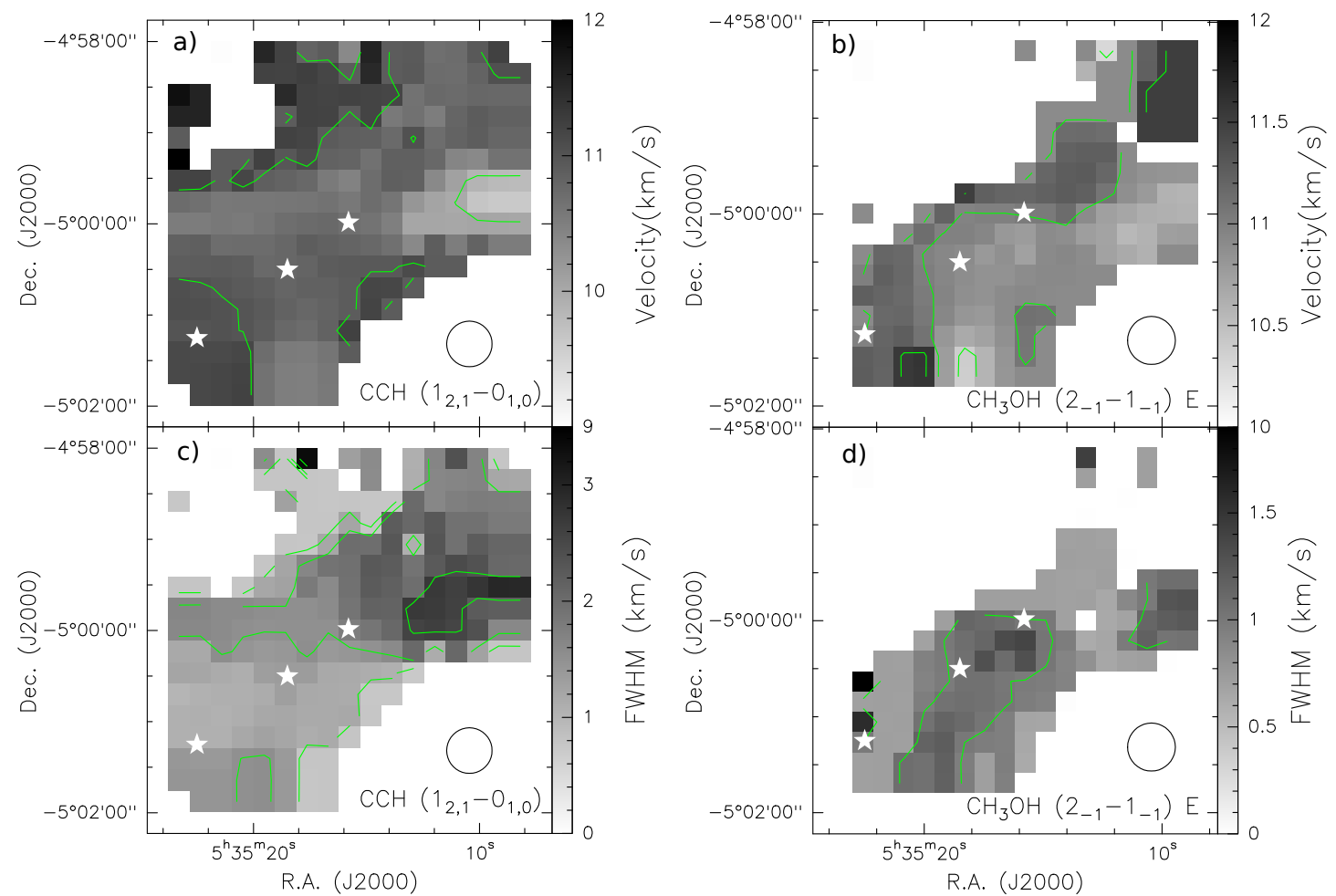

Fig. B.1. Moment maps of $\mathrm{CCH}$ and $\mathrm{CH}_{3} \mathrm{OH} ;(a)$ and $(c)$ moments 1 and 2 of the line $\mathrm{CCH}(N=1-0, J=3 / 2-1 / 2, F=1-0)(a)$, $(c)$, respectively; $(b)$ and $(d)$ moments 1 and 2 of the line $\mathrm{CH}_{3} \mathrm{OH}\left(2_{-1}-1_{-1}\right.$ E) respectively. The velocity integration is between 7.9 and $12.8 \mathrm{~km} \mathrm{~s}^{-1}$ and the threshold has been set at $3 \sigma$ for both lines. Contours levels for Moment 1 are 10 and $11 \mathrm{~km} \mathrm{~s}^{-1}$ for $\mathrm{CCH}$ and $10.5,11$ and $11.5 \mathrm{~km} \mathrm{~s}^{-1}$ for $\mathrm{CH}_{3} \mathrm{OH}^{\mathrm{C}} \mathrm{Contour}^{-1}$ levels for Moments 2 are $1,1.5$ and $2.5 \mathrm{~km} \mathrm{~s}^{-1}$ for $\mathrm{CCH}$ and $1 \mathrm{~km} \mathrm{~s}^{-1}$ for $\mathrm{CH}_{3} \mathrm{OH}$.

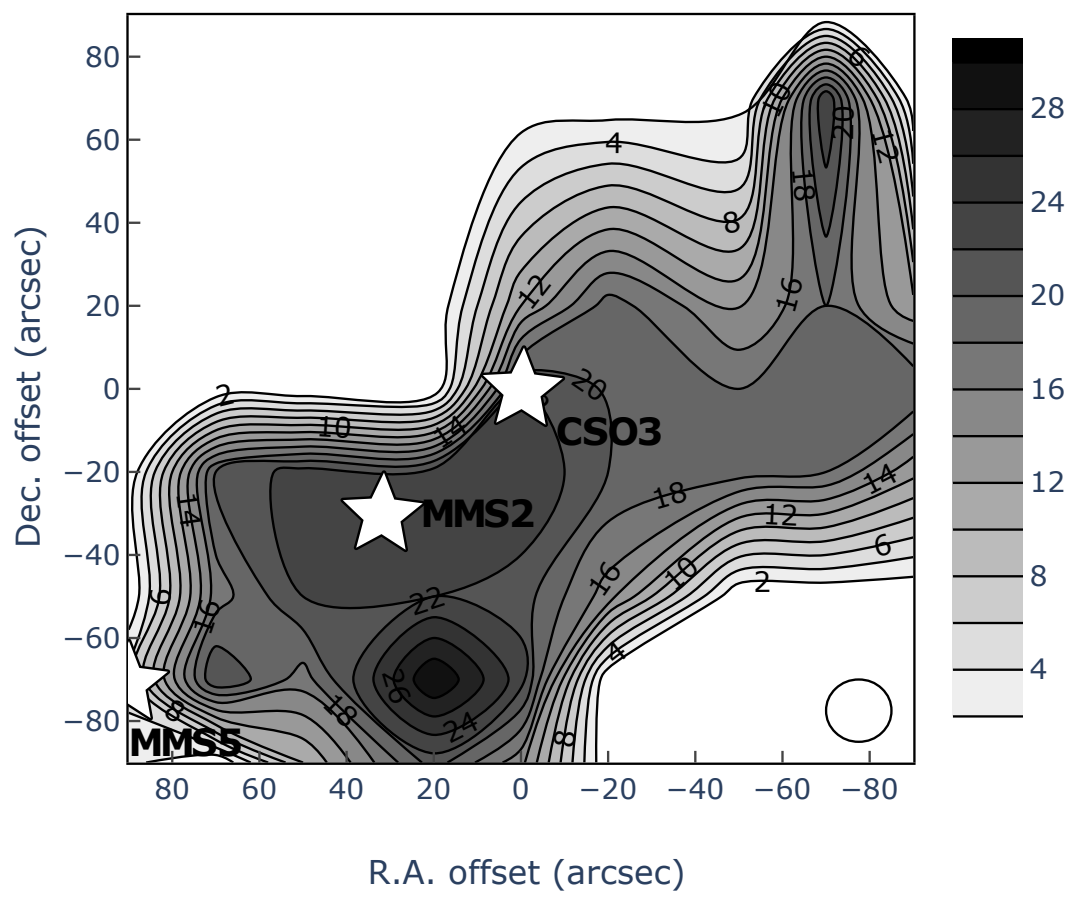

Fig. B.2. Intensity ratio of the $\mathrm{CH}_{3} \mathrm{OH}$ lines $2_{-1}-1_{-1} \mathrm{E}$ and $2_{0}-1_{0} \mathrm{E}$. The lines chosen are optically thin. We see clearly that the ratio is constant throughout the filament. Error on the line intensity ratio is less than 3. 
Table B.4. Gaussian fit parameters for narrow component in MMS5.

\begin{tabular}{|c|c|c|c|c|c|}
\hline Molecule & Frequency & $\begin{array}{c}\text { Area } \\
{\left[\mathrm{mK} \cdot \mathrm{km} \mathrm{s}^{-1}\right]}\end{array}$ & $\begin{array}{c}V_{\mathrm{lsr}} \\
{\left[\mathrm{km} \mathrm{s}^{-1}\right]}\end{array}$ & $\begin{array}{l}F W H M \\
{\left[\mathrm{~km} \mathrm{~s}^{-1}\right]}\end{array}$ & $\begin{array}{l}T_{\text {peak }} \\
{[\mathrm{mK}]}\end{array}$ \\
\hline \multirow{9}{*}{$\mathrm{CH}_{3} \mathrm{OH}$} & 84.521 & $245 \pm 60$ & $11.4 \pm 0.2$ & $1.1 \pm 0.2$ & $216 \pm 10$ \\
\hline & 239.746 & $207 \pm 19$ & $10.8 \pm 0.1$ & $1.8 \pm 0.2$ & $108 \pm 17$ \\
\hline & 241.700 & $250 \pm 90$ & $11.1 \pm 0.1$ & $1.1 \pm 0.1$ & $216 \pm 17$ \\
\hline & 241.767 & $880 \pm 70$ & $11.2 \pm 0.1$ & $0.9 \pm 0.1$ & $880 \pm 21$ \\
\hline & 241.791 & $1020 \pm 40$ & $11.2 \pm 0.1$ & $0.9 \pm 0.1$ & $1020 \pm 19$ \\
\hline & 241.879 & $280 \pm 20$ & $11.0 \pm 0.1$ & $1.6 \pm 0.1$ & $163 \pm 20$ \\
\hline & 241.887 & $60 \pm 10$ & $11.2 \pm 0.1$ & $0.9 \pm 0.2$ & $60 \pm 16$ \\
\hline & 243.915 & $264 \pm 17$ & $11.0 \pm 0.1$ & $1.6 \pm 0.1$ & $151 \pm 18$ \\
\hline & 261.805 & $416 \pm 33$ & $11.1 \pm 0.1$ & $1.2 \pm 0.1$ & $320 \pm 27$ \\
\hline \multirow{15}{*}{$\mathrm{CCH}$} & 87.284 & $670 \pm 11$ & $11.2 \pm 0.2$ & $1.1 \pm 0.2$ & $477 \pm 10$ \\
\hline & 87.316 & $4184 \pm 12$ & $11.2 \pm 0.2$ & $1.0 \pm 0.2$ & $3450 \pm 13$ \\
\hline & 87.328 & $2334 \pm 20$ & $11.2 \pm 0.2$ & $1.0 \pm 0.2$ & $1930 \pm 11$ \\
\hline & 87.402 & $2132 \pm 26$ & $11.2 \pm 0.2$ & $0.9 \pm 0.2$ & $1910 \pm 17$ \\
\hline & 87.407 & $1041 \pm 90$ & $11.1 \pm 0.2$ & $1.1 \pm 0.2$ & $862 \pm 15$ \\
\hline & 87.446 & $654 \pm 13$ & $11.3 \pm 0.2$ & $1.1 \pm 0.2$ & $488 \pm 12$ \\
\hline & 261.978 & $130 \pm 16$ & $11.0 \pm 0.1$ & $1.0 \pm 0.2$ & $124 \pm 19$ \\
\hline & 262.004 & $2582 \pm 36$ & $11.0 \pm 0.1$ & $1.0 \pm 0.1$ & $2360 \pm 21$ \\
\hline & 262.006 & $2104 \pm 22$ & $11.0 \pm 0.1$ & $1.0 \pm 0.1$ & $1970 \pm 21$ \\
\hline & 262.064 & $1601 \pm 10$ & $11.0 \pm 0.1$ & $0.9 \pm 0.1$ & $1610 \pm 23$ \\
\hline & 262.067 & $1556 \pm 70$ & $11.0 \pm 0.1$ & $1.0 \pm 0.1$ & $1410 \pm 23$ \\
\hline & 262.078 & $289 \pm 15$ & $11.0 \pm 0.1$ & $1.1 \pm 0.1$ & $258 \pm 20$ \\
\hline & 262.208 & $274 \pm 13$ & $11.0 \pm 0.2$ & $1.0 \pm 0.1$ & $252 \pm 18$ \\
\hline & 262.236 & $79 \pm 15$ & $10.7 \pm 0.1$ & $1.0 \pm 0.2$ & $73 \pm 16$ \\
\hline & 262.250 & $86 \pm 17$ & $11.0 \pm 0.1$ & $0.7 \pm 0.2$ & $118 \pm 24$ \\
\hline
\end{tabular}

Table B.5. Gaussian fit parameters for narrow component in MMS2.

\begin{tabular}{|c|c|c|c|c|c|}
\hline Molecule & Frequency & $\begin{array}{c}\text { Area } \\
{\left[\mathrm{mK}^{2} \cdot \mathrm{km} \mathrm{s}^{-1}\right]}\end{array}$ & $\begin{array}{c}V_{\mathrm{lsr}} \\
{\left[\mathrm{km} \mathrm{s}^{-1}\right]} \\
\end{array}$ & $\begin{array}{l}F W H M \\
{\left[\mathrm{~km} \mathrm{~s}^{-1}\right]} \\
\end{array}$ & $\begin{array}{l}T_{\text {peak }} \\
{[\mathrm{mK}]}\end{array}$ \\
\hline \multirow{8}{*}{$\mathrm{CH}_{3} \mathrm{OH}$} & 84.521 & $362 \pm 15$ & $11.1 \pm 0.2$ & $1.2 \pm 0.2$ & $273 \pm 9$ \\
\hline & 239.746 & $86 \pm 13$ & $11.0 \pm 0.1$ & $1.7 \pm 0.3$ & $48 \pm 12$ \\
\hline & 241.700 & $269 \pm 13$ & $11.0 \pm 0.1$ & $1.3 \pm 0.1$ & $199 \pm 16$ \\
\hline & 241.767 & $1220 \pm 20$ & $11.0 \pm 0.1$ & $1.3 \pm 0.1$ & $901 \pm 13$ \\
\hline & 241.791 & $1603 \pm 10$ & $11.0 \pm 0.1$ & $1.3 \pm 0.1$ & $1160 \pm 13$ \\
\hline & 241.879 & $97 \pm 12$ & $11.2 \pm 0.1$ & $1.3 \pm 0.2$ & $72 \pm 14$ \\
\hline & 243.915 & $139 \pm 11$ & $11.2 \pm 0.1$ & $1.5 \pm 0.2$ & $71 \pm 12$ \\
\hline & 261.805 & $298 \pm 12$ & $11.0 \pm 0.1$ & $1.2 \pm 0.1$ & $239 \pm 15$ \\
\hline \multirow{14}{*}{$\mathrm{CCH}$} & 87.284 & $957 \pm 16$ & $10.9 \pm 0.2$ & $1.6 \pm 0.2$ & $578 \pm 11$ \\
\hline & 87.316 & $7084 \pm 15$ & $10.8 \pm 0.2$ & $1.6 \pm 0.2$ & $4290 \pm 12$ \\
\hline & 87.328 & $3981 \pm 17$ & $10.9 \pm 0.2$ & $1.5 \pm 0.2$ & $2480 \pm 14$ \\
\hline & 87.402 & $4165 \pm 18$ & $10.8 \pm 0.2$ & $1.5 \pm 0.2$ & $2610 \pm 15$ \\
\hline & 87.407 & $1930 \pm 15$ & $10.7 \pm 0.2$ & $1.5 \pm 0.2$ & $1190 \pm 15$ \\
\hline & 87.446 & $1021 \pm 16$ & $10.9 \pm 0.2$ & $1.6 \pm 0.2$ & $608 \pm 11$ \\
\hline & 261.978 & $188 \pm 13$ & $11.1 \pm 0.1$ & $1.5 \pm 0.1$ & $120 \pm 16$ \\
\hline & 262.004 & $3927 \pm 21$ & $11.1 \pm 0.1$ & $1.4 \pm 0.1$ & $2570 \pm 23$ \\
\hline & 262.006 & $3334 \pm 16$ & $11.2 \pm 0.1$ & $1.6 \pm 0.1$ & $2000 \pm 16$ \\
\hline & 262.064 & $2996 \pm 16$ & $11.2 \pm 0.1$ & $1.4 \pm 0.1$ & $1940 \pm 18$ \\
\hline & 262.067 & $2203 \pm 15$ & $11.2 \pm 0.1$ & $1.5 \pm 0.1$ & $1360 \pm 16$ \\
\hline & 262.078 & $360 \pm 20$ & $11.1 \pm 0.1$ & $1.3 \pm 0.1$ & $257 \pm 14$ \\
\hline & 262.208 & $353 \pm 12$ & $11.1 \pm 0.1$ & $1.4 \pm 0.1$ & $241 \pm 14$ \\
\hline & 262.250 & $129 \pm 13$ & $11.2 \pm 0.1$ & $1.3 \pm 0.1$ & $91 \pm 17$ \\
\hline
\end{tabular}

Table B.6. Gaussian fit parameters for narrow component in CSO3.

\begin{tabular}{cccccc}
\hline \hline Molecule & Frequency & $\begin{array}{c}\text { Area } \\
{\left[\mathrm{mK}_{\mathrm{km} \mathrm{s}}{ }^{-1}\right]}\end{array}$ & $\begin{array}{c}V_{\mathrm{lsr}} \\
{\left[\mathrm{km} \mathrm{s}^{-1}\right]}\end{array}$ & $\begin{array}{c}F W H M \\
{\left[\mathrm{~km} \mathrm{~s}^{-1}\right]}\end{array}$ & $\begin{array}{c}T_{\text {peak }} \\
{[\mathrm{mK}]}\end{array}$ \\
\hline & 84.521 & $192 \pm 32$ & $11.2 \pm 0.2$ & $1.0 \pm 0.2$ & $179 \pm 8$ \\
& 241.700 & $160 \pm 13$ & $11.2 \pm 0.1$ & $1.0 \pm 0.1$ & $157 \pm 17$ \\
$\mathrm{CH}_{3} \mathrm{OH}$ & 241.767 & $700 \pm 10$ & $11.1 \pm 0.1$ & $0.9 \pm 0.1$ & $725 \pm 11$ \\
& 241.791 & $820 \pm 40$ & $11.1 \pm 0.1$ & $0.9 \pm 0.1$ & $898 \pm 16$ \\
& 241.879 & $42 \pm 9$ & $11.1 \pm 0.1$ & $0.6 \pm 0.2$ & $62 \pm 15$ \\
& 261.805 & $205 \pm 9$ & $11.1 \pm 0.1$ & $0.9 \pm 0.1$ & $220 \pm 13$ \\
\hline & 87.284 & $470 \pm 15$ & $11.2 \pm 0.2$ & $1.0 \pm 0.2$ & $320 \pm 12$ \\
& 87.316 & $2578 \pm 50$ & $11.2 \pm 0.2$ & $0.9 \pm 0.2$ & $2560 \pm 15$ \\
& 87.328 & $1745 \pm 14$ & $11.2 \pm 0.2$ & $1.0 \pm 0.2$ & $1600 \pm 11$ \\
& 87.402 & $1647 \pm 29$ & $11.1 \pm 0.2$ & $1.0 \pm 0.2$ & $1620 \pm 18$ \\
& 87.407 & $991 \pm 18$ & $11.1 \pm 0.2$ & $1.1 \pm 0.2$ & $851 \pm 13$ \\
& 87.446 & $438 \pm 153$ & $11.3 \pm 0.2$ & $1.0 \pm 0.2$ & $401 \pm 12$ \\
& 261.978 & $72 \pm 11$ & $11.0 \pm 0.1$ & $0.8 \pm 0.1$ & $83 \pm 14$ \\
& 262.004 & $1900 \pm 40$ & $11.1 \pm 0.1$ & $1.0 \pm 0.1$ & $1890 \pm 16$ \\
& 262.006 & $1840 \pm 11$ & $11.1 \pm 0.1$ & $0.8 \pm 0.1$ & $1040 \pm 12$ \\
& 262.064 & $1510 \pm 10$ & $11.1 \pm 0.1$ & $1.0 \pm 0.1$ & $1390 \pm 14$ \\
& 262.067 & $680 \pm 10$ & $11.1 \pm 0.1$ & $0.8 \pm 0.1$ & $775 \pm 10$ \\
& 262.078 & $193 \pm 10$ & $11.1 \pm 0.1$ & $1.0 \pm 0.1$ & $177 \pm 13$ \\
& 262.208 & $187 \pm 12$ & $11.1 \pm 0.1$ & $1.0 \pm 0.1$ & $177 \pm 17$ \\
& 262.250 & $72 \pm 11$ & $11.1 \pm 0.1$ & $1.2 \pm 0.2$ & $56 \pm 13$ \\
\hline
\end{tabular}

Table B.7. Gaussian fit parameters for narrow component in SIMBA-a.

\begin{tabular}{cccccc}
\hline \hline Molecule & Frequency & $\begin{array}{c}\text { Area } \\
{\left[\mathrm{mK}_{\mathrm{km} \mathrm{s}}{ }^{-1}\right]}\end{array}$ & $\begin{array}{c}V_{\mathrm{lsr}} \\
{\left[\mathrm{km} \mathrm{s}^{-1}\right]}\end{array}$ & $\begin{array}{c}F W H M \\
{\left[\mathrm{~km} \mathrm{~s}^{-1}\right]}\end{array}$ & $\begin{array}{c}T_{\text {peak }} \\
{[\mathrm{mK}]}\end{array}$ \\
\hline $\mathrm{CH}_{3} \mathrm{OH}$ & 84.521 & $226 \pm 71$ & $10.5 \pm 0.2$ & $0.9 \pm 0.2$ & $241 \pm 8$ \\
\hline \multirow{6}{*}{$\mathrm{CCH}$} & 87.284 & $327 \pm 40$ & $10.5 \pm 0.2$ & $1.3 \pm 0.2$ & $233 \pm 13$ \\
& 87.316 & $2000 \pm 50$ & $10.4 \pm 0.2$ & $1.1 \pm 0.2$ & $1630 \pm 16$ \\
& 87.328 & $1165 \pm 49$ & $10.5 \pm 0.2$ & $1.2 \pm 0.2$ & $950 \pm 15$ \\
& 87.402 & $1147 \pm 46$ & $10.4 \pm 0.2$ & $1.1 \pm 0.2$ & $1000 \pm 16$ \\
& 87.446 & $554 \pm 64$ & $10.4 \pm 0.2$ & $1.2 \pm 0.2$ & $442 \pm 14$ \\
\hline
\end{tabular}




\section{Appendix C: LTE methods \& results}

Here we present the methods used to perform the LTE analysis and the results obtained.

\section{C.1. Single-pointing}

\section{C.1.1. $\mathrm{CH}_{3} \mathrm{OH}$ lines}

In the case of the methanol lines, we used the usual rotational diagram approach, which assumes optically thin lines and LTE level populations. To this end, we included all lines with a detection threshold of $3 \sigma$ and assumed extended emission. We note

$\mathrm{CSO} 33$

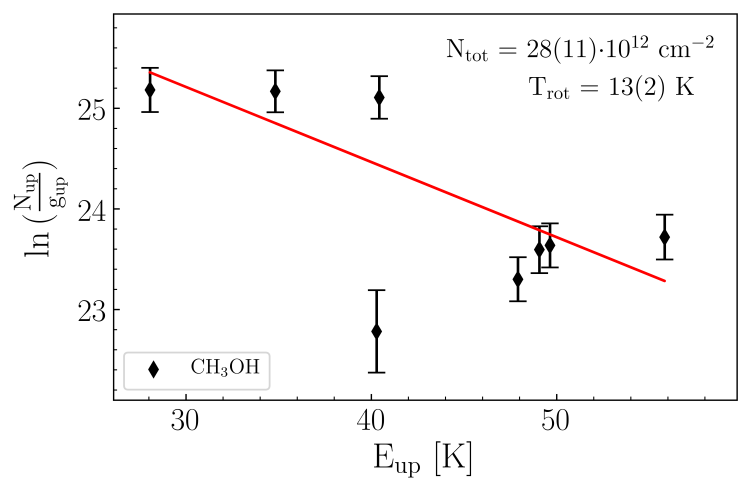

MMS9

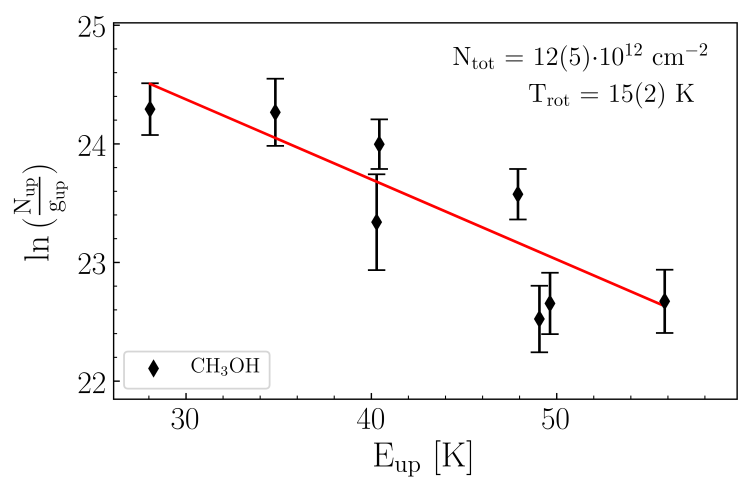

MMS2

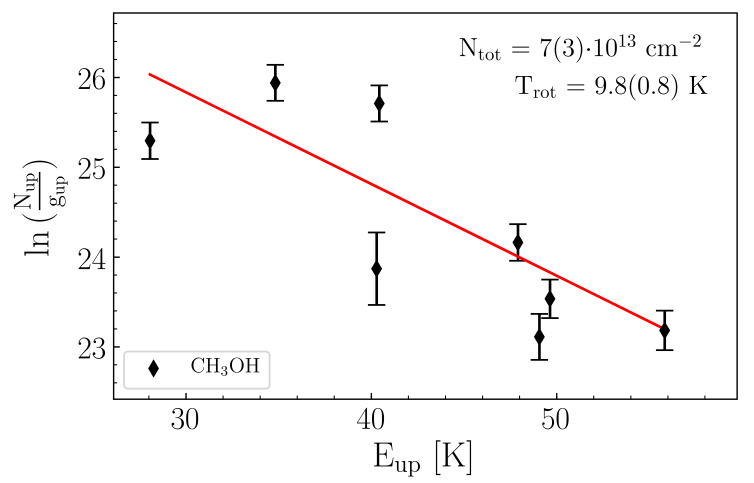

that we verified a posteriori that the optically thin lines approximation is valid: we used the ULSA (Unbiased Line Spectral Analysis) package developed at IPAG, which is a LTE radiative transfer code to verify a posteriori this assumption. The opacity values of the $\mathrm{CH}_{3} \mathrm{OH}$ lines given were less than 0.1. The rotational diagrams are presented in Fig. C.1 and the mean derived parameters are listed in Table C.1. In the six sources, the mean derived rotational temperatures and methanol beam-averaged column densities are $13.0 \pm 1.5 \mathrm{~K}$ and $(4 \pm 2) \times 10^{13} \mathrm{~cm}^{-2}$, respectively. However, we observe a scatter of the points from the linear fit in every rotational diagram, probably due to non-LTE effects.
FIRla

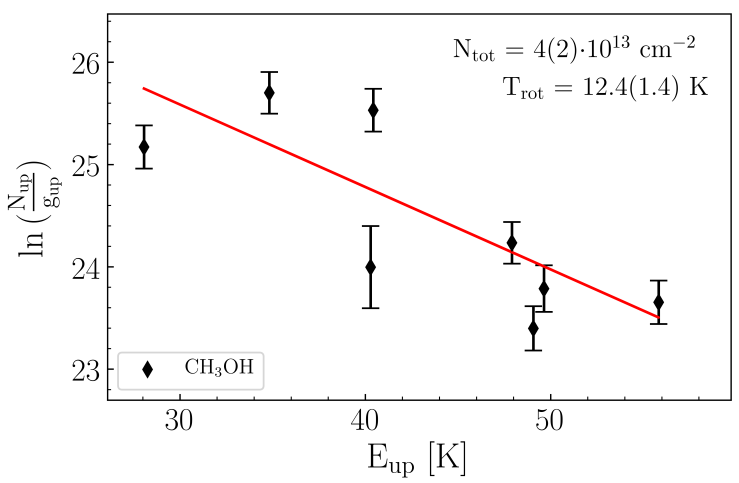

MMS5

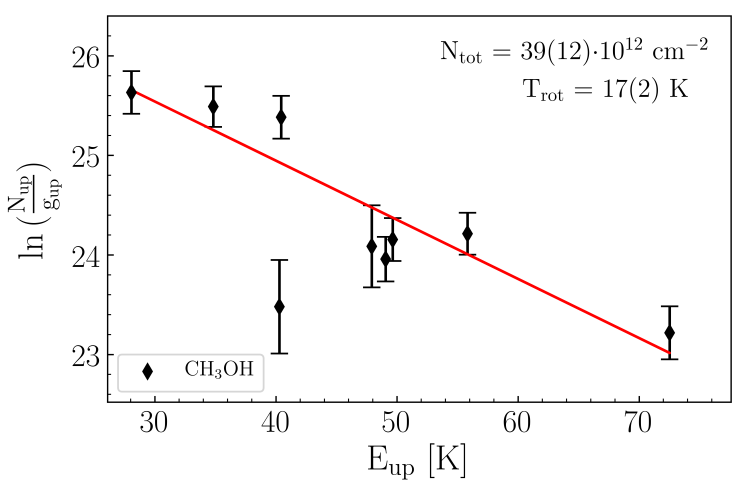

$\mathrm{CSO} 3$

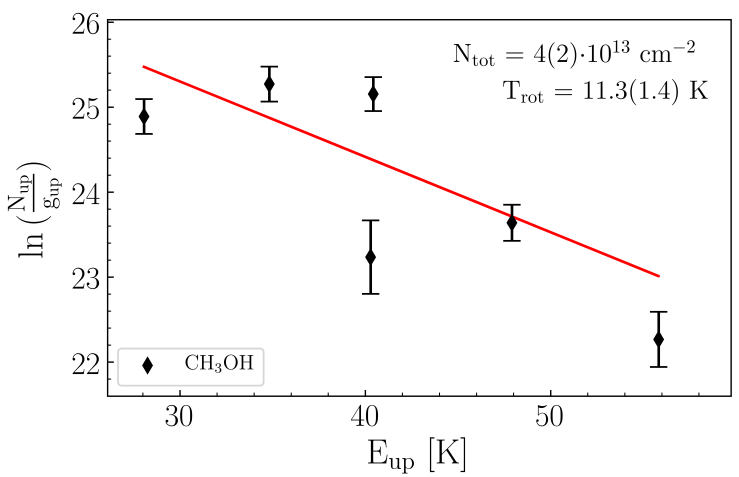

Fig. C.1. Rotational diagrams of $\mathrm{CH}_{3} \mathrm{OH}$ for each source. 
Table C.1. Rotational temperatures and beam-averaged column densities of $\mathrm{CH}_{3} \mathrm{OH}$ and $\mathrm{CCH}$ towards seven out of the nine target sources (Table 2).

\begin{tabular}{|c|c|c|c|c|c|c|c|c|c|}
\hline \multirow{2}{*}{ Source } & \multicolumn{2}{|c|}{ IRAM $1 \mathrm{~mm}$ + Nobeyama $3 \mathrm{~mm}$} & \multicolumn{2}{|c|}{ IRAM $1 \mathrm{~mm}$} & \multicolumn{2}{|c|}{ Nobeyama $3 \mathrm{~mm}$} & \multicolumn{2}{|c|}{ Mean $\mathrm{CCH}$} & \multirow{2}{*}{$\begin{array}{c}\text { Ratio } \\
{[\mathrm{CCH}] /\left[\mathrm{CH}_{3} \mathrm{OH}\right]}\end{array}$} \\
\hline & $\begin{array}{c}T_{\mathrm{CH}_{3} \mathrm{OH}} \\
{[\mathrm{K}]}\end{array}$ & $\begin{array}{c}N_{\mathrm{CH}_{3} \mathrm{OH}} \\
{\left[\times 10^{13} \mathrm{~cm}^{-2}\right]}\end{array}$ & $\begin{array}{c}T_{\mathrm{CCH}} \\
{[\mathrm{K}]} \\
\end{array}$ & $\begin{array}{c}N_{\mathrm{CCH}} \\
{\left[\times 10^{14} \mathrm{~cm}^{-2}\right]}\end{array}$ & $\begin{array}{c}T_{\mathrm{CCH}} \\
{[\mathrm{K}]} \\
\end{array}$ & $\begin{array}{c}N_{\mathrm{CCH}} \\
{\left[\times 10^{14} \mathrm{~cm}^{-2}\right]}\end{array}$ & $\begin{array}{c}T_{\mathrm{CCH}} \\
{[\mathrm{K}]} \\
\end{array}$ & $\begin{array}{c}N_{\mathrm{CCH}} \\
{\left[\times 10^{14} \mathrm{~cm}^{-2}\right]} \\
\end{array}$ & \\
\hline CSO33 & $13 \pm 2$ & $3 \pm 1$ & $11 \pm 1$ & $11.6 \pm 3.5$ & $11 \pm 3$ & $5 \pm 2$ & $11.0 \pm 2.5$ & $8.0 \pm 1.5$ & $22 \pm 10$ \\
\hline FIR1a & $12 \pm 1$ & $4 \pm 2$ & $17 \pm 3$ & $4 \pm 1$ & $17 \pm 6$ & $11 \pm 9$ & $17.0 \pm 4.5$ & $7.5 \pm 5.0$ & $19 \pm 16$ \\
\hline MMS9 & $15 \pm 2$ & $1.2 \pm 0.5$ & $14 \pm 2$ & $4 \pm 1$ & $15 \pm 5$ & $7 \pm 5$ & $14.5 \pm 3.5$ & $6 \pm 3$ & $50 \pm 33$ \\
\hline MMS5 & $17 \pm 2$ & $4 \pm 1$ & $14 \pm 2$ & $4.5 \pm 1.4$ & $13 \pm 4$ & $10 \pm 6$ & $13.5 \pm 3.0$ & $7.0 \pm 3.5$ & $17 \pm 10$ \\
\hline MMS2 & $10 \pm 1$ & $7 \pm 3$ & $11 \pm 1$ & $8.2 \pm 2.5$ & $10 \pm 3$ & $13.7 \pm 6.5$ & $10.5 \pm 2.0$ & $11 \pm 5$ & $14 \pm 8$ \\
\hline $\mathrm{CSO} 3$ & $11 \pm 1$ & $4 \pm 2$ & $23 \pm 4$ & $3 \pm 1$ & $11 \pm 3$ & $13 \pm 7$ & $17 \pm 8.5$ & $8 \pm 4$ & $20 \pm 14$ \\
\hline SIMBA-a & $\ldots$ & $\ldots$ & $\ldots$ & $\ldots$ & $5 \pm 1$ & $11 \pm 2$ & $5 \pm 1$ & $11 \pm 2$ & $\ldots$ \\
\hline
\end{tabular}

\section{C.1.2. $\mathrm{CCH}$ lines}

We clearly detect all the components from the $\mathrm{CCH}(N=1-0)$ transition and around eight to nine (out of 11) hyperfine components of the $\mathrm{CCH}(N=3-2)$ transition depending on the source. In order to derive excitation temperatures and column densities for the hyperfine structure of $\mathrm{CCH}$, we used the Hyperfine fitting Structure (HfS) Tool in the CLASS software package. We derived the parameters separately for the data at $1 \mathrm{~mm}$ and at $3 \mathrm{~mm}$ because the HfS routine treats only one hyperfine transition at a time. By doing the analysis for the two transitions, we verified that we obtained the same physical parameters for the two transitions. The opacities derived show that most of the sources are moderately optically thick with values ranging from 0.8 to 2.2 at $1 \mathrm{~mm}$ and from 0.6 to 3.3 at $3 \mathrm{~mm}$. The derived line widths, FWHM, and rest velocities, $V_{\mathrm{lsr}}$, are similar to those derived from the Gaussian fits for most sources. The line widths may be larger for sources in which the line profile shows two components, such as the source SIMBA-a (see Appendix A).

The routine reads an input file containing the number of the components of the multiplet and their relative velocities, with respect to a chosen hyperfine component (here we chose the line at $262.004 \mathrm{GHz}$ ), as well as their relative intensities. We used the predicted frequencies and intensities of the $\mathrm{CCH}$ lines for the $N=3-2$ transition, taken from Ziurys et al. (1982). In order to check the results and the predicted values, we used all the components of the multiplet, detected or not. The outputs given by the routine are the following: $\mathrm{p}_{1}=T_{\mathrm{mb}} \times \tau$, the rest velocity $V_{\text {lsr }}$, the width of the lines $\Delta V$ (labelled here as FWHM) and the total opacity of the multiplet $\mathrm{p} 4=\tau$. From those parameters, we can extract the excitation temperature, $T_{\mathrm{ex}}$, and the total column density of $\mathrm{CCH}, N_{\text {tot }}$, for each source thanks to Eqs. (C.1), (C.3), (C.2), and (C.4).

$J_{T_{\mathrm{ex}}}=J_{T_{\mathrm{bg}}}+\frac{\mathrm{p} 1}{\mathrm{p} 4}$

where $J(T)$, the intensity in units of temperature, is defined as:
$J(T)=\frac{h v}{k_{\mathrm{B}} T} \frac{1}{e^{h v / k_{\mathrm{B}} T}-1}$,

where $h, v, k_{\mathrm{B}}$ and $T$ are the Planck constant, the frequency, the Boltzmann constant and the temperature respectively.

This leads to:

$$
T_{\mathrm{ex}}=\frac{h v / k_{\mathrm{B}}}{\ln \left(1+\frac{h v / k_{\mathrm{B}}}{J_{T_{\mathrm{bg}}}+\frac{\mathrm{pl}}{\mathrm{p} 4}}\right)} .
$$

We then can calculate the total column density $N_{\mathrm{CCH}}$ :

$N_{\mathrm{CCH}}=\frac{8 \pi v^{3} \tau \Delta V Q\left(T_{\mathrm{ex}}\right)}{A_{i j} g_{j} c^{3}} \frac{e^{E_{u} / T_{\mathrm{ex}}}}{e^{h c / v T_{\mathrm{ex}}}-1}$,

where $E_{u}, A_{i j}, g_{j}, Q\left(T_{\mathrm{ex}}\right), \mathrm{c}$ and $T_{\mathrm{ex}}$ are the upper level energy, the Einstein coefficient, the statistical weight of the upper level energy, partition function of the excitation temperature, the celerity and the excitation temperature, respectively.

The results of the hyperfine fit and of the LTE analysis are shown in Tables C.2 and C.1 respectively. The excitation temperatures derived at $1 \mathrm{~mm}$ and at $3 \mathrm{~mm}$ are similar, as well as the total column densities. We thus averaged the results for the two transitions. The mean excitation temperature ranges from 5 to $17 \mathrm{~K}$ and the column density from $6 \times 10^{14}$ to $11 \times 10^{14} \mathrm{~cm}^{-2}$.

\section{C.2. OTF Map}

To derive the excitation temperatures and the column densities of each position of the map, we used the same methods as for the single-pointing. We took into account only positions with at least 3 detected lines of each molecules. The derived parameters are shown in Table C.3 and the results in Fig. C.2. The rotational temperatures range from 5 to $33 \mathrm{~K}$ and the column densities range from $2 \times 10^{13}$ to $16 \times 10^{13} \mathrm{~cm}^{-2}$ for $\mathrm{CH}_{3} \mathrm{OH}$. For $\mathrm{CCH}$, temperatures ranges from 4 to $15 \mathrm{~K}$ and column densities ranges from $1 \times 10^{14}$ to $11 \times 10^{14} \mathrm{~cm}^{-2}$. 
M. Bouvier et al.: Hunting for hot corinos and WCCC sources in the OMC-2/3 filament

Table C.2. Results of the hyperfine structure fit of $\mathrm{CCH}$ for each source, at $1 \mathrm{~mm}$ and $3 \mathrm{~mm}$.

\begin{tabular}{|c|c|c|c|c|c|}
\hline Telescope & Source & $\begin{array}{c}T_{\mathrm{mb}} * \tau \\
{[\mathrm{K}]}\end{array}$ & $\begin{array}{c}V_{\mathrm{lsr}} \\
{\left[\mathrm{km} \mathrm{s}^{-1}\right]}\end{array}$ & $\begin{array}{c}F W H M \\
{\left[\mathrm{~km} \mathrm{~s}^{-1}\right]}\end{array}$ & $\tau_{\text {main }}$ \\
\hline \multirow{6}{*}{ 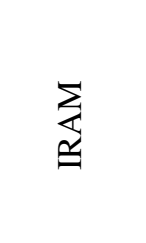 } & CSO33 & $13 \pm 6$ & $10.4 \pm 0.1$ & $1.5 \pm 0.1$ & 2.2 \\
\hline & FIR1a & $9 \pm 5$ & $11.5 \pm 0.1$ & $1.2 \pm 0.1$ & 0.8 \\
\hline & MMS9 & $8 \pm 4$ & $11.4 \pm 0.1$ & $1.0 \pm 0.1$ & 1.0 \\
\hline & MMS5 & $9 \pm 7$ & $11.0 \pm 0.1$ & $1.1 \pm 0.1$ & 1.0 \\
\hline & MMS2 & $10 \pm 4$ & $11.1 \pm 0.1$ & $1.4 \pm 0.1$ & 1.7 \\
\hline & $\mathrm{CSO} 3$ & $7 \pm 5$ & $11.0 \pm 0.1$ & $1.1 \pm 0.1$ & 0.4 \\
\hline \multirow{7}{*}{$\begin{array}{l}\widetilde{\Xi} \\
\text { స్ల } \\
\text { ठ } \\
\text { Z }\end{array}$} & CSO33 & $6 \pm$ & $10.6 \pm$ & $1.3 \pm$ & 0.8 \\
\hline & FIR1a & $8 \pm 3$ & $11.8 \pm 0.2$ & $1.6 \pm 0.2$ & 0.6 \\
\hline & MMS9 & $9.0 \pm 3.5$ & $11.6 \pm 0.2$ & $1.1 \pm 0.2$ & 0.7 \\
\hline & MMS5 & $12 \pm 5$ & $11.2 \pm 0.2$ & $1.2 \pm 0.2$ & 1.2 \\
\hline & MMS2 & $15 \pm 6$ & $10.8 \pm 0.2$ & $1.4 \pm 0.2$ & 2.1 \\
\hline & $\mathrm{CSO} 3$ & $13 \pm 5$ & $10.9 \pm 0.2$ & $1.6 \pm 0.2$ & 1.5 \\
\hline & SIMBA-a & $7 \pm 3$ & $10.8 \pm 0.2$ & $1.7 \pm 0.2$ & 3.3 \\
\hline
\end{tabular}

\section{$\mathrm{CCH}$}

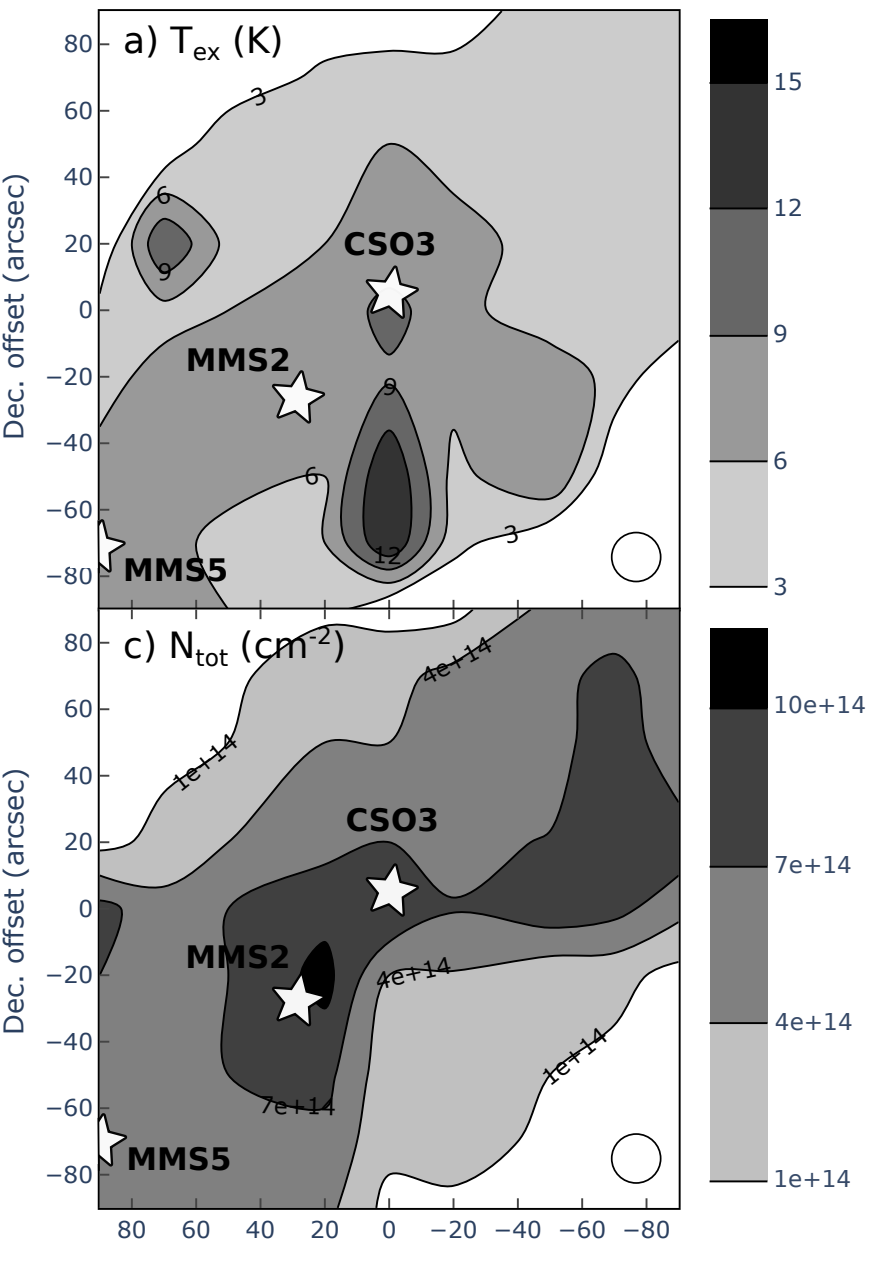

R.A. offset $(\operatorname{arcsec})$
$\mathrm{CH}_{3} \mathrm{OH}$

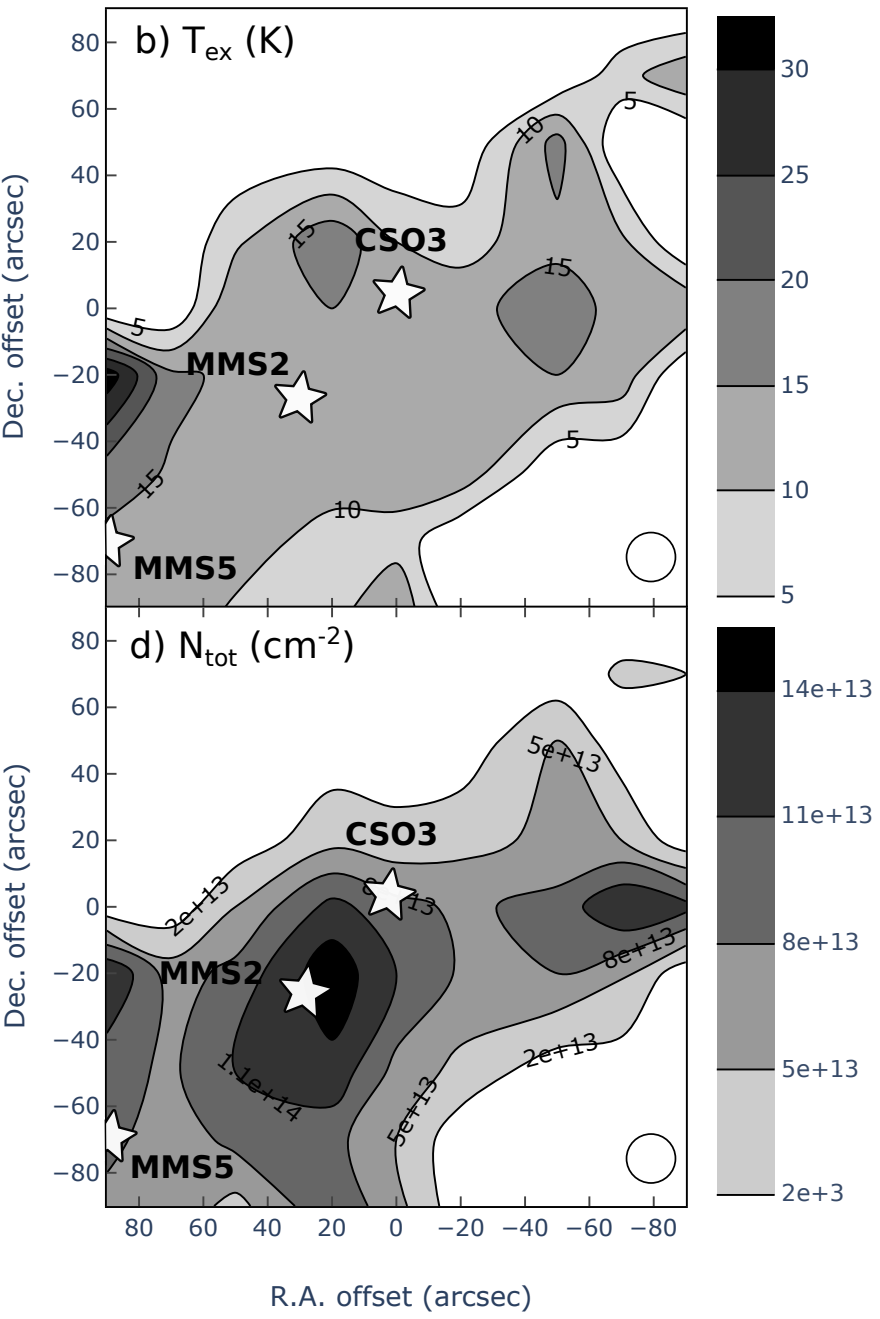

Fig. C.2. LTE results for the OTF map. The size of the beam is shown by a white filled circle at the bottom right of each map. $(a$ and $b)$ : derived excitation temperature, Tex, of $\mathrm{CCH}$ and $\mathrm{CH}_{3} \mathrm{OH}$ respectively. $\left(c\right.$ and $d$ ): derived total column density, Ntot, of $\mathrm{CCH}$ and $\mathrm{CH}_{3} \mathrm{OH}$, respectively. 
A\&A 636, A19 (2020)

Table C.3. Derived excitation temperatures and column densities of $\mathrm{CCH}$ and $\mathrm{CH}_{3} \mathrm{OH}$ from the LTE analysis.

\begin{tabular}{|c|c|c|c|c|c|c|}
\hline \multicolumn{2}{|c|}{ Coordinates } & \multicolumn{2}{|c|}{$\mathrm{CH}_{3} \mathrm{OH}$} & \multicolumn{2}{|c|}{$\mathrm{CCH}$} & \multirow{2}{*}{$\begin{array}{c}\text { Ratio } \\
{[\mathrm{CCH}] /\left[\mathrm{CH}_{3} \mathrm{OH}\right]}\end{array}$} \\
\hline $\begin{array}{l}\text { Offset RA } \\
\text { [arcsec] }\end{array}$ & $\begin{array}{l}\text { Offset Dec } \\
\text { [arcsec] }\end{array}$ & $\begin{array}{l}T_{\mathrm{ex}} \\
{[\mathrm{K}]}\end{array}$ & $\begin{array}{c}N_{\mathrm{tot}} \\
{\left[\times 10^{13} \mathrm{~cm}^{-2}\right]}\end{array}$ & $\begin{array}{l}T_{\mathrm{ex}} \\
{[\mathrm{K}]}\end{array}$ & $\begin{array}{c}N_{\mathrm{tot}} \\
{\left[\times 10^{14} \mathrm{~cm}^{-2}\right]}\end{array}$ & \\
\hline+90 & -90 & $14 \pm 10$ & $7 \pm 3$ & $8.5 \pm 0.5$ & $5 \pm 2$ & $7 \pm 4$ \\
\hline+90 & -70 & $14 \pm 2$ & $9 \pm 2$ & $7 \pm 1$ & $7 \pm 2$ & $8 \pm 3$ \\
\hline+90 & -50 & $17 \pm 3$ & $9 \pm 2$ & $7 \pm 1$ & $6 \pm 2$ & $7 \pm 3$ \\
\hline+90 & -20 & $33 \pm 11$ & $14 \pm 3$ & $5 \pm 1$ & $7 \pm 1$ & $5 \pm 1$ \\
\hline+90 & 0 & $\ldots$ & $\ldots$ & $4 \pm 1$ & $8 \pm 1$ & $\ldots$ \\
\hline+70 & -90 & $15 \pm 2$ & $7 \pm 1$ & $7 \pm 1$ & $5 \pm 2$ & $7 \pm 3$ \\
\hline+70 & -70 & $14 \pm 1$ & $6 \pm 1$ & $7 \pm 1$ & $5 \pm 1$ & $8 \pm 2$ \\
\hline+70 & -50 & $14.5 \pm 1.5$ & $7.5 \pm 1.0$ & $7 \pm 1$ & $6 \pm 2$ & $8 \pm 3$ \\
\hline+70 & -20 & $16 \pm 2$ & $6.5 \pm 1.0$ & $7 \pm 1$ & $6 \pm 2$ & $9 \pm 3$ \\
\hline+70 & 0 & $\ldots$ & $\ldots$ & $5 \pm 1$ & $5 \pm 1$ & $\ldots$ \\
\hline+70 & +20 & $\ldots$ & $\ldots$ & $12 \pm 4$ & $2 \pm 1$ & $\ldots$ \\
\hline+50 & -90 & $9 \pm 2$ & $4 \pm 1$ & $6 \pm 1$ & $5 \pm 1$ & $12.5 \pm 4$ \\
\hline+50 & -70 & $14 \pm 1$ & $9 \pm 1$ & $5 \pm 1$ & $6 \pm 1$ & $7 \pm 1$ \\
\hline+50 & -50 & $13 \pm 1$ & $11 \pm 2$ & $7 \pm 1$ & $7 \pm 2$ & $6 \pm 2$ \\
\hline+50 & -20 & $14 \pm 1$ & $9 \pm 1$ & $8 \pm 1$ & $7 \pm 3$ & $8 \pm 3$ \\
\hline+50 & 0 & $15 \pm 3$ & $5 \pm 1$ & $6 \pm 1$ & $7 \pm 1$ & $14 \pm 2$ \\
\hline+50 & +50 & $\ldots$ & $\ldots$ & $6 \pm 1$ & $1.0 \pm 0.2$ & $\ldots$ \\
\hline+20 & -90 & $8 \pm 2$ & $10.5 \pm 1.0$ & $4.5 \pm 1.0$ & $5 \pm 1$ & $5 \pm 1$ \\
\hline+20 & -70 & $6.5 \pm 1.0$ & $9 \pm 2$ & $6 \pm 1$ & $6 \pm 1$ & $7 \pm 2$ \\
\hline+20 & -50 & $14 \pm 1$ & $13 \pm 2$ & $6 \pm 1$ & $8 \pm 2$ & $6 \pm 2$ \\
\hline+20 & -20 & $15 \pm 2$ & $16 \pm 2$ & $8.5 \pm 1.0$ & $11 \pm 4$ & $7 \pm 3$ \\
\hline+20 & 0 & $15 \pm 2$ & $12 \pm 2$ & $7 \pm 1$ & $9 \pm 3$ & $7.5 \pm 3$ \\
\hline+20 & +20 & $\ldots$ & $\ldots$ & $6 \pm 1$ & $6 \pm 1$ & $\ldots$ \\
\hline+20 & +50 & $\ldots$ & $\ldots$ & $4 \pm 1$ & $4 \pm 1$ & $\ldots$ \\
\hline+20 & +70 & $\ldots$ & $\ldots$ & $4 \pm 1$ & $4 \pm 1$ & $\ldots$ \\
\hline 0 & -90 & $14 \pm 2$ & $6 \pm 1$ & $\ldots$ & $\ldots$ & $\ldots$ \\
\hline 0 & -70 & $8 \pm 1$ & $5 \pm 1$ & $15 \pm 6$ & $2 \pm 1$ & $4 \pm 2$ \\
\hline 0 & -50 & $12.5 \pm 1.0$ & $7 \pm 1$ & $15 \pm 4$ & $2 \pm 2$ & $3 \pm 2$ \\
\hline 0 & -20 & $14 \pm 1$ & $11 \pm 2$ & $8.5 \pm 1.0$ & $4 \pm 2$ & $4 \pm 2$ \\
\hline 0 & 0 & $13 \pm 1$ & $9 \pm 1$ & $10 \pm 2$ & $10 \pm 5$ & $11 \pm 6$ \\
\hline 0 & +20 & $10 \pm 2$ & $3 \pm 1$ & $7 \pm 1$ & $7 \pm 2$ & $23 \pm 10$ \\
\hline 0 & +50 & $\ldots$ & $\ldots$ & $6 \pm 1$ & $4 \pm 1$ & $\ldots$ \\
\hline 0 & +70 & $\ldots$ & $\ldots$ & $5 \pm 1$ & $3 \pm 1$ & $\ldots$ \\
\hline-20 & -70 & $\ldots$ & $\ldots$ & $4 \pm 1$ & $3 \pm 1$ & $\ldots$ \\
\hline-20 & -50 & $13 \pm 1$ & $4 \pm 1$ & $5 \pm 1$ & $2 \pm 1$ & $5 \pm 3$ \\
\hline-20 & -20 & $12 \pm 1$ & $6 \pm 1$ & $\ldots$ & $\ldots$ & $\ldots$ \\
\hline-20 & 0 & $\ldots$ & $\ldots$ & $5.5 \pm 1.0$ & $7 \pm 1$ & $\ldots$ \\
\hline-20 & +20 & $8 \pm 2$ & $4 \pm 1$ & $7 \pm 1$ & $6 \pm 2$ & $15 \pm 6$ \\
\hline-20 & +50 & $\ldots$ & $\ldots$ & $5 \pm 1$ & $5 \pm 1$ & $\ldots$ \\
\hline-20 & +70 & $\ldots$ & $\ldots$ & $5 \pm 1$ & $5 \pm 1$ & $\ldots$ \\
\hline-50 & -50 & $\ldots$ & $\ldots$ & $9 \pm 1$ & $1.0 \pm 0.2$ & $\ldots$ \\
\hline-50 & -20 & $15 \pm 2$ & $8 \pm 1$ & $8 \pm 1$ & $2 \pm 1$ & $2.5 \pm 1.0$ \\
\hline-50 & 0 & $18 \pm 2$ & $9 \pm 1$ & $4 \pm 1$ & $9 \pm 1$ & $10 \pm 2$ \\
\hline-50 & +20 & $\ldots$ & $\ldots$ & $5 \pm 1$ & $6 \pm 1$ & $\ldots$ \\
\hline-50 & +50 & $17 \pm 3$ & $5 \pm 1$ & $5 \pm 1$ & $5 \pm 1$ & $10 \pm 3$ \\
\hline-50 & +70 & $\ldots$ & $\ldots$ & $4 \pm 1$ & $6 \pm 1$ & $\ldots$ \\
\hline-50 & +90 & $\ldots$ & $\ldots$ & $6 \pm 1$ & $5 \pm 1$ & $\ldots$ \\
\hline-70 & -20 & $13 \pm 1$ & $5.5 \pm 1$ & $5 \pm 1$ & $2 \pm 2$ & $4 \pm 4$ \\
\hline-70 & 0 & $13 \pm 1$ & $14 \pm 2$ & $5 \pm 1$ & $8 \pm 1$ & $6 \pm 1$ \\
\hline-70 & +20 & $11 \pm 1$ & $5 \pm 1$ & $4 \pm 1$ & $9 \pm 1$ & $18 \pm 4$ \\
\hline-70 & +50 & $\ldots$ & $\ldots$ & $4 \pm 1$ & $10 \pm 9$ & $\ldots$ \\
\hline-70 & +70 & $8 \pm 2$ & $2.5 \pm 1$ & $4 \pm 1$ & $8 \pm 1$ & $32 \pm 13$ \\
\hline-70 & +90 & $\ldots$ & $\ldots$ & $5 \pm 1$ & $5 \pm 4$ & $\ldots$ \\
\hline-90 & 0 & $14.5 \pm 1.0$ & $12 \pm 2$ & $5.5 \pm 1.0$ & $5 \pm 1$ & $4 \pm 1$ \\
\hline-90 & +20 & $\ldots$ & $\ldots$ & $4 \pm 1$ & $9 \pm 1$ & $\ldots$ \\
\hline-90 & +50 & $\ldots$ & $\ldots$ & $6 \pm 1$ & $4 \pm 1$ & $\ldots$ \\
\hline-90 & +70 & $14 \pm 11$ & $2 \pm 1$ & $5 \pm 1$ & $5 \pm 1$ & $25 \pm 13$ \\
\hline-90 & +90 & $\ldots$ & $\ldots$ & $6 \pm 1$ & $4 \pm 4$ & $\ldots$ \\
\hline
\end{tabular}

Notes. Only positions with results (at least three lines) are shown here. 